INVESTIGATION OF THE IMPACTS OF LOCAL MICROCLIMATE ON PV ENERGY EFFICIENCY AND OUTDOOR THERMAL COMFORT

\author{
by \\ Jonathan Graham \\ Honours Bachelor of Arts, Architectural Studies, University of Toronto 2018
}

\author{
An MRP \\ presented to Ryerson University \\ in partial fulfillment of the \\ requirements for the degree of \\ Master of Building Science \\ in the program of \\ Building Science
}

Toronto, Ontario, Canada, 2020

(C) Jonathan Graham 2020 


\section{AUTHOR'S DECLARATION}

I hereby declare that I am the sole author of this MRP. This is a true copy of the MRP, including any required final revisions.

I authorize Ryerson University to lend this MRP to other institutions or individuals for the purpose of scholarly research

I further authorize Ryerson University to reproduce this MRP by photocopying or by other means, in total or in part, at the request of other institutions or individuals for the purpose of scholarly research.

I understand that my MRP may be made electronically available to the public. 


\title{
INVESTIGATION OF THE IMPACTS OF LOCAL MICROCLIMATE ON PV ENERGY EFFICIENCY AND OUTDOOR THERMAL COMFORT
}

Master of Building Science, 2020

Jonathan Graham

Ryerson University

Building Science

\begin{abstract}
Cities are increasingly incentivizing rooftop photovoltaics (PV) for the reduction of greenhouse gas emissions together with more urban forestry and high albedo surfaces for the mitigation the of urban heat island (UHI) effects. Previous interventions are proven to be effective in isolation, but their combined performance is seldom considered. Through microclimate simulations of a neighbourhood in Brampton, Ontario, this study investigates the trade-offs between large-scale deployments of rooftop PV, street trees and cool roofs. The performance of each intervention is compared in terms of PV efficiency and the Universal Thermal Climate Index (UTCI) values. The study shows that street trees can reduce the energy output of rooftop PV significantly depending on their height and location, and such, there is need for solar access laws in Ontario. Further, adopting rooftop PV instead of cool roofs can result in a pedestrian environment up to $0.5{ }^{\circ} \mathrm{C}$ higher UTCI during a heat wave.
\end{abstract}




\section{ACKNOWLEDGEMENTS}

- Dr. Umberto Berardi, for supervising this MRP and encouraging me to perform my best

- Dr. Terri Peters, for being the second reader of this MRP

- Robert McKaye and Geoffrey Turnbull of KPMB Architects, for helping me develop my methodology and for equipping me with software and computer resources during my Mitacs internship

- Dr. Zahra Jandaghian, for sharing her knowledge and expertise in climate modelling, for advice about writing and presenting, and for inspiring me to pursue this research topic

- Helge Simon and Tim Sinsel of ENVI-met, for technical support and information

- Antonello Di Nunzio, for publishing and maintaining the ENVI-BUG plugin

- Yizhao Tan, for advice about Python and data analysis

This work was supported by Mitacs through the Mitacs Accelerate program (Internship Reference Number: IT4857).

A portion of this work was used for a project delivered to the Friends of the Greenbelt Foundation of Ontario, entitled "Examining the Role of Green Infrastructure and the Greenbelt's Urban River Valleys in Building Resilience to Climate Change and the Impacts of Extreme Heat". The author would like to acknowledge Thomas Bowers of the Friends of the Greenbelt Foundation, Jacqueline Hamilton of the Toronto Region Conservation Authority, and other experts involved in that project. 


\section{TABLE OF CONTENTS}

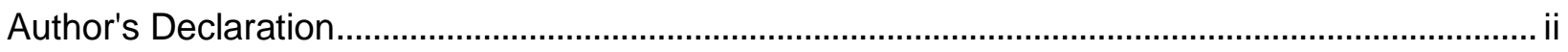

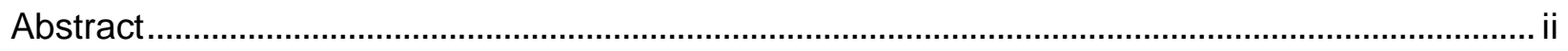

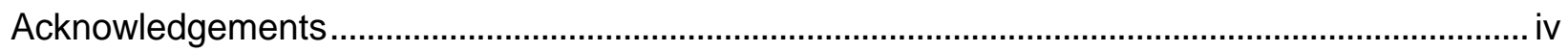

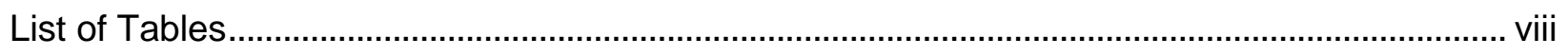

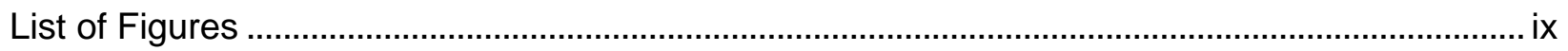

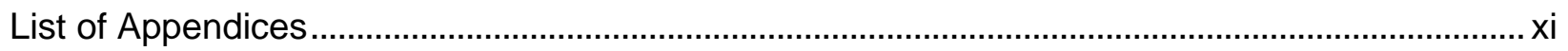

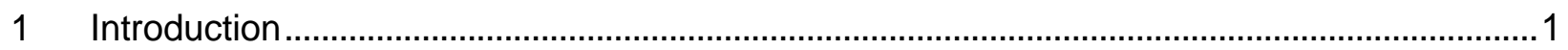

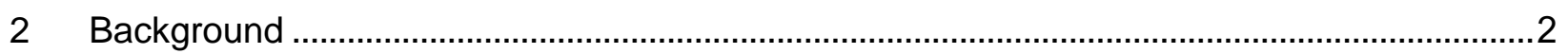

2.1 Outdoor Thermal Comfort ............................................................................................ 2

2.1.1 Human Heat Balance ...................................................................................... 2

2.1.2 Mean Radiant Temperature ..................................................................................

2.1.3 Human Thermal Comfort Indices ......................................................................... 4

2.1.4 Outdoor Thermal Comfort Autonomy.................................................................. 6

$2.2 \quad$ Urban Heat Island Mitigation Strategies..................................................................... 6

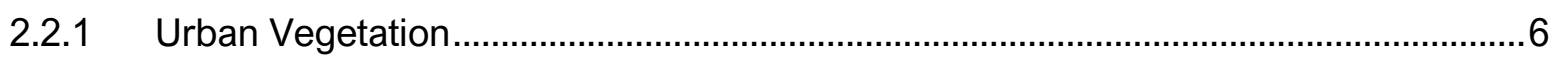

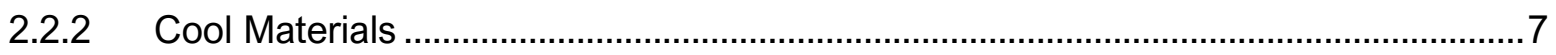

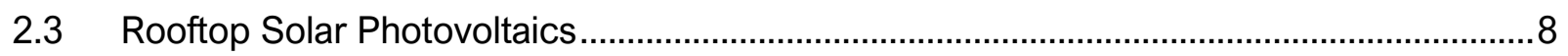

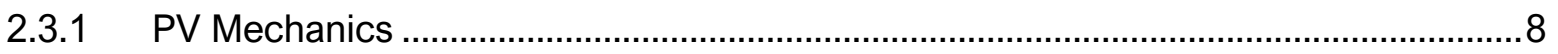

2.3.2 Rooftop PV Energy Balance ............................................................................. 8

2.3.3 Indirect Effects on Microclimate .......................................................................

2.3.4 Temperature-Dependent Efficiency .....................................................................

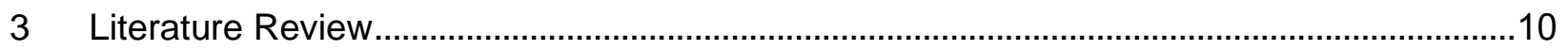

3.1 Simulating Urban Heat Island Mitigation Strategies ...................................................10

3.2 Human Thermal Comfort Simulations ......................................................................... 12

3.3 Simulating Large-Scale Deployments of Solar Photovoltaics .........................................12 
3.3.1 Reported Impact on Air Temperature................................................................13

3.3.2 Reported Impact on Sensible Heat Flux..............................................................14

3.3.3 Methodologies and Assumptions ..........................................................................14

3.3.4 Criticisms of Previous Research...............................................................................15

3.4 Modelling the Temperature-Dependent Efficiency of PV ……………………...............15

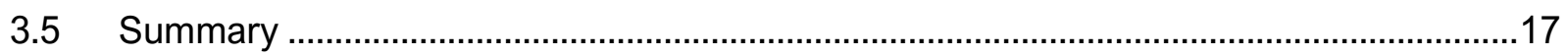

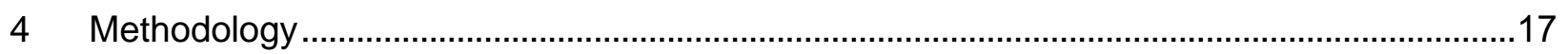

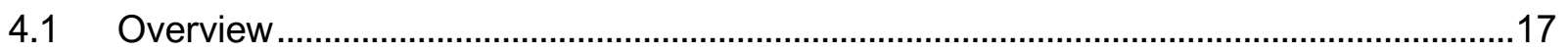

4.2 Outdoor Thermal Comfort Simulations ……………………………………………......19

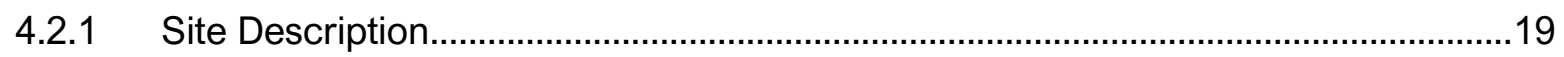

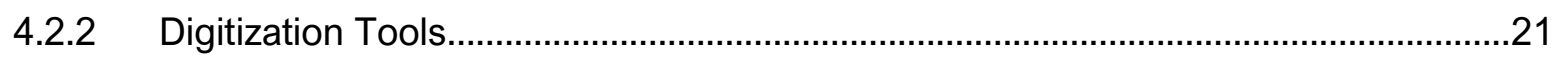

4.2.3 Meteorological Boundary Conditions ………………..............................................21

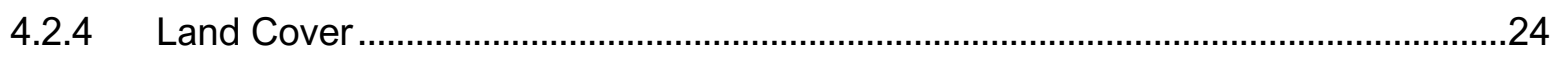

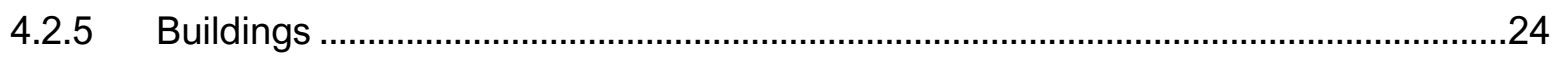

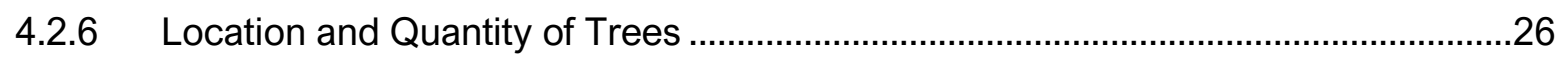

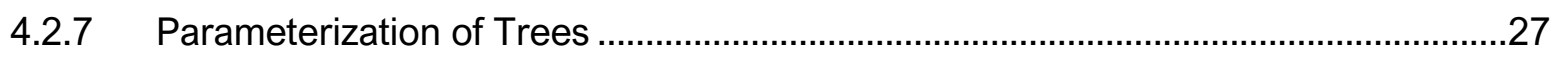

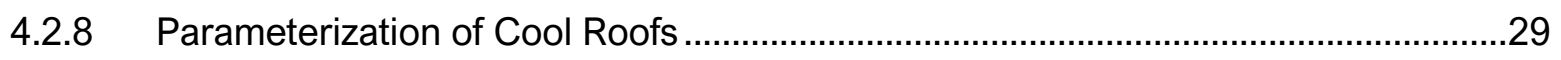

4.2.9 Parameterization of Rooftop Photovoltaics .............................................................29

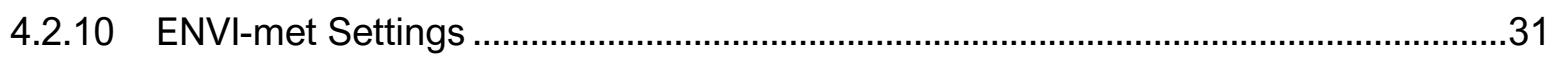

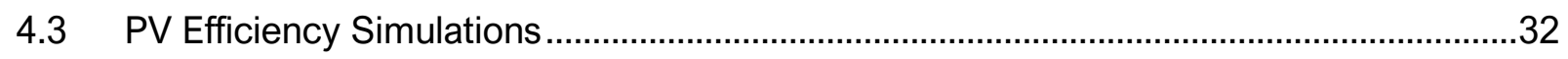

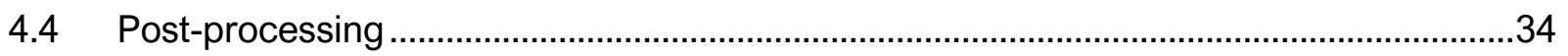

4.4.1 Calculation of Human Thermal Comfort...................................................................34

4.4.2 Calculation of Outdoor Thermal Comfort Autonomy ……………………..................34

4.4.3 Calculation of Temperature-Dependent PV Efficiency..............................................35

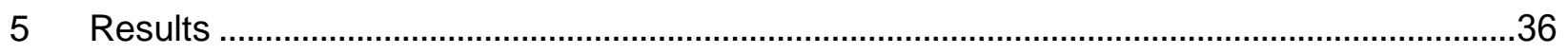

$5.1 \quad$ Validation of Baseline ..................................................................................................... 


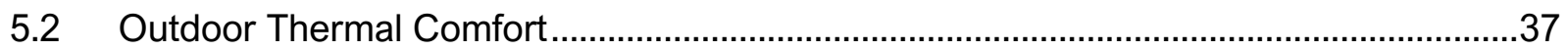

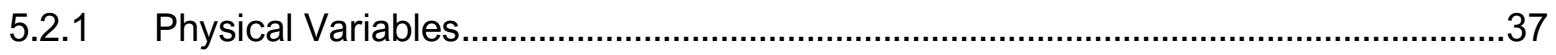

5.2.2 Universal Thermal Climate Index .........................................................................42

5.2.3 Outdoor Thermal Comfort Autonomy ..............................................................45

5.3 Energy Efficiency of Rooftop PV..............................................................................46

5.3.1 Temperature-Dependent Efficiency .................................................................46

5.3.2 Power and Energy Output ..................................................................................49

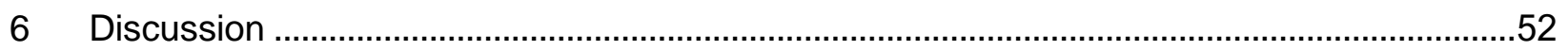

6.1 Effect of the Interventions on Outdoor Thermal Comfort .............................................52

6.2 Effect of the Interventions on PV Energy Efficiency ...................................................54

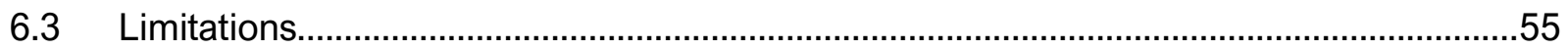

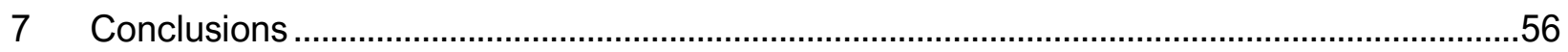

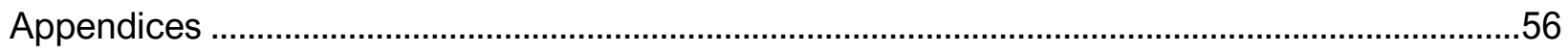

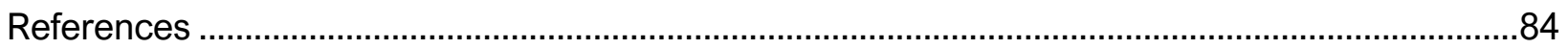




\section{LIST OF TABLES}

Table 1 - Overview of scenarios simulated to assess outdoor thermal comfort..........................19

Table 2 - Weather statistics for July 5, 2018 at Toronto Pearson International Airport................23

Table 3 - Meteorological conditions used to initialize the ENVI-met model in Open mode..........23

Table 4 - Hygrothermal and optical properties of land cover materials........................................24

Table 5 - Material properties assigned to the walls and roofs of buildings. .................................26

Table 6 - Tree canopy coverage for each scenario........................................................................27

Table 7 - Parameters for a heart-shaped deciduous tree with small trunk. ...................................29

Table 8 - Material properties assigned to PV surfaces.................................................................31

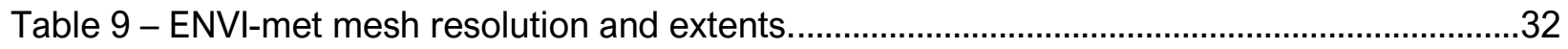

Table 10 - Overview of scenarios simulated to assess PV energy efficiency..............................33

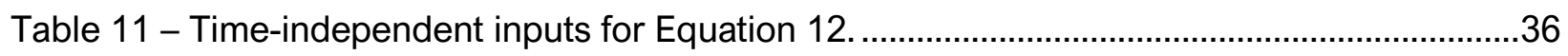

Table 12 - Spatial average (a) and maximum (b) UTCI deltas (relative to the baseline simulation)

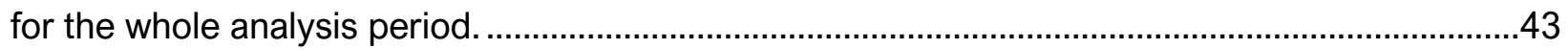

Table 13 - Spatial OTCA for each scenario, assuming an analysis period from 6:00 to 20:00, a comfort criterion of $9{ }^{\circ} \mathrm{C}<\mathrm{UTCl}<26^{\circ} \mathrm{C}$.

Table 14 - PV efficiency spatially and temporally averaged over the rooftop area and 4-day analysis period. 


\section{LIST OF FIGURES}

Figure 1 - Human heat balance in an outdoor environment.......................................................2

Figure 2 - UTCI 'reference condition' concept. The UTCI equivalent temperature $\left[{ }^{\circ} \mathrm{C}\right]$ is linked to the conditions under study by a predicted physiological response................................................. 5

Figure 3 - Overview of the present study. Green shaded boxes indicate outputs to be analyzed.

Figure 4 - Area under investigation in Brampton as shown by satellite image (top) and ENVI-met

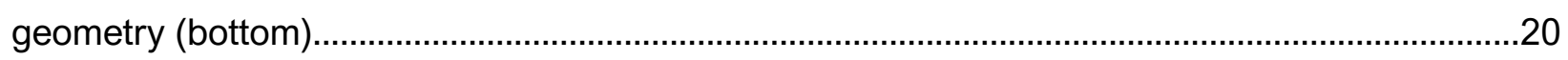

Figure 5 - a) typical two-storey detached house in the study area, b) one of the three-storey townhomes, c) one of the two parks, d) the elementary school. .21

Figure 6 - Hourly air temperature, relative humidity, wind direction and wind speed as measured at Toronto Pearson International Airport on July 5, 2018.

Figure 7 - Frequency of trees for a) the Baseline and Renewables scenarios, b) the Hybrid scenario, and c) the UHI Mitigation scenario. Each red circle represents a tree...........................27

Figure 8 - To-scale depiction of a LAD of $0.3 \mathrm{~m}^{2} \mathrm{~m}-{ }^{3}$. Each green triangle is a leaf. .28 Figure 9 - 10 metre tall tree after being meshed into ENVI-met. Each box represents a grid cell. Note that cells are not scaled to their actual dimensions in this illustration (see section 4.2.10). 29 Figure 10 - Close-up of the Renewables scenario in Rhino. Blue surfaces are PV solar panels. 31 Figure 11 - UTCl classified into thermal stress categories (Błażejczyk et al., 2010). The 'no thermal stress' category was used as upper and lower bounds for OTCA calculations. .35 Figure 12 - Air temperature as measured at Toronto Pearson International Airport versus the average of the validation points for the Baseline simulation. 37

Figure 13 - Slices (A,B,C,D) and the section analyzed. .38

Figure 14 - Spatial average of hourly air temperature for each of the four scenarios, for each slice.

Figure 15 - Air temperature at 15:00, as seen from the section cut in Figure 13. .40 Figure 16 - Spatial average of hourly specific humidity for each of the four scenarios, for each slice.

Figure 17 - Spatial average of hourly mean radiant temperature for each of the four scenarios, for each slice.

Figure 18 - Spatial average of hourly wind speed for each of the four scenarios, for each slice. 
Figure 19 - Spatial average of UTCI for each of the four scenarios, for each slice.

Figure 20 - UTCI heatmaps at 12:00 and 15:00.

Figure 21 - OTCA heatmaps for each scenario, considering an analysis period from 6:00 to 20:00 and a comfort criterion of $9{ }^{\circ} \mathrm{C}<\mathrm{UTCl}<26^{\circ} \mathrm{C}$.

Figure 22 - Solar conversion efficiency with no trees (00_NS), with trees planted to the North (above), and with trees planted to the South (below). Areas shaded yellow indicate global tilted irradiance. Values are spatially-averaged over the rooftop area. 47 Figure 23 - Solar conversion efficiency with no trees (00_NS/00_EW), with trees planted to the North and South (above), and with trees planted to the East and West (below). Areas shaded yellow indicate global tilted irradiance. Values are spatially-averaged over the rooftop area. .....48 Figure 24 - PV power and energy output with no trees (00_NS), with trees planted to the North (above), and with trees planted to the South (below). .50

Figure 25 - PV power and energy output with no trees (00_NS/00_EW), with trees planted to the North and South (above), and with trees planted to the East and West (below). .51

Figure 26 - Average energy produced per day for each of the 14 scenarios. .52 


\section{LIST OF APPENDICES}

Appendix A - Results of Studies Simulating UHI Mitigation Strategies ..........................................57

Appendix B - Results of Studies Simulating Microclimate Effects of Rooftop PV ..........................59

Appendix C - Mesoscale and Microscale Atmospheric Models ......................................................60

Appendix D - Equations Governing ENVI-met Plant Behaviour ......................................................61

Appendix E - Results from the Greenbelt Simulations ..................................................................62

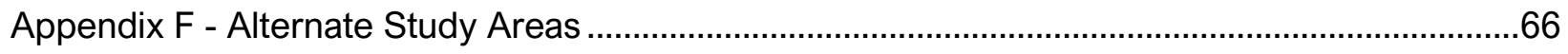

Appendix G - Grasshopper Script Used to Digitize the Study Area...............................................67

Appendix H - Python Script for Calculation of OTCA ……...........................................................68

Appendix I - Python Script for Calculation of PV Energy Efficiency................................................69

Appendix J - Validation of Alternate Baseline Simulation.................................................................75

Appendix K - Tabular Summaries of Physical Meteorological Results .............................................76

Appendix L - Air Temperatures Contributing to PV Cell Temperature Calculations ........................78

Appendix M - Wind Speeds Contributing to PV Cell Temperature Calculations .............................80

Appendix N - Global Tilted Irradiance Values Contributing to PV Cell Temperature ......................82 


\section{INTRODUCTION}

Public concern for urban resilience has appeared in the form of Canadian legislation and incentive programs promoting a sustainable development which must be responsive to climate change at a local and global scale (City of Toronto, 2019). Priority outcomes of these efforts include improved air quality, reduced waste, stormwater management, protection of ecological functions, reduction of greenhouse gas emissions and mitigation of the urban heat island (UHI) effect. An increasing list of strategies and technologies address these priorities. However, items on this list often compete in the same territory. An example in this sense is roof surface area. An abundance of research hails the effectiveness of high-reflectivity cool roofs for UHI mitigation, green roofs for storm water management, and solar photovoltaic (PV) roofs for reduced greenhouse gas emissions. Because these technologies excel at different aspects of resilience, it is difficult to argue that one is a better use of roof space than the other.

While it is futile to rank resilient interventions of different intentions, it is crucial to understand their effects when deployed in a common environment. Urban resilience is achieved not merely through a barrage of interventions, but rather through a suite of complementary strategies and technologies which are tailored to a particular condition. Thus, it is relevant to assess the synergies and conflicts between alternative resilient interventions.

Two priority outcomes of sustainable urban policy are reduced greenhouse gas emissions and mitigated UHI. Some interventions which may help achieve this are rooftop PV, street trees and cool roofs. Several relationships between these strategies can be hypothesized. For example, street trees reduce air temperature, which in turn may improve the performance of solar PV, because $\mathrm{PV}$ is known to be more efficient at lower temperatures. On the other hand, trees can also shade rooftop PV, making it less useful. From the perspective of UHI mitigation, rooftop PV substitutes what could be a surface of comparatively higher solar absorptance, e.g. cool roof.

The purpose of this study is to quantify trade-offs between rooftop PV, street trees and cool roofs in terms of outdoor thermal comfort and PV conversion efficiency. Experiments will be conducted using computational fluid dynamics (CFD) microclimate simulations of a suburb in Brampton, Ontario. The results of a scenario dedicated to UHI mitigation, a scenario dedicated to renewable energy production, and a scenario aiming to balance the two will yield insights on the optimal combination of interventions. In particular, it will be determined whether the microclimate 
enhancements offered by street trees can improve the efficiency of rooftop PV, and whether rooftop PV affects microclimate in the pedestrian domain.

\section{BACKGROUND}

The purpose of this section is to explain theories and concepts about outdoor thermal comfort, mechanics behind UHI mitigation strategies, and the PV energy balance.

\subsection{Outdoor Thermal Comfort}

\subsubsection{Human Heat Balance}

Thermal comfort is defined as the "condition of mind that expresses satisfaction with the thermal environment" (ASHRAE, 2017a). Central to this state is the human heat balance (Figure 1), which is modelled by the following equation (Fanger, 1972):

$$
S=M-W-E-(R+C)
$$

Equation 1

where $S$ is the rate of heat storage in an individual, $M$ is the metabolic rate of the individual, $W$ is the mechanical work being done by the individual, $E$ is evaporative heat loss, $R$ is radiative heat exchange with the environment and $C$ is convective heat exchange with the environment.

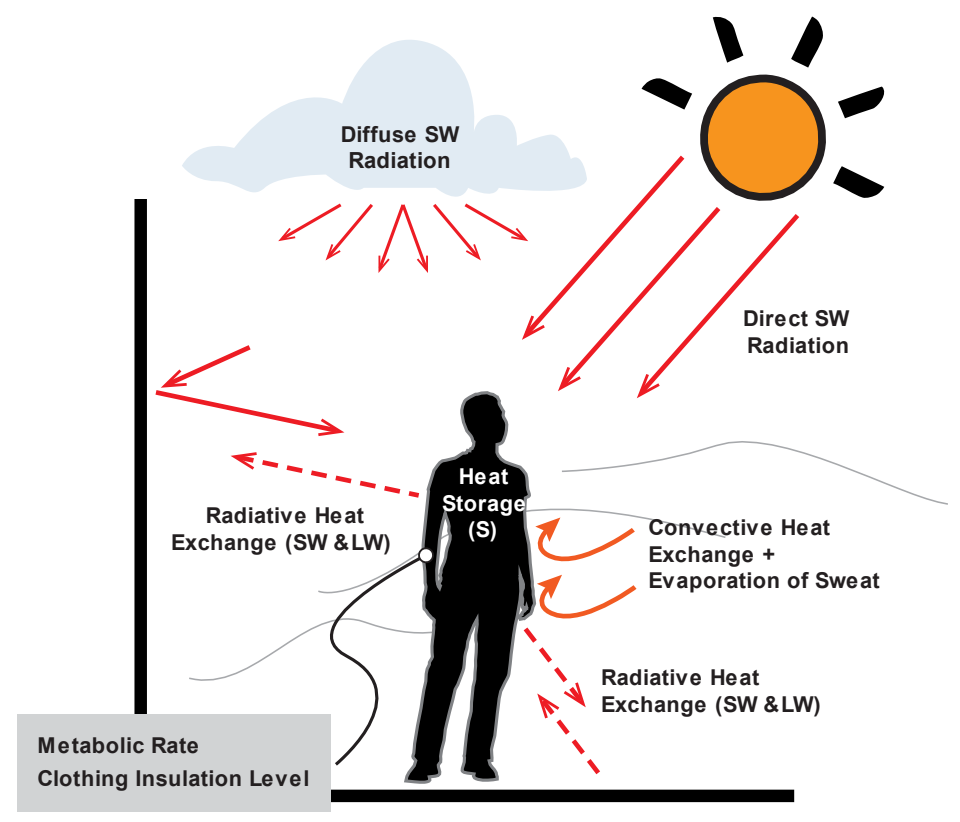

Figure 1 - Human heat balance in an outdoor environment. 
Meteorological parameters affecting this heat balance are air temperature $\left({ }^{\circ} \mathrm{C}\right)$, radiant temperature $\left({ }^{\circ} \mathrm{C}\right)$, air velocity $(\mathrm{m} / \mathrm{s})$ and humidity $(\%)$ (ASHRAE, 2017a). For example, air velocity controls $C$ (the rate of convective cooling on an individual's skin) and humidity controls $E$ (the potential for evaporative cooling through sweating). An additional two thermo-physiological parameters also effect the human heat balance: metabolic rate (met) and clothing insulation level (clo) (ASHRAE, 2017a).

\subsubsection{Mean Radiant Temperature}

Of all the variables affecting the human heat balance, perhaps the most influential is radiant temperature. In fact, some researchers have argued that radiant temperature is more indicative of thermal comfort than air temperature (Thorsson et al., 2014). For most applications, radiant temperature is assessed by the mean radiant temperature (MRT), which is defined as "the temperature of a uniform, black enclosure that exchanges the same amount of heat by radiation with the occupant as the actual surroundings" (ASHRAE, 2017a). This definition considers both longwave and shortwave incident radiation. The black enclosure in this case is representative of a material with an emissivity close to unity, meaning it reemits almost all absorbed radiation as thermal radiation. It is necessary for the definition to incorporate a hypothetical uniform enclosure because it would be impractical to measure the temperatures and angle factors of every surface in a real environment. $T_{m r t}$ is traditionally measured using a globe thermometer or pyranometers and pyrgeometer (Matzarakis, 2018).

For indoor environments, $T_{m r t}$ is often assumed to be equivalent to air temperature. Outdoors, however, $T_{m r t}$ can be much higher than ambient air temperature - especially under a clear summer sky (Thorsson et al., 2014). In this context, buildings have a double effect on MRT: sunlit walls reflect additional shortwave radiation and emit additional longwave radiation, causing an increase in $T_{m r t}$; while shadows cast by buildings cause a decrease in $T_{m r t}$.

When simulating thermal comfort, it is crucial to account for MRT. In an outdoor environment, this is made difficult due to the spatiotemporal variability of sun and shade combined with the myriad of materials - each with their own radiative properties - in a real urban environment. Most microclimate simulation tools use a formula based on the Stefan-Boltzmann law wherein a hypothetical human body is parametrized as a collection of isothermal surfaces with given emissivities, albedos, and projected area factors (Matzarakis, 2018). The shortwave and longwave radiation incident on the hypothetical human body - which is influenced by sky and surface view 
factors - is computed using an Indexed View Sphere (IVS) algorithm (ENVI-met), raytracing (Honeybee and Ladybug) or fisheye photographs (RayMan) (Naboni et al., 2017).

\subsubsection{Human Thermal Comfort Indices}

To enable more accurate measurements and predictions of human thermal comfort, human thermal comfort indices (HTCls) have been proposed. HTCls incorporate several physical meteorological variables to yield one value representative of relative comfort or discomfort. Humidex is an example of an $\mathrm{HTCl}$ used in Canadian meteorology since 1965 (Environment \& Climate Change Canada, 2013). It combines air temperature and humidity in a single number representative of the perceived sensation of an average person. This relationship is modelled by the following equation (Environment \& Climate Change Canada, 2019):

$$
\text { Humidex }=T+0.5555(P-10)
$$

Equation 2

where $T$ is air temperature $\left({ }^{\circ} \mathrm{C}\right)$ and $P$ is vapour pressure $(\mathrm{hPa})$. Another index used in meteorology is the Apparent Temperature (AT), which is comprised of air temperature, humidity and air velocity (Steadman, 1984):

$$
A T=-2.7+1.04(T)+2\left(\frac{P}{10}\right)-0.65(V)
$$

Equation 3

where $T$ is air temperature $\left({ }^{\circ} \mathrm{C}\right), P$ is vapour pressure $(\mathrm{hPa})$ and $V$ is wind speed at 10 metres height $(\mathrm{m} / \mathrm{s})$. Both these indices use linear equations which only account for a subset of the factors affecting the human heat balance. More sophisticated indices which account for more of the relevant meteorological and thermo-physical parameters have been proposed too.

The Predicted Mean Vote (PMV) index (Fanger, 1972) is widely used in building engineering to assess indoor spaces. It consists of an algorithm incorporating all four relevant meteorological parameters (air temperature, humidity, radiation, and air velocity) plus clothing insulation level and metabolic rate of the individual. It yields a predicted level of comfort on a seven-point scale ranging from cold to hot, which can also be used to estimate the percentage of people dissatisfied under a particular condition.

The Universal Thermal Climate Index (UTCI) is widely used for studying outdoor thermal comfort. Like PMV, it combines all four relevant meteorological variables in an algorithm, although it is usually applied as a $6^{\text {th }}$ order polynomial for computational efficiency (Matzarakis, 2018). It yields an 'equivalent temperature' which corresponds to the air temperature of the reference condition 
that yields the same physiological response as the study condition (Figure 2). The reference condition is characterized by $0.5 \mathrm{~m} / \mathrm{s}$ winds at 10 metres, $50 \%$ relative humidity, and an MRT equivalent to the air temperature (effectively an indoor condition) (Jendritzky et al., 2012). A unique aspect of UTCI is that it incorporates an adaptive clothing model which automatically adjusts the value of 'clo' depending on temperature. Further, metabolic rate is always assumed to be $135 \mathrm{~W} / \mathrm{m}^{2}$ (Jendritzky et al., 2012). Thus, UTCl does not allow physiological parameters to be set. In the past few years, UTCI has become a popular tool among architects and engineers trying to gain precise control over the effects of their interventions on outdoor thermal comfort (Henning Larsen, 2019).

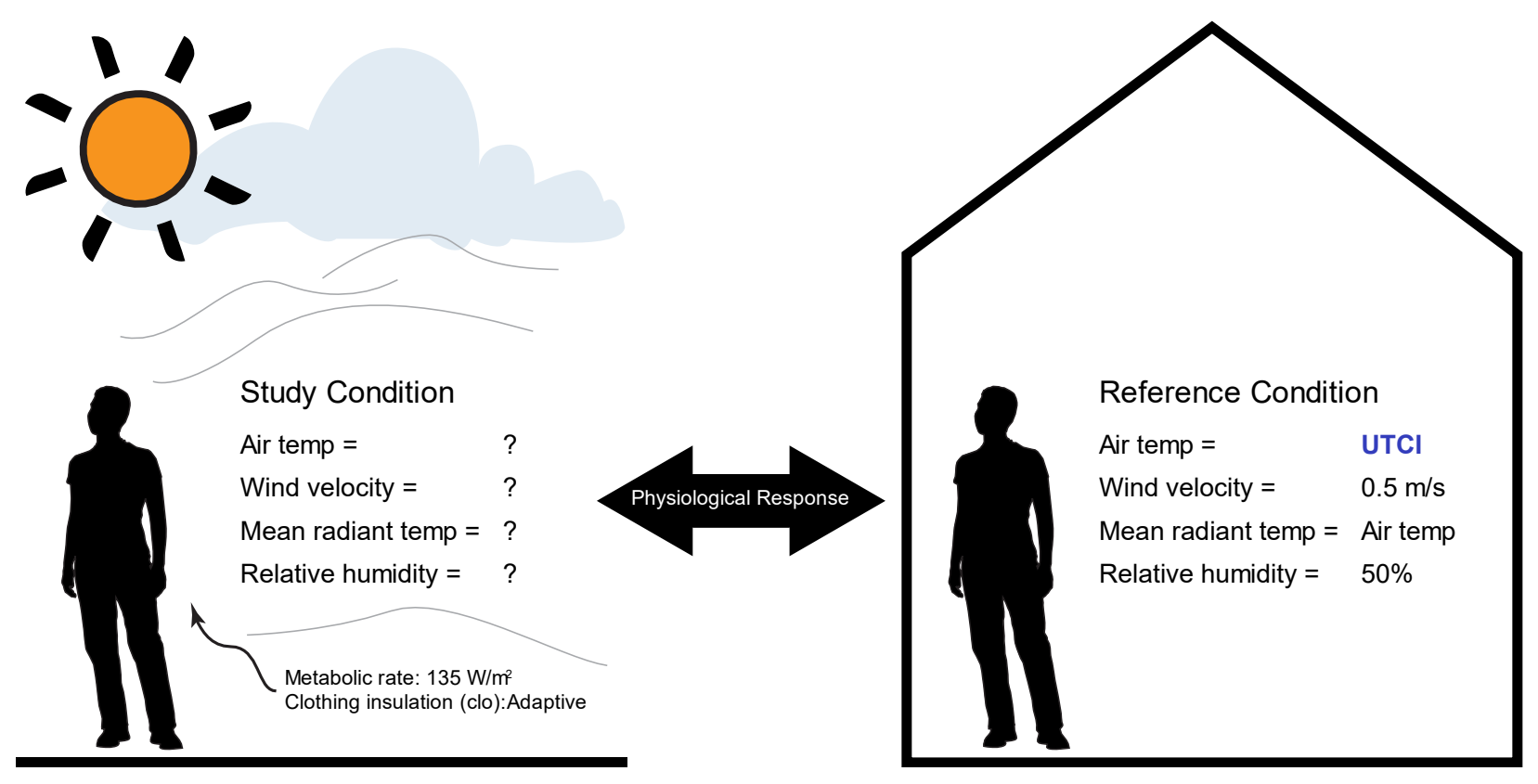

Figure 2 - UTCI 'reference condition' concept. The UTCl equivalent temperature $\left[{ }^{\circ} \mathrm{C}\right]$ is linked to the conditions under study by a predicted physiological response.

In academia, one of the most popular HTCls outdoor thermal comfort assessment is the Physiological Equivalent Temperature (PET). Like UTCI, it uses a sophisticated algorithm to report an equivalent temperature in the reference condition. The reference condition for PET is characterized by $0.1 \mathrm{~m} / \mathrm{s}$ winds, a vapour pressure of $12 \mathrm{hPa}$ and an MRT equivalent to the air temperature (Höppe, 1999). PET does not automatically adjust clothing insulation, and thus some consider it a more physically-based (as opposed to behaviourally-based) HTCI (Matzarakis, 2018). A limitation of all HTCls is that their models are derived from collections of empirical data which are only representative of the selected sample of people interviewed. Even if clothing and activity 
level is accounted for, thermal sensation is influenced by complex psychological factors such as naturalness, expectations and perceived control; which cannot be parameterized in numerical models (Chen \& Ng, 2012). These elements can only be captured through context-specific field data and questionnaires (Canan et al., 2019).

\subsubsection{Outdoor Thermal Comfort Autonomy}

The utility of $\mathrm{HTCls}$ can be enhanced by incorporating them into Outdoor Thermal Comfort Autonomy (OTCA) calculations, which add a temporal dimension to what are essentially point-intime observations (Nazarian et al., 2019). The concept of OTCA borrows from Daylight Autonomy, which is a metric describing the percentage of time a space is adequately lit by daylight (Reinhart et al., 2006). Similarly, OTCA is a metric describing the amount time a space is thermally comfortable given hourly $\mathrm{HTCl}$ observations and a comfort criterion. The calculation of OTCA is given by (Nazarian et al., 2019):

$$
\begin{aligned}
\text { OTCA } & =\frac{1}{N} \frac{1}{n} \sum_{k=1}^{N} \sum_{h_{r}=h_{i}}^{h_{f}} T C_{k, h r} \\
T C_{k, h r} & =\left\{\begin{array}{c}
1 \text { if } A_{\text {lower }}<H T C I<A_{\text {upper }} \\
\text { else } 0
\end{array}\right.
\end{aligned}
$$

Equation 4

where $N$ is the space's number of occupied days, $n$ is the number of occupied hours, $h_{i}$ is the initial occupied hour, $h_{f}$ is the final occupied hour, HTCI is the observed $\mathrm{HTCl}$ value at a given hour, $A_{\text {lower }}$ is the lowest value of that $H T C I$ considered comfortable, and $A_{\text {upper }}$ is the highest value of that $H T C I$ considered comfortable. This metric is highly customizable in that the period of use, $\mathrm{HTCl}$ and comfort criteria is user-defined. Further developments of this metric are Continuous OTCA and Spatial OTCA: Continuous OTCA awards partial credit for $\mathrm{HTCl}$ observations falling outside of the comfort criteria, while Spatial OTCA identifies the percentage of a space that falls within the comfort criteria for at least $50 \%$ of the occupied period (Nazarian et al., 2019).

\subsection{Urban Heat Island Mitigation Strategies}

\subsubsection{Urban Vegetation}

Trees and grasses cool the atmosphere through transpiration, a natural by-product of photosynthesis which was first theorized during the $18^{\text {th }}$ century. Transpiration describes the vaporization of water inside a leaf. The process can be summarized as a repartitioning of sensible 
heat into latent heat, similar to what occurs in the evaporator side of an air conditioner. However, the immediate air temperature reduction caused by trees is mostly confined to the top of the canopy (Erell et al., 2011).

Besides air temperature, vegetation also affects humidity, air velocity and MRT - the remaining ingredients to the human heat balance. Humidity is clearly increased during transpiration. In hot weather, this can be detrimental to human thermal comfort because it limits the rate of sweat evaporation (Erell et al., 2011). Also, in terms of air velocity, trees can be a source of aerodynamic drag which limits the effectiveness of convective cooling on the human body (Ghaffarianhoseini et al., 2015). In fact, most of the perceived cooling caused by trees is due to shading, or more specifically the absorption and reflection of shortwave radiation at the tree canopy (Erell et al., 2011). This results in a reduction of MRT at human height, albeit to varying extents depending on a few factors.

\subsubsection{Cool Materials}

A factor contributing to $\mathrm{UHI}$ is the abundance of dark materials, such as asphalt, used in cities. It is not actually the colour of the material that matters but rather the solar reflectivity, or albedo. In general, the lower the albedo of a material, the greater the solar absorptivity. Absorbed solar radiation is inevitably released as sensible heat and longwave (thermal) radiation, thus contributing to $\mathrm{UHI}$. The albedo of surfaces in urban areas ranges from 0.20 to 0.35 , meaning up to $80 \%$ of incident solar radiation is converted to heat and thermal radiation (Akbari et al., 1990).

Cool materials rely on the premise that by increasing surface albedo (while maintaining high emissivities), ambient air temperatures will be reduced. This occurs because the materials themselves will remain cooler, offering less sensible heat to be removed into the air by convection. Typical albedos for cool materials range from 0.7 to 0.85 (Santamouris \& Synnefa, 2016). Typical applications are on roofs in the form of white PVC membranes or white asphalt shingles. Similar to case with trees, the air temperature reductions caused by cool roofs are mainly experienced at roof height, well above the pedestrian domain (Tsoka et al., 2018). Cool facades and cool pavements may bring these air temperature reductions closer to pedestrian height, however there is a risk of reflecting the incoming solar radiation towards the pedestrians themselves, thereby increasing MRT and harming thermal comfort (Taleghani \& Berardi, 2018). 


\subsection{Rooftop Solar Photovoltaics}

\subsubsection{PV Mechanics}

Modern solar photovoltaic (PV) cells use photons from sunlight to dislodge electrons in a semiconducting material, such as crystalline silicon. The resulting movement of electrons between two oppositely charged regions of the material is captured as electric direct current (Petela, 2010). Not all photons have sufficient energy to cause this reaction. For crystalline silicon, solar conversion can only occur with photons having a wavelength less than $1.13 \mu \mathrm{m}$ (near infrared) (Labouret \& Villoz, 2003). The remainder of the solar spectrum, if absorbed, becomes heat. Further losses occur through recombination, a process by which dislodged electrons are bound back to atoms (Petela, 2010). This unconverted solar radiation also becomes heat. The proportion of solar radiation flux which a solar panel is able to convert into electricity is described by its solar conversion efficiency $(\eta)$. This varies depending on semiconductor material, solar panel design, application, and environmental conditions. As of May 2019, efficiencies as high as 39\% have been achieved in laboratories, but commercially-available panels are usually around $20 \%$ efficient (Green et al., 2019).

\subsubsection{Rooftop PV Energy Balance}

PV is an attractive means of displacing centrally-located power utilities with distributed renewable energy. Rooftop systems are particularly effective, and account for $74 \%$ of all PV capacity in the United States (Scherba et al., 2011). They are present on most net-zero energy buildings (NZEBs) and can satisfy a large portion of a building's annual electrical loads. (Kummert \& Robert, 2012). The energy balance of a PV-equipped roof is markedly different from that of a traditional roof, as shown by the energy balance equation for a solar panel (Masson et al., 2014):

$$
S W^{\downarrow}+L W^{\downarrow}+L W_{\text {roof }}^{\uparrow}=S W_{\text {panel }}^{\uparrow}+L W_{\text {panel }}^{\uparrow}+L W_{\text {panel }}^{\downarrow}+H+E_{\text {prod }}
$$

Equation 5

where $S W^{\downarrow}$ is the incoming shortwave radiation from the sun, $L W^{\downarrow}$ is the incoming longwave radiation from the atmosphere, $L W_{\text {roof }}^{\uparrow}$ is the longwave radiation emitted from the roof and intercepted by the underside of the solar panel, $S W_{\text {panel }}^{\uparrow}$ is shortwave radiation reflected off the panel (a product of its albedo), $L W_{\text {panel }}^{\downarrow}$ is longwave radiation emitted and reflected by the panel (a product of its surface temperature and emissivity), $L W_{\text {panel }}^{\downarrow}$ is longwave radiation emitted from 
the panel downwards towards the roof, $H$ is sensible heat flux from the solar panel to the air, and $E_{\text {prod }}$ is electricity produced by the panel.

Two major conclusions can be drawn from this energy balance. First, solar panels shade roofs, in other words reducing the amount of solar radiation arriving at the building. This has positive implications for cooling energy load, but negative implications for heating energy load (Masson et al., 2014). Second, solar panels may emit additional longwave radiation to roofs (Scherba et al., 2011). This has positive implications for heating energy load, but negative implications for cooling energy load.

\subsubsection{Indirect Effects on Microclimate}

Clearly, a more efficient solar panel will produce more electricity. However, there is also potential for local atmospheric benefits. Claude-Alain Roulet (2001) hypothesized that "the heat released to the town will decrease as soon as the photovoltaic conversion efficiency is larger than the average albedo of the city". This is because, in theory, less of the solar radiation intercepted by the roof will be converted into sensible heat as it is being converted into electricity (more $E_{\text {prod }}$ equals less $H, L W_{\text {panel }}^{\downarrow}$ and $\left.L W_{\text {panel }}^{\downarrow}\right)$. With less sensible heat flux, there is less heat that can be carried away by convection, resulting in decreased air temperatures. Taken into the context of the UHI effect experienced in many cities today, Roulet's observation has been called an "indirect benefit" of rooftop PV (Taha, 2013; Salamanca et al., 2016). Other researchers have argued that this theory relies on drastic oversimplifications of the PV panel energy balance, and that PV will certainly cause warming in an urban environment (see section 3.3.4) (Pham et al., 2019).

\subsubsection{Temperature-Dependent Efficiency}

The effect of PV cell temperature on the PV electrical efficiency $(\eta)$ is well documented. The nameplate efficiency reported by solar panel manufacturers refers to performance under Standard Testing Conditions (STC) of an irradiance of $1000 \mathrm{~W} / \mathrm{m}^{2}$, an AM1.5 irradiance spectrum ${ }^{1}$ and a cell temperature of $25^{\circ} \mathrm{C}$ (IEC, 2016). Under actual operating conditions, cell temperature is often greater than $25^{\circ} \mathrm{C}$, causing efficiency to be less than the nameplate. For crystalline silicon cells, the drop in efficiency - known as the temperature coefficient $\left(\beta_{r e f}\right)$ - is approximately $0.4 \%$ per ${ }^{\circ} \mathrm{C}$ increase of cell temperature above the STC reference temperature (Bücher, 1997).

\footnotetext{
${ }_{1}^{1} \mathrm{AM} 1.5$ is a reference spectrum describing the terrestrial solar irradiance typically received by a surface tilted $37^{\circ}$ towards the equator under U.S. standard atmospheric conditions (NREL, 2019).
} 
Depending on location, this can lead to power production $30 \%$ less than expected from STC conditions (Bücher, 1997). This limitation of PV has led to the development of hybrid PV/thermal collectors (PV/T) which use coolant loops (i.e. glycol) to remove unwanted heat from the cells (Notton et al., 2005). It seems natural to conclude that UHI mitigation strategies would be complementary to these efforts, however it is important to note that cell temperature is not equivalent to ambient air temperature as it will be discussed in section 3.4.

\section{LITERATURE REVIEW}

\subsection{Simulating Urban Heat Island Mitigation Strategies}

The most ambitious proposals for mitigating UHI involve infrastructure-scale modifications - for example, the addition of trees, green roofs or cool materials to a whole city. At first, these proposals were tested using small-scale mock-ups (Parker, 1982), then computer energy balance models (EBMs) (Akbari et al., 1990; Sailor, 1994), and more recently microscale computational fluid dynamic (CFD) models (Ng et al., 2012; Taleghani et al., 2014). The benefit of computer simulations is that large-scale changes to real urban morphologies can be forecasted quickly. For example, Jandaghian \& Akbari (2018) looked at the effects of increasing the surface albedo of all roofs and pavements in Sacramento, Chicago and Houston - a considerable geographic area. Other large-scale changes recently simulated include the addition of green roofs (Rosenzweig et al., 2006), trees (Berardi \& Wang, 2016) and water ponds (Taleghani et al., 2014) to entire neighbourhoods.

The results of studies modelling large-scale deployments of heat mitigation strategies generally show meaningful reductions in UHI. Of course, the magnitude of cooling varies by the heat mitigation tactic deployed. When 2-metre air temperature is considered (hereafter termed T2), installing cool pavements has demonstrated reductions between $0.4{ }^{\circ} \mathrm{C}$ and $1.4{ }^{\circ} \mathrm{C}$, assuming albedo increases between 0.2 and 0.6 (Taleghani \& Berardi, 2018; Santamouris et al., 2018). However, as pointed out by Wang et al. (2016), the maximum cooling effect is only achieved where the sky view factor is high. The presence of clouds also diminishes the effect (Rosenzweig et al., 2006). Cool roofs have generally shown T2 reductions of lesser magnitude and are mostly ineffective in areas of tall buildings (Santamouris et al., 2018; Ma et al., 2018; Tsoka et al., 2018).

Increasing vegetation is another heat mitigation tactic extensively simulated. Green roofs have demonstrated daytime $\mathrm{T} 2$ reductions in the range of $0.2{ }^{\circ} \mathrm{C}$ to $0.6{ }^{\circ} \mathrm{C}$ (Rosenzweig et al., 2006; 
Berardi, 2016). However, as with cool roofs, their effectiveness depends on building height. $\mathrm{Ng}$ et al. (2012) recorded negligible T2 cooling effects when green roofs were simulated in an area of 60-storey buildings in Hong Kong. Leaf area index ( $\mathrm{LAl}$ ) and soil irrigation rate are also relevant factors which control rate at which sensible heat is exchanged for latent heat (Berardi, 2016; Ma et al., 2018). For heat mitigation purposes, street trees have shown to be a more robust tactic, achieving reductions between $0.5^{\circ} \mathrm{C}$ and $1.8{ }^{\circ} \mathrm{C}$ when canopy coverage is increased by $10 \%$ to 55\% ( $\mathrm{Ng}$ et al., 2012; Wang et al., 2016; Santamouris et al., 2018). Under selected conditions, however, trees can increase local air temperature by dampening wind speeds and thus the potential for convective cooling (Ghaffarianhoseini et al., 2015). When street trees and cool pavement are simulated together, $\mathrm{T} 2$ reductions close to $2{ }^{\circ} \mathrm{C}$ are seen (Tsoka et al., 2018).

The temporal characteristics of heat mitigation strategies have also been tested through simulations. For cool materials, peak cooling is reported to occur between solar noon and late afternoon (Jandaghian \& Akbari, 2018; Sailor, 1994). This coincides with the time of maximum solar insolation, where albedo can have the greatest influence on urban radiative fluxes. For green roofs, peak cooling can occur several hours later, and sometimes overnight (Berardi, 2016; Ma et al., 2018). Sailor (1994) attributes this to the fact that evapotranspiration rates are positively correlated with air temperature, which usually peaks several hours after insolation does. Street trees offer peak cooling around the same time as cool materials, although some studies have reported that the cooling duration is shorter for trees (Sailor, 1994; Wang et al., 2016). This is supportive of the hypothesis of Erell et al. (2011), which claims that most of the cooling attributable to trees is due to shading, which in itself only occurs when solar radiation is arriving at the tree canopy.

An important consideration when comparing the results of simulations is the deployment rate assumed for the intervention being studied. In most of the reviewed literature, the maximum technical potential of a mitigation strategy is determined and simulations are run at or below this threshold (Taha, 2013; Taleghani et al., 2016). However, technical feasibility varies from location to location. For example, Rosenzweig et al. (2006) estimated that $64 \%$ of New York City's surface area qualified for albedo increase. Expectedly, their simulations showed that temperature reductions up to $0.94{ }^{\circ} \mathrm{C}$ could be attained through a cool materials campaign. Meanwhile, a city with lower-intensity development and more green space would have experienced less of a temperature reduction from the same intervention. 


\subsection{Human Thermal Comfort Simulations}

Recently, the interest in human health and wellbeing has brought outdoor thermal comfort to the foreground of urban climate research (Chen \& Ng, 2012). This movement has been further propelled by the development of CFD microclimate models. These models permit explicit representation of building and tree geometry, which is important for the calculation of MRT and wind flow. This is in contrast to mesoscale models, such as Weather Research and Forecasting (WRF), which require heavy parameterization of urban morphologies. For a more complete comparison of microscale and mesoscale atmospheric models, see Appendix C.

Strategies successful at reducing $\mathrm{T} 2$ tend to be successful at reducing perceived temperature. Sun et al. (2016) simulated 100\% deployment of green roofs in the Greater Beijing Region and found a median pedestrian-height Apparent Temperature (AT) decrease of $1{ }^{\circ} \mathrm{C}$. While evapotranspiration did cause humidity to increase, the reduction in sensible heat resulted in a net improvement to thermal comfort. This agrees with Taleghani et al.'s (2016) study done for a lowrise residential neighbourhood in Los Angeles, which reported an average $0.6{ }^{\circ} \mathrm{C}$ decrease in PET if green roofs were adopted on all buildings. In Bilbao, Lobaccaro \& Acero (2015) simulated the addition of 5-metre high trees to several barren urban canyons and saw the peak pedestrianheight PET drop by up to $10^{\circ} \mathrm{C}$. They attributed this mainly to the creation of new shadows, in which MRT was significantly lowered. Ma et al. (2018) reported 2-metre AT reductions around 0.7 ${ }^{\circ} \mathrm{C}$ when the albedo of all roofs in Sydney was increased to 0.64 . However, they admitted that their model (Weather Research and Forecasting) tends to overestimate the impact of cool roofs on surface-level meteorology. Finally, Wang et al. (2016) simulated the combined effects of cool pavements, cool roofs and $10 \%$ more trees in Toronto and found PET reductions up $4.6{ }^{\circ} \mathrm{C}$.

Table A-1 summarizes the main findings of studies simulating UHI mitigation strategies. Overall, street trees seem to yield the most consistent benefit to summertime outdoor thermal comfort. Further, as was the case with air temperature, HTCls, when measured at pedestrian height, are less affected by rooftop mitigation strategies.

\subsection{Simulating Large-Scale Deployments of Solar Photovoltaics}

The microclimatic consequences of adopting rooftop PV on a large scale are relatively unknown. Only a handful of studies simulate meteorological variable before and after the addition of rooftop PV to a whole neighbourhood or city. Among these studies, there is reasonable agreement that 
rooftop PV can cause cooling up to $0.5^{\circ} \mathrm{C}$ in the pedestrian realm. However, some researchers have criticized the simplifications made in these studies.

\subsubsection{Reported Impact on Air Temperature}

Taha (2013) used the mesoscale model MM5 to simulate the impact of rooftop PV on air temperature and UHI during a Los Angeles heat wave. Various deployment rates and PV efficiencies were simulated, plus a "high albedo city" scenario. The results showed that with the addition of rooftop PV, 5-metre air temperatures could be reduced by up to $0.15^{\circ} \mathrm{C}$ in the present context, and $0.2^{\circ} \mathrm{C}$ if the PV was deployed in a future high albedo city.

In Paris, Masson et al. (2014) used the mesoscale Town Energy Balance model to run a similar experiment. High albedo scenarios were not considered, although solar hot water collectors and building energy consumption was analyzed. The results showed cooling up to $0.3^{\circ} \mathrm{C}$ relative to the base case. They hypothesized this would reduce the total population affected by heat stress for more than half of the day by $4 \%$, using UTCI as a metric for thermal comfort.

Salamanca et al. (2016) compared the effects of cool roofs, rooftop PV, and mixtures of the two on T2 and regional cooling energy demand in Phoenix and Tucson during a 10-day heat wave. A unique coupling of the mesoscale Weather Research and Forecasting model and a building energy model was used to carry out this task. In terms of $\mathrm{T} 2$, reductions between $0.4{ }^{\circ} \mathrm{C}$ and 0.8 ${ }^{\circ} \mathrm{C}$ were obtained for citywide deployments of rooftop PV.

Moving towards microscale simulations, Cortes et al. (2015) used a 5-metre resolution CFD model nested in a WRF model to simulate a $400 \mathrm{~m} \times 400 \mathrm{~m}$ district of Osaka, Japan during a clear summer day. The combined impact of rooftop and facade PV was assessed, and the pedestrian-level temperature was reported to drop $0.1^{\circ} \mathrm{C}$ on average and $0.4^{\circ} \mathrm{C}$ at most.

Most recently, Ma et al. (2018), aiming to identify the best heat mitigation strategy for Sydney in terms of thermal comfort, used WRF to compare cool roofs, PV roofs and green roofs. For the PV scenario, a maximum T2 decrease of around $1^{\circ} \mathrm{C}$ was reported in the city centre.

Masson et al. (2014) and Salamanca et al. (2016) also examined the temporal qualities of PV's cooling effect. In contrast to cool roofs, Masson et al. reported that the impact of rooftop PV was greatest at night. Salamanca et al. came to the same conclusion after obtaining cooling magnitudes twice as large from 02:00 to 06:00 versus from 07:00 to 19:00. Masson et al. attributed this phenomenon to the fact that rooftop solar panels shield thermally-massive buildings from 
daytime solar radiation, thus reducing the amount of heat they reemit at night. Table B-1 summarizes the main findings of studies simulating citywide deployments of rooftop PV.

\subsubsection{Reported Impact on Sensible Heat Flux}

While this literature review is mostly concerned with variables directly related to human thermal comfort, one well-cited paper slightly outside of that scope is worth mentioning. Scherba et al. (2011) used EnergyPlus to model the effects of adding PV over a black roof, green roof and cool roof in six U.S. cities during the summer. The variable assessed was total sensible heat flux from the roof. It was found that the addition of PV to a cool or green roof increases peak flux by an average of $120 \mathrm{~W} / \mathrm{m}^{2}$ and $95 \mathrm{~W} / \mathrm{m}^{2}$ respectively.

\subsubsection{Methodologies and Assumptions}

Many experimental controls influence the magnitude and timing of cooling observed for large scale PV deployments. For example, as with any heat mitigation strategy, the deployment rate assumed will have a significant bearing on T2. Taha (2013) tested both a "reasonably high deployment" (20\%-50\% roof coverage) and a "high deployment" (60\%-90\% roof coverage) scenario based on market estimates and land use classifications. Expectedly, the high deployment scenario caused the most change. Cortes et al. (2015) only tested an extreme scenario in which all buildings had $100 \%$ coverage of roof and facade PV and obtained one of the largest cooling magnitudes found in literature. This implies that denser applications of PV are more likely to cause temperature changes. Another controlling factor is the height of buildings in the study area. As with cool roofs and green roofs, the effect of PV on the pedestrian realm is expected to diminish as vertical distance increases, although this effect is not explicitly remarked in literature. Lastly, the pre-existing qualities of the roofs themselves are also an important factor - in particular their assumed albedo. Most of the reviewed literature assumes a baseline albedo of around 0.2. If the albedo of solar panels is in the range of $0.06-0.01$ (Taha, 2013), a higher baseline albedo should be unfavourable to the cooling effect of PV.

Some assumptions are unique to parameterizations of PV. One of the most important is electrical efficiency. In 2001, Claude-Alain Roulet posited that increased efficiency of solar panels should not only lead to increased power output but localized cooling as well. Taha (2013) tested this correlation by simulating five different electrical efficiencies (10\%, 15\%, 20\%, 25\% and 30\%) based on performance levels attainable in 2013 and predicted for the future. Solar conversion was modelled in MM5 using the principle of "effective albedo", whereby the solar panel albedos 
were uprated to account for the radiation that was absorbed and converted to electricity (see section 4.2.8). Measurable impacts (cooling or warming) were not observed until efficiency was raised past $20 \%$, and the maximum temperature decrease of $0.15{ }^{\circ} \mathrm{C}$ was only achieved in the $30 \%$ efficiency scenario. Thus, it is implied that a small degree of cooling via PV is only possible with extremely high performing modules. Another relevant experimental control pertains to the geometry of the solar panels. In most of the reviewed literature, rooftop PV is modelled as the original roof itself with altered optical and thermal properties. Exceptions are Masson et al. (2014), who modified the Town Energy Balance model to account for longwave radiation emitted from the panel to the roof and shortwave radiation blocked by the panels; Salamanca et al. (2016) who achieved a similar parameterization in Weather Research and Forecasting; and Cortes et al. (2015), who treated the panels as surfaces offset $60 \mathrm{~mm}$ from the building which are sensitive to convective heat removal on both sides. Clearly, the precision with which the solar panel geometry is modelled will affect the results.

\subsubsection{Criticisms of Previous Research}

As was just demonstrated, representations of rooftop PV in climate simulations tend to involve several assumptions and simplifications due to scale at which the models operate. Recently, Pham et al. (2019) argued that these simplifications draw into question the results obtained. In particular, Pham et al. pointed out that Taha's parameterization (2013) treats the ground, buildings and PV as a single surface, neglecting to account for the fact that a citywide implementation of PV would constitute an addition of two surfaces (both sides of the elevated PV) on which convective heat transfer could act. They suggest this neglection of convective surface area led to an underestimation of sensible heat flux to the atmosphere. Indeed, it has been argued by others that elevated solar cells are especially susceptible to convective heat removal (Skoplaki et al., 2008). Only Cortes et al. (2015) considered this aspect.

\subsection{Modelling the Temperature-Dependent Efficiency of PV}

The relationship between PV cell temperature and electrical efficiency is expressed by the temperature coefficient $\left(\beta_{\text {ref }}\right)$ of a solar panel. However, cell temperature is a property specific to PV. Thus, it is necessary to estimate cell temperature from local meteorological parameters. Dozens of correlations exist to fill this need, most of them requiring at least ambient air temperature and irradiation, although a few consider wind speed as well (Skoplaki \& Palyvos, 2009). Some correlations are specific to certain application of PV. 
Of the climate simulations reviewed, Masson et al. (2014) and Salamanca et al. (2016) also consider the potential power output of the PV. To do this, they employ a simple formula for cell temperature:

$$
T_{\text {cell }}=T_{\text {air }}+k_{T} G_{T}
$$

Equation 6

where $T_{\text {air }}$ is the ambient air temperature, $G_{T}$ is the solar radiation arriving at the PV plane, and $k_{T}$ is the Ross coefficient $\left[\mathrm{K} \cdot \mathrm{m}^{2} \mathrm{~W}^{-1}\right]$ which relates radiation to temperature. This value of $T_{\text {cell }}$ is subsequently used in the formula (Masson et al., 2014):

$$
R\left(T_{\text {cell }}\right)=\min \left\{1 ; 1-0.005 \times\left(T_{\text {cell }}-298.15\right)\right\}
$$

Equation 7

where $R\left(T_{\text {cell }}\right)$ is the proportion of the nameplate efficiency achieved, 0.005 is the assumed $\beta_{\text {ref }}$ and 298.15 is the STC cell temperature [K]. Some of the more sophisticated cell temperature correlations relate local meteorological parameters to NOCT (Nominal Operating Cell Temperature) conditions. NOCT $\left(T_{N O C T}\right)$ itself describes the cell temperature as measured under a set of standard conditions (Duffie \& Beckman, 2013). These standard conditions differ from STC and are instead defined by the so-called Normal Terrestrial Environment (NTE), which consists of:

- Solar irradiance of $800 \mathrm{~W} / \mathrm{m}^{2}$

- Wind speed of $1 \mathrm{~m} / \mathrm{s}$

- Ambient air temperature of $20^{\circ} \mathrm{C}$

For most crystalline silicon solar panels, these conditions produce a $T_{N O C T}$ between $43^{\circ} \mathrm{C}$ and 47 ${ }^{\circ} \mathrm{C}$ (Bücher, 1997). By relating $\beta_{r e f}, T_{N O C T}$, NTE conditions and actual local conditions, a more precise estimate of PV efficiency can be obtained. This is exemplified by a correlation by Skoplaki \& Palyvos (2009):

$$
\eta_{i}=\eta_{\text {ref }}\left\{1-\beta_{\text {ref }}\left[T_{a, i}-T_{\text {ref }}+\left(\frac{9.5}{5.7+3.8 V_{w, i}}\right)\left(T_{N O C T}-T_{a, i}\right) \frac{G_{T, i}}{G_{N O C T}}\right]\right\}
$$

Equation 8

where $\eta_{i}$ is the actual PV efficiency at hour $i, \eta_{\text {ref }}$ is the ideal efficiency measured under STC, $\beta_{r e f}$ is a temperature coefficient $\left({ }^{\circ} \mathrm{C}^{-1}\right), T_{r e f}$ is STC air temperature $\left({ }^{\circ} \mathrm{C}\right), T_{N O C T}$ is NOCT in the NTE $\left({ }^{\circ} \mathrm{C}\right), V_{w, i}$ is local wind velocity $(\mathrm{m} / \mathrm{s})$ and $G_{N O C T}$ is global solar flux in the NTE $\left(\mathrm{W} / \mathrm{m}^{2}\right)$. This correlation reflects a generic PV module, and is an improvement over the one used by Masson et al. (2014) in that it accounts for wind velocity. The wind coefficient assumes $T_{N O C T}$ was obtained in $1 \mathrm{~m} / \mathrm{s}$ winds, therefore values of $V_{w, i}$ greater than $1 \mathrm{~m} / \mathrm{s}$ will lead to a reduction of cell 
temperature (Duffie \& Beckman, 2013). The present study will use this approach as opposed to that in Equation 6 and 7.

\subsection{Summary}

This literature review has looked at recent studies assessing the microclimatic effects of heat island mitigation strategies and rooftop PV. There have been few attempts to quantify the pedestrian-height effects of rooftop PV deployment, especially in comparison to the multitude of studies examining green roofs and cool roofs. Rarer are studies considering the effects of rooftop PV on outdoor thermal comfort as defined by HTCls. As a result of these deficiencies, there is limited consensus on the consequences of displacing traditional UHI mitigation strategies with extensive PV installations. Further, there has been limited research on the effects of UHI mitigation strategies, specifically street trees, on the temperature-dependent performance of PV. The present study aims to quantify the trade-offs between UHI mitigation strategies and de-centralized urban renewables in terms of outdoor thermal comfort and PV solar conversion efficiency.

\section{METHODOLOGY}

\subsection{Overview}

In order to assess the trade-offs between rooftop PV and UHI mitigation actions, a series of numerical microclimate simulations were performed (Figure 3). The 3D CFD model ENVI-met v4.4 was selected for the task because of its ability to compute surface-plant-air interactions at a fine spatial resolution. Further, its ability to predict wind flow and MRT is validated in literature (Naboni et al., 2017; Toparlar et al., 2017). This is important because these two variables have a large influence on human thermal comfort.

Two sets of simulations were performed: one to address outdoor thermal comfort and one to address PV energy efficiency. The outdoor thermal comfort simulations consider a neighbourhood under three scenarios which are representative of varying levels of commitment to renewable energy or UHI mitigation. These scenarios were analyzed in terms of pedestrian-level UTCI and OTCA. The PV efficiency simulations consider a single building in the neighbourhood under 14 combinations of tree height and placement. These combinations were assessed in terms of PV solar conversion efficiency, power and energy produced. 


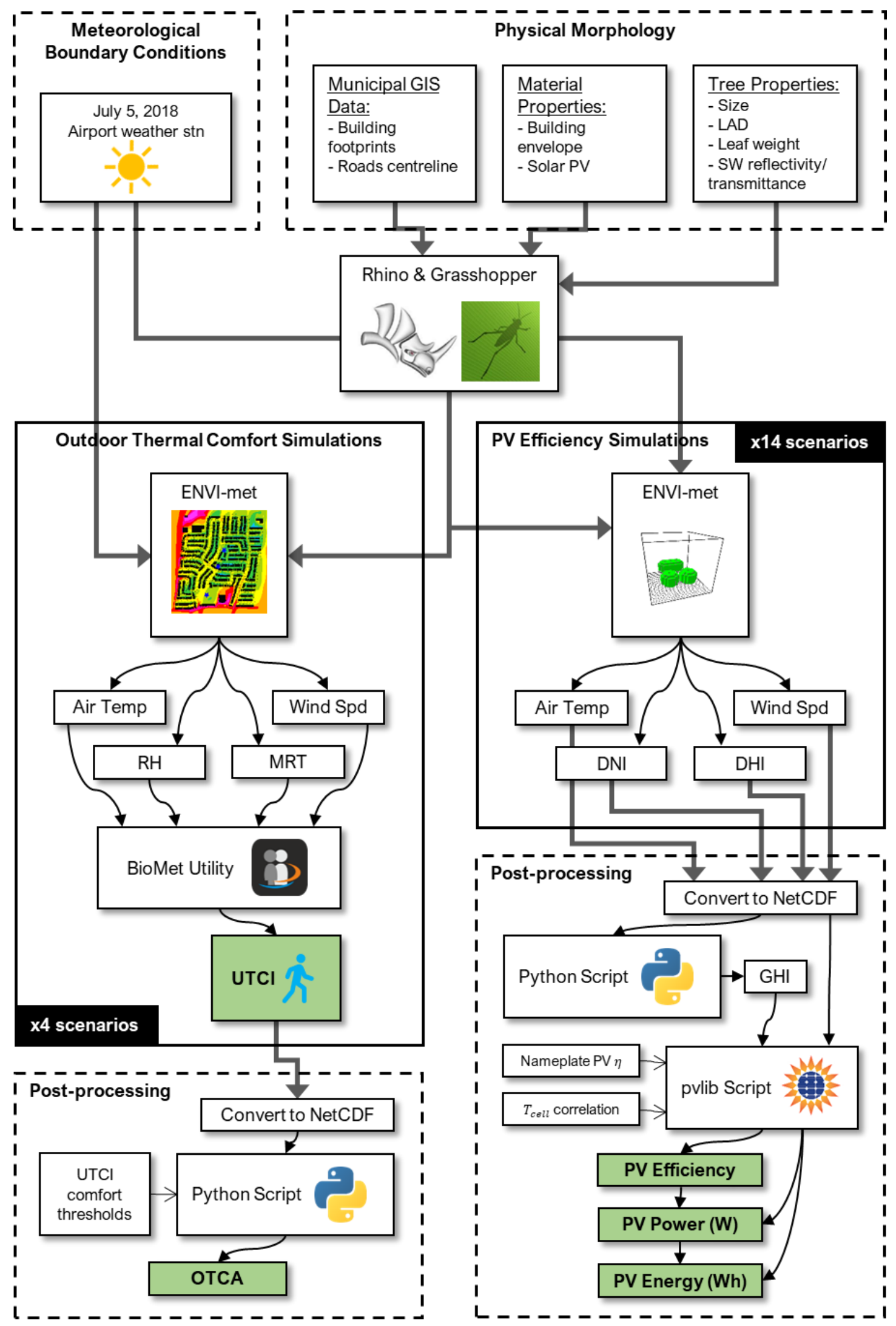

Figure 3 - Overview of the present study. Green shaded boxes indicate outputs to be analyzed. 


\subsection{Outdoor Thermal Comfort Simulations}

The three scenarios of the neighbourhood-scale outdoor thermal comfort simulations were designed with consideration towards the reviewed literature (Appendix A, B). For the UHI Mitigation scenario, the tree canopy coverage was increased and cool roofs were selected over green roofs from the standpoint of practicality. Rooftop PV was chosen to represent renewable energy technologies because it lends to residential retrofits and directly competes with cool roofs for real estate. The Hybrid scenario involves adding PV and increasing tree canopy coverage, albeit to a lesser extent than in the UHI Mitigation scenario. This is to account for the likelihood that tree-planting would be quelled, so as not to shade the PV panels too.

Table 1 - Overview of scenarios simulated to assess outdoor thermal comfort.

\begin{tabular}{ll}
\hline Baseline & As observed today \\
\hline UHI Mitigation & $\begin{array}{l}\text { Symbolic of a policy dedicated to urban heat mitigation: all roofs are } \\
\text { converted to cool roofs and tree canopy coverage is increased by the } \\
\text { maximum amount possible on streets and in parks. }\end{array}$ \\
\hline Renewables & $\begin{array}{l}\text { Symbolic of a policy aiming to maximize renewable energy production: all } \\
\text { roofs are completely covered with PV. }\end{array}$ \\
\hline Hybrid & $\begin{array}{l}\text { Symbolic of a policy aiming to balance urban heat mitigation and renewable } \\
\text { energy: baseline roofs are completely covered with PV while the existing } \\
\text { tree canopy coverage is increased on streets only, by } 50 \% \text { of that in the UHI } \\
\text { Mitigation scenario. }\end{array}$ \\
\hline
\end{tabular}

\subsubsection{Site Description}

The study area is a suburb in Brampton, Ontario, Canada (Figure 4). Its precise location is $43^{\circ} 39^{\prime} 59^{\prime \prime} \mathrm{N}, 79^{\circ} 46^{\prime} 32^{\prime \prime} \mathrm{W}$. Buildings are mainly two-storey detached homes, plus a minority of three-storey townhomes (Figure 5a, b). Contained in the study area are two small parks, an elementary school and a shopping plaza (Figure 5c, d). Land cover is mostly impervious (asphalt or concrete), with grass covering only the parks and a small portion of the parcels associated with each home. The total area under investigation is $0.75 \mathrm{~km}^{2}$.

Brampton is located in ASHRAE Thermal Climate Zone 5A, which corresponds to "Cool" overall conditions (ASHRAE, 2019). Despite this, air temperatures regularly exceed $30^{\circ} \mathrm{C}$ during the summer, thus indicating the relevance of UHI mitigation strategies in this area. Suburbs like the one under study constitute a large portion of the Greater Toronto Area and are rapidly expanding in Canada. Moreover, they contain valuable outdoor recreational spaces whose future enjoyment 
hinges on climate change. This particular neighbourhood was selected on the basis of its homogeneity and significant potential for greening. A homogenous context means simulation results are less likely to be influenced by unique features. Undesirable unique features in this case were ponds, rapid changes in elevation, or dissimilar buildings. By avoiding these features, the results are more representative of all low-rise residential neighbourhoods.

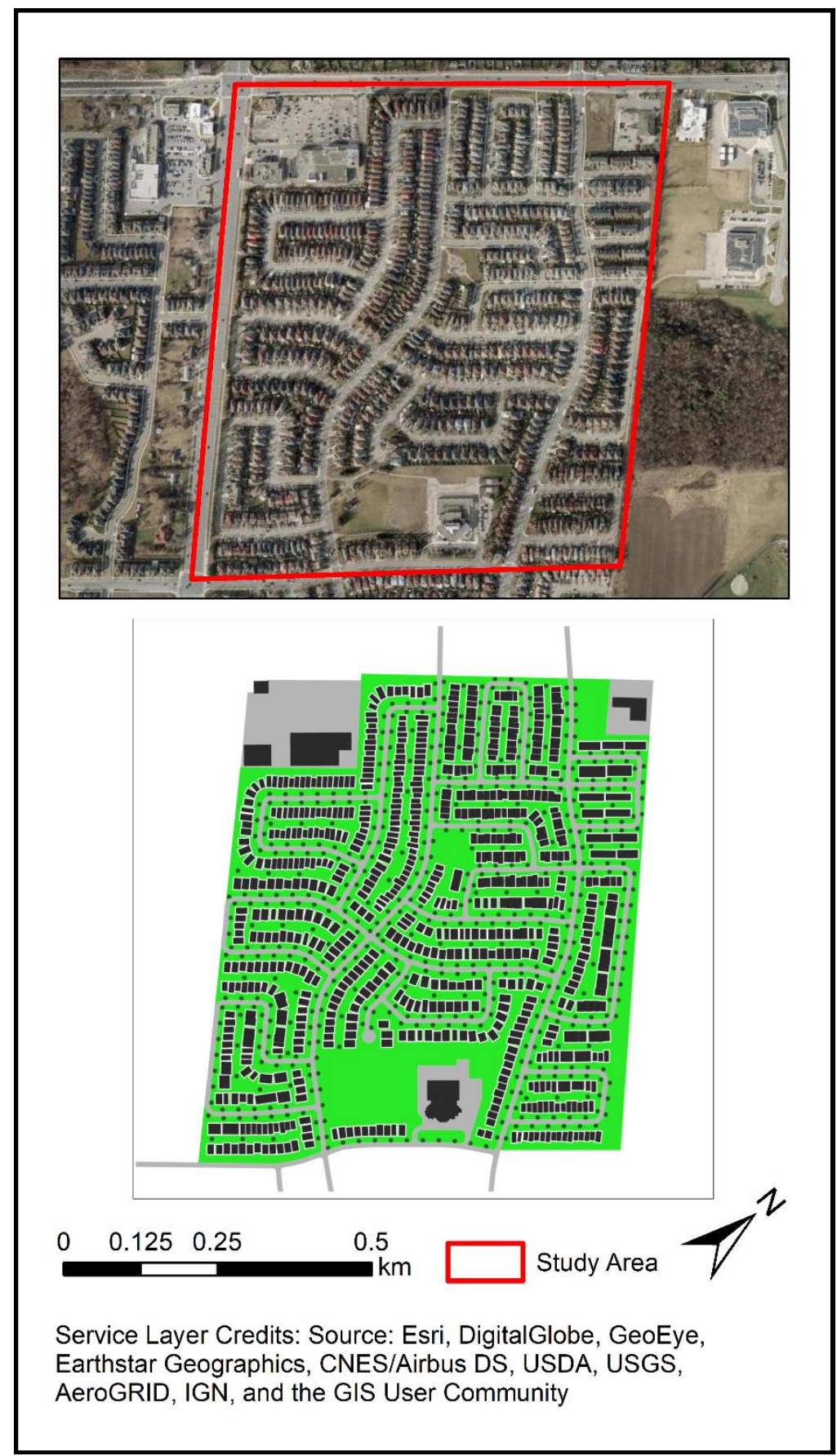

Figure 4 - Area under investigation in Brampton as shown by satellite image (top) and ENVI-met geometry (bottom). 
a)

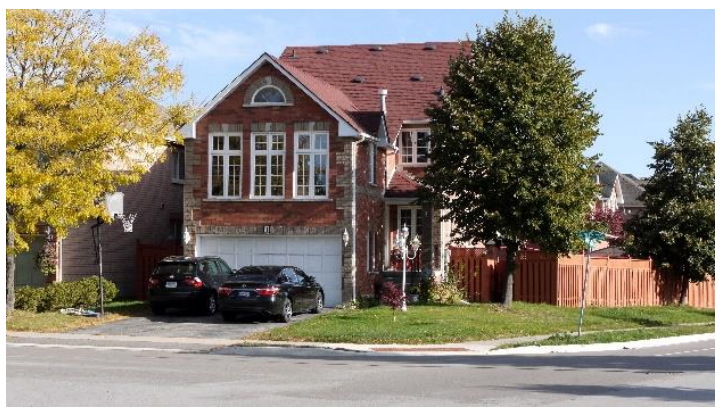

c)

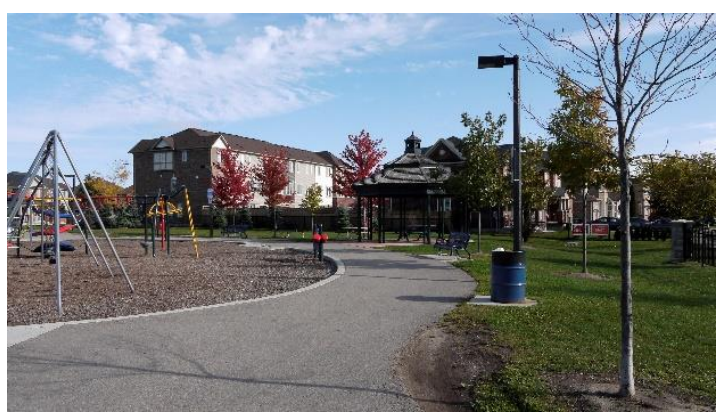

b)

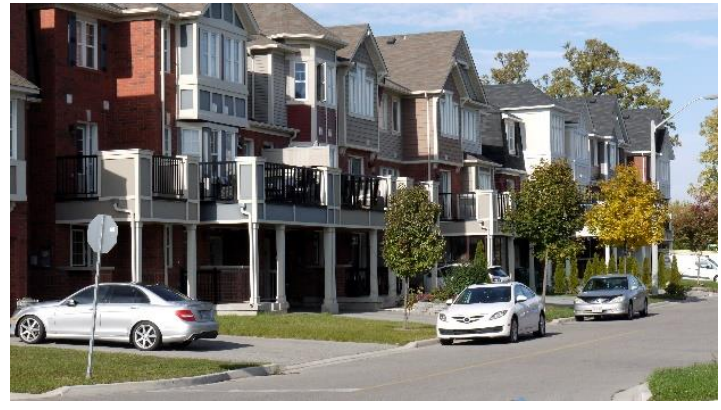

d)

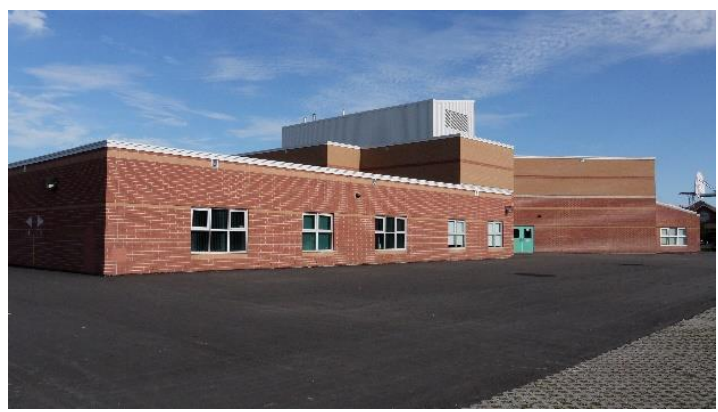

Figure $5-a$ ) typical two-storey detached house in the study area, b) one of the three-storey townhomes, c) one of the two parks, d) the elementary school

\subsubsection{Digitization Tools}

The physical morphology of the study area was constructed using Rhino, a 3D computer-aided design (CAD) program; Grasshopper, a visual scripting interface for Rhino; Ladybug, an environmental analysis plugin for Grasshopper; and ENVI-BUG, a plugin for Ladybug that converts Rhino geometry to an ENVI-met model (Fabbri et al., 2017). This workflow was selected over the proprietary ENVI-met model editors because repetitive elements such as houses can be drawn more precisely in a dedicated CAD software. Three additional models of the study area were created for a separate project delivered to the Friends of the Greenbelt Foundation, Ontario. A selection of results from this project is provided in Appendix $\mathrm{E}$.

\subsubsection{Meteorological Boundary Conditions}

Due to the computational intensity of ENVI-met, simulations are normally run for not longer than a single day representative of the weather condition being assessed. With such a short analysis period, it is critical that the meteorological boundary conditions defining this 'representative day' 
are realistic. For this study, the problem being addressed is urban overheating, and thus the boundary conditions are representative of a hot summer day.

Weather data was acquired from Environment and Climate Change Canada's Historical Data portal in CSV format. Meteorological variables are air temperature $\left({ }^{\circ} \mathrm{C}\right)$, dew point temperature $\left({ }^{\circ} \mathrm{C}\right)$, relative humidity $(\%)$, wind direction (in 10 degree increments), wind speed $(\mathrm{km} / \mathrm{h})$, visibility and air pressure relative to Mean Sea Level (MSL). The weather station selected is located at Toronto Pearson International Airport, which is approximately $12 \mathrm{~km}$ from the study area.

July 5, 2018 was selected as a representative day. The conditions on this day and the three days prior closely resemble the US National Weather Service's definition of a heat wave, which is three or more consecutive days with the temperature reaching or exceeding $90{ }^{\circ} \mathrm{F}\left(32.22{ }^{\circ} \mathrm{C}\right)$. The maximum air temperature on July 5,2018 was $33.2{ }^{\circ} \mathrm{C}$ at $16: 00$. The minimum air temperature was $22.6^{\circ} \mathrm{C}$ at $21: 00$. Relative humidity ranged from $93 \%$ at $23: 00$ to $50 \%$ at $14: 00$. Mean wind speed was $3.13 \mathrm{~m} / \mathrm{s}$, and the most common wind direction was from 160 degrees. A complete summary of the day is provided in Figure 6 and Table 2.

ENVI-met supports three methods of supplying meteorological conditions to the lateral boundaries of the model: open, cyclic and closed. In open mode, the model is given an initial condition and the values of the next grid cell closest to the inflow border is copied to the inflow border at each time step. By contrast, in cyclic mode, values at the outflow border are copied to the inflow border. In closed mode, predefined conditions are supplied to the inflow border at half-hour intervals. These predefined conditions can follow an idealized diurnal profile (simple forcing) or real meteorological data (full forcing).

For this study, open mode was selected because it gives the most agency to the model itself, which is optimal for assessing relative differences between scenarios (

Table 3). The initial $2 \mathrm{~m}$ temperature and humidity were set to $24.4^{\circ} \mathrm{C}$ and $62 \% \mathrm{RH}$, respectively, which corresponds to conditions observed at the airport at 3:00. Wind speed and direction were set to $3.13 \mathrm{~m} / \mathrm{s}$ and 160 degrees respectively, which are the mean and mode values, respectively, for July 5, 2018. Roughness length at the weather station, which is used to construct the logarithmic wind profile, was assumed to be 0.01 in accordance with the short grass covering much of Toronto Pearson International Airport. Cloud coverage was set to 0 octas in order to maximize solar radiation and create a scenario most conducive to urban overheating. 

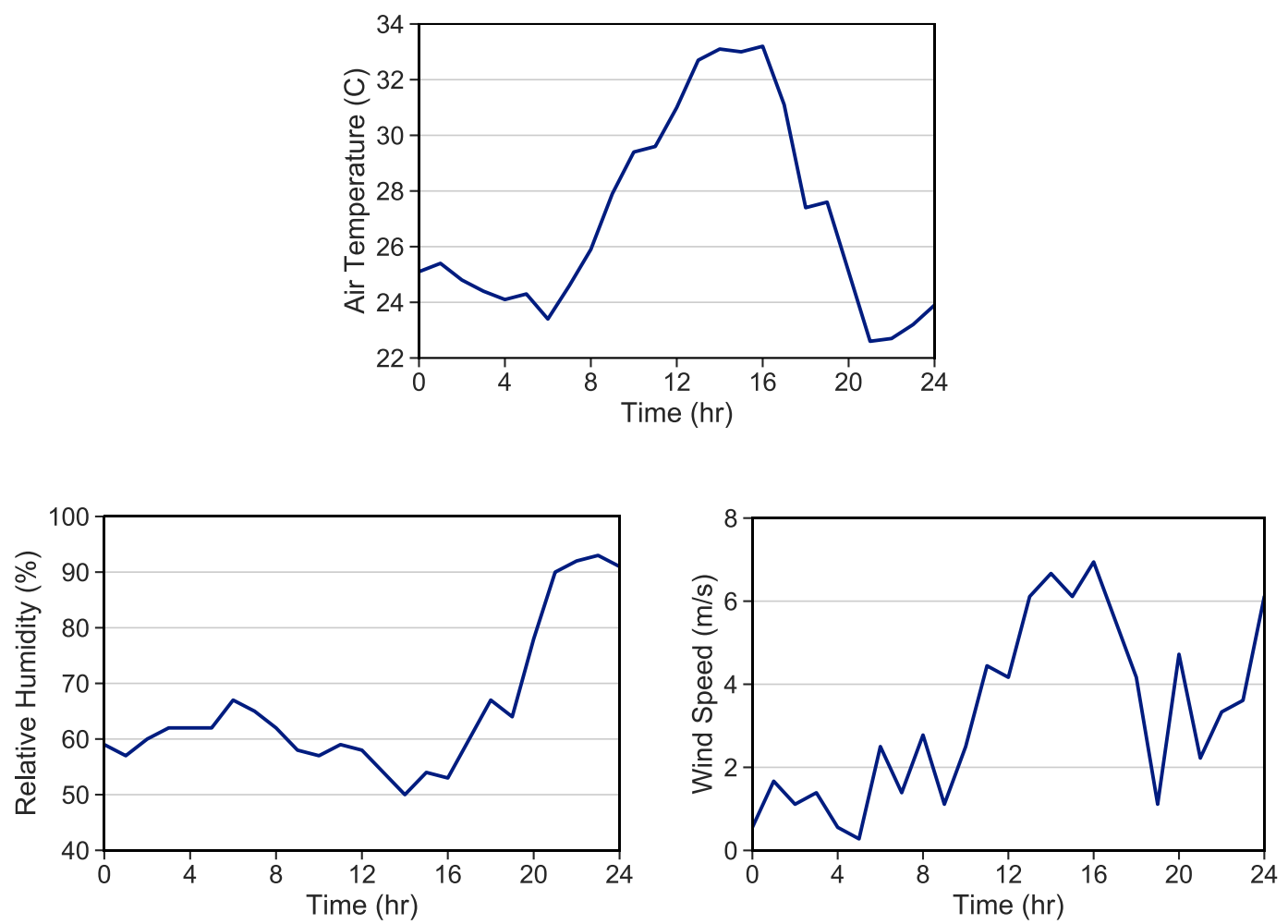

Figure 6 - Hourly air temperature, relative humidity, wind direction and wind speed as measured at Toronto Pearson International Airport on July 5, 2018.

Table 2 - Weather statistics for July 5, 2018 at Toronto Pearson International Airport.

\begin{tabular}{llll} 
& Min & Mean & Max \\
\hline Air Temperature $\left({ }^{\circ} \mathbf{C}\right)$ & 22.6 & 27.15 & 33.2 \\
\hline Relative Humidity (\%) & 50.0 & 64.29 & 93.0 \\
\hline Wind Speed (m/s) & 0.28 & 3.13 & 6.94 \\
\hline
\end{tabular}

Table 3 - Meteorological conditions used to initialize the ENVI-met model in Open mode.

\begin{tabular}{lr}
\hline Initial $\mathbf{2}$ m Air Temperature & $24.4^{\circ} \mathrm{C}$ \\
\hline Initial $\mathbf{2}$ m Relative Humidity & $62 \%$ \\
\hline $\mathbf{1 0} \mathbf{~}$ Wind Speed & $3.13 \mathrm{~m} / \mathrm{s}$ \\
\hline $\mathbf{1 0} \mathbf{m}$ Wind Direction & $160 \mathrm{~m} / \mathrm{s}$ \\
\hline Cloud Coverage & 0 octas
\end{tabular}




\subsubsection{Land Cover}

For all scenarios, two surface profiles were used: $10 \mathrm{~cm}$ thick asphalt roads and $5 \mathrm{~cm}$ grass. Asphalt roads were digitized using a roads centreline shapefile from the City of Brampton geospatial data portal (City of Brampton, 2019). The file contains a series of polylines representing the centreline of all roads in the study area. Before working on the file, distortion was corrected by projecting the polylines to Universal Transverse Mercator (UTM) Zone 17N, which is the zone that Brampton falls within. To convert the geometry to surfaces, the file was exported to Rhino where each polyline was offset to give a constant road width of $8 \mathrm{~m}$. A radius of $5 \mathrm{~m}$ was used to fillet intersections. These dimensions are loosely based on construction drawings from the City of Brampton Engineering \& Construction Division (City of Brampton, 2013). In ENVI-met, grass is treated as a 2D surface capable of evapotranspiration. More information on how evapotranspiration is parameterized is provided in section 4.2.7.

Table 4 shows the hygrothermal and optical properties assigned to the three land cover materials, which are default properties in the ENVI-met software. Note that shortwave reflectivity $(\boldsymbol{\rho})$ is only considered for the top layer materials visible to the sky, and shortwave transmittance $(\boldsymbol{\tau})$ is only considered for grass. In terms of topography, the site was assumed to be flat.

Table 4 - Hygrothermal and optical properties of land cover materials.

\begin{tabular}{|c|c|c|c|c|c|c|c|}
\hline & 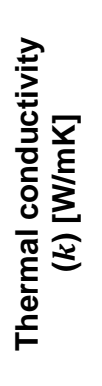 & 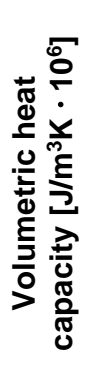 & 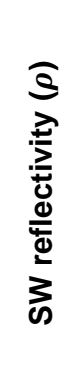 & 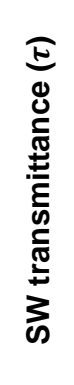 & 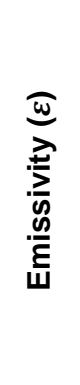 & 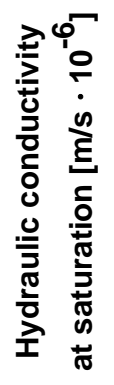 & 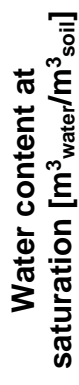 \\
\hline Asphalt road $(10 \mathrm{~cm})$ & 0.90 & 2.25 & 0.20 & & 0.90 & 0.00 & 0.00 \\
\hline Grass (5 cm) & & & 0.20 & 0.30 & & & \\
\hline Silty Clay Loam & 0.00 & 1.32 & & & & 1.70 & 0.48 \\
\hline
\end{tabular}

\subsubsection{Buildings}

Digitization of the buildings began with a building footprints shapefile from the City of Brampton geospatial data portal (City of Brampton, 2018). The file resolves all buildings in the study area with reasonable accuracy, as verified by satellite imagery. Before working on the file, distortion was corrected by projecting the geometry to Universal Transverse Mercator Zone 17N in ArcGIS. 
Next, the file was exported to Rhino where small accessory structures such as garden sheds and gazebos were removed. These structures were deemed insignificant towards the experiment and unlikely to be sampled by ENVI-met's coarse mesh. Next, each house footprint was traced by a rectangle which was then extruded according to building height. Only two building heights were assumed: $7.5 \mathrm{~m}$ (2 storeys) and $11.25 \mathrm{~m}$ (3 storeys). An exception to this rule was the elementary school, which has a one storey portion $4.5 \mathrm{~m}$ high and a two storey portion $7.5 \mathrm{~m}$ high. The result of these operations was 759 rectangular polysurfaces, which were meshed into ENVI-met using Grasshopper and ENVI-BUG. See Appendix G for the Grasshopper script used.

In ENVI-met, building assemblies determine heat flux from the indoors ${ }^{2}$ and surface radiative fluxes. Thus, it is important their constituent materials are given accurate thermal and optical properties. For exterior roof and wall materials, ENVI-met considers thermal conductivity, specific heat, emissivity, shortwave absorptivity, shortwave transmittance and shortwave reflectivity (albedo). An assembly can contain up to three layers of materials. For the present study, one wall assembly and one roof assembly were created under the assumption that all buildings in the study area are wood-framed brick veneer structures typical of the Greater Toronto Area. The properties used to emulate these assemblies are provided in Table 5.

\footnotetext{
${ }^{2}$ Interior setpoint temperatures were assumed to be $19.85^{\circ} \mathrm{C}$ for all buildings, which is the ENVI-met default.
} 
Table 5 - Material properties assigned to the walls and roofs of buildings.

\begin{tabular}{|c|c|c|c|c|c|c|c|c|c|c|}
\hline & 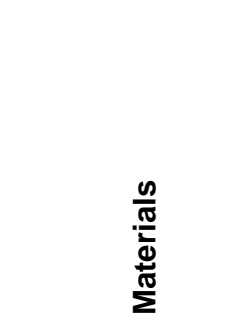 & 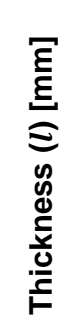 & 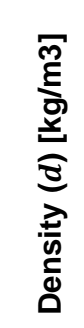 & 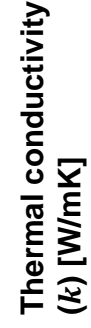 & 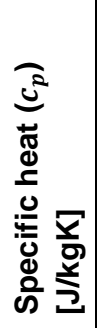 & 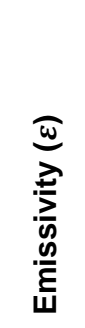 & 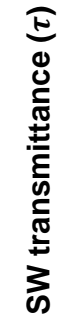 & 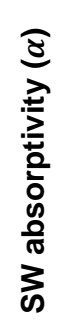 & 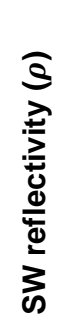 & 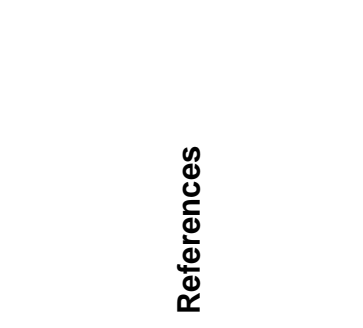 \\
\hline \multirow{3}{*}{$\overline{\bar{N}}$} & Brick & 100 & 1920 & 0.90 & 800 & 0.9 & 0.0 & 0.7 & 0.3 & $\begin{array}{l}\alpha, \rho: \text { Straube \& Burnett } \\
(2005) \\
\tau: \text { ENVI-met default } \\
\text { All else: (ASHRAE, } \\
2017 \mathrm{~b} \text { ) }\end{array}$ \\
\hline & $\begin{array}{l}\text { Fibreglass batt } \\
\text { insulation }\end{array}$ & 100 & 11 & 0.04 & 800 & 0.9 & 0.0 & 0.5 & 0.5 & $\begin{array}{l}\tau, \alpha, \rho: \text { ENVI-met default } \\
\text { All else: (ASHRAE, } \\
\text { 2017b) }\end{array}$ \\
\hline & Gypsum board & 15 & 640 & 0.16 & 1150 & 0.9 & 0.0 & 0.5 & 0.5 & $\begin{array}{l}\tau, \alpha, \rho: \text { ENVI-met default } \\
\text { All else: (ASHRAE, } \\
\text { 2017b) }\end{array}$ \\
\hline \multirow{3}{*}{ ¿ัo } & Asphalt shingle & 15 & 920 & 0.19 & 1000 & 0.90 & 0.0 & 0.8 & 0.2 & $\begin{array}{l}\rho, \varepsilon \text { : Erell et al. (2011) } \\
\tau, \alpha \text { : inferred from Erell et } \\
\text { al. (2011) } \\
\text { All else: ASHRAE (2017) }\end{array}$ \\
\hline & Plywood & 15 & 540 & 0.11 & 1880 & 0.90 & 0.0 & 0.5 & 0.5 & $\begin{array}{l}\tau, \alpha, \rho: \text { assumed } \\
\text { All else: ASHRAE (2017) }\end{array}$ \\
\hline & $\begin{array}{l}\text { Fibreglass batt } \\
\text { insulation }\end{array}$ & 600 & 11 & 0.04 & 800 & 0.90 & 0.0 & 0.5 & 0.5 & $\begin{array}{l}\tau, \alpha, \rho: \text { ENVI-met default } \\
\text { All else: ASHRAE (2017) }\end{array}$ \\
\hline
\end{tabular}

\subsubsection{Location and Quantity of Trees}

Since trees are modelled explicitly in ENVI-met, it was necessary to 'place' individual trees in the model domain. Instead of doing this according to the exact site conditions - which would yield unnecessary precision - typical frequencies of trees relative to the road centreline were established. Using satellite images of the study area, it was observed that a tree is present on the front lawn of a house every $26 \mathrm{~m}$ of road length. Trees in backyards, meanwhile, are present about every $50 \mathrm{~m}$. This rule of thumb was used to place trees throughout the study area for the Baseline case. Front lawn trees were assumed to be $7 \mathrm{~m}$ from the road centreline, and backyard trees were 
assumed to at the midpoint between the rear facade of houses. Trees in the parks were not considered for the Baseline case.

For the UHI Mitigation scenario, maximum tree canopy coverage was affected by increasing both the front lawn and backyard tree frequencies to $13 \mathrm{~m}$. This was determined to be the smallest interval at which tree canopies would not overlap. In addition, trees were manually placed in the two parks.

For the Hybrid scenario, $50 \%$ of the maximum street and backyard trees were placed by using front lawn and backyard tree frequencies of $20 \mathrm{~m}$ and $32 \mathrm{~m}$, respectively. Trees in parks were not considered for the Hybrid scenario. Figure 7 illustrates the tree frequencies for all scenarios. The total number of trees for each scenario is reported in Table 6.

a)

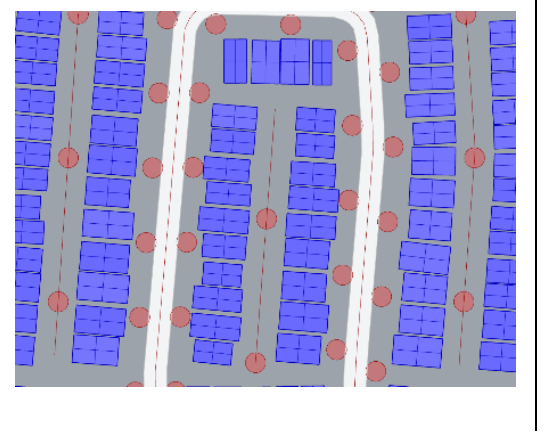

b)

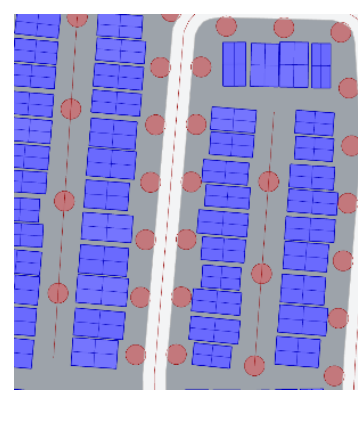

c)

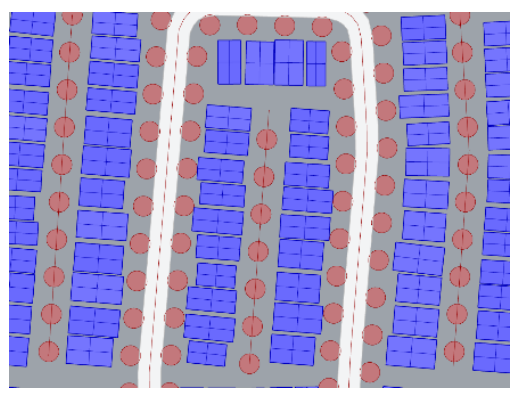

Figure 7 - Frequency of trees for a) the Baseline and Renewables scenarios, b) the Hybrid scenario, and c) the UHI Mitigation scenario. Each red circle represents a tree.

Table 6 - Tree canopy coverage for each scenario.

\begin{tabular}{lcc}
\hline & $\begin{array}{c}\text { Canopy Coverage } \\
\text { (\% of study area) }\end{array}$ & Number of Trees \\
\hline Baseline & $4.8 \%$ & 445 \\
\hline UHI Mitigation & $11.6 \%$ & 1064 \\
\hline Renewables & $4.8 \%$ & 445 \\
\hline Hybrid & $6.4 \%$ & 585 \\
\hline
\end{tabular}

\subsubsection{Parameterization of Trees}

In ENVI-met, trees have explicit geometry and are incorporated into the 3D model mesh. This enables consideration of the wind dampening and shading effects of trees, as well as evaporative cooling and humidification through transpiration. A selection of the equations used to model these phenomena are provided in Equation D-1 to Equation D-8 (Bruse \& Fleer, 1998). From the 
equations, it can be observed that tree behaviour is determined by leaf area density (LAD), leaf area index (LAl), stomatal resistance, leaf weight, leaf shortwave albedo and leaf shortwave transmittance.

Among these parameters, ENVI-met allows users to edit $\mathrm{LAD}^{3}$, leaf weight, leaf albedo and leaf transmittance. Given the unavailability of most of this information, it was decided to use the software's default values for a "sparse, heart-shaped deciduous tree with small trunk" (Table 7), which was deemed most descriptive of the trees on site. This default tree came with a LAD of 0.3 $\mathrm{m}^{2} \mathrm{~m}^{-3}$, meaning there is $0.3 \mathrm{~m}^{2}$ of single-sided leaf area for each cubic metre of tree volume (Figure 8). This is an average value for Aspen and Balsam trees (Stadt \& Lieffers, 2000). In terms of geometry, a crown width and height of $7 \mathrm{~m}$ and $10 \mathrm{~m}$, respectively, was selected ${ }^{4}$. This configuration was used for all trees in the model area and all scenarios. Figure 9 shows the digitized crown geometry.

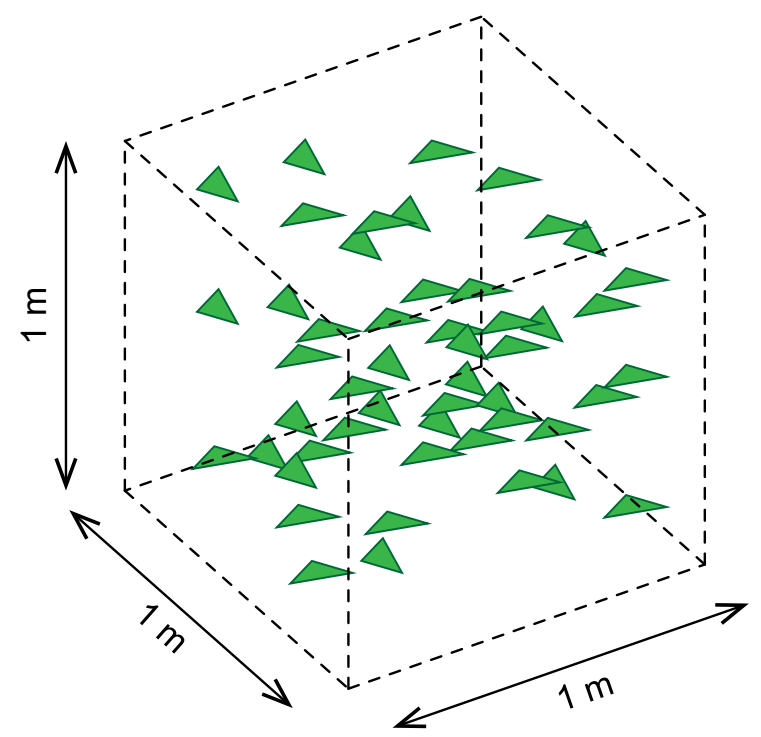

Figure 8 - To-scale depiction of a LAD of $0.3 \mathrm{~m}^{2} \mathrm{~m}-{ }^{3}$. Each green triangle is a leaf.

\footnotetext{
${ }^{3}$ Leaf area density (LAD) describes the one-sided leaf area per unit canopy volume, whereas leaf area index (LAI) describes the one-sided leaf area per unit ground surface area.

${ }^{4}$ After being meshed into ENVI-met, the interpolated crown width becomes $9 \mathrm{~m}$.
} 

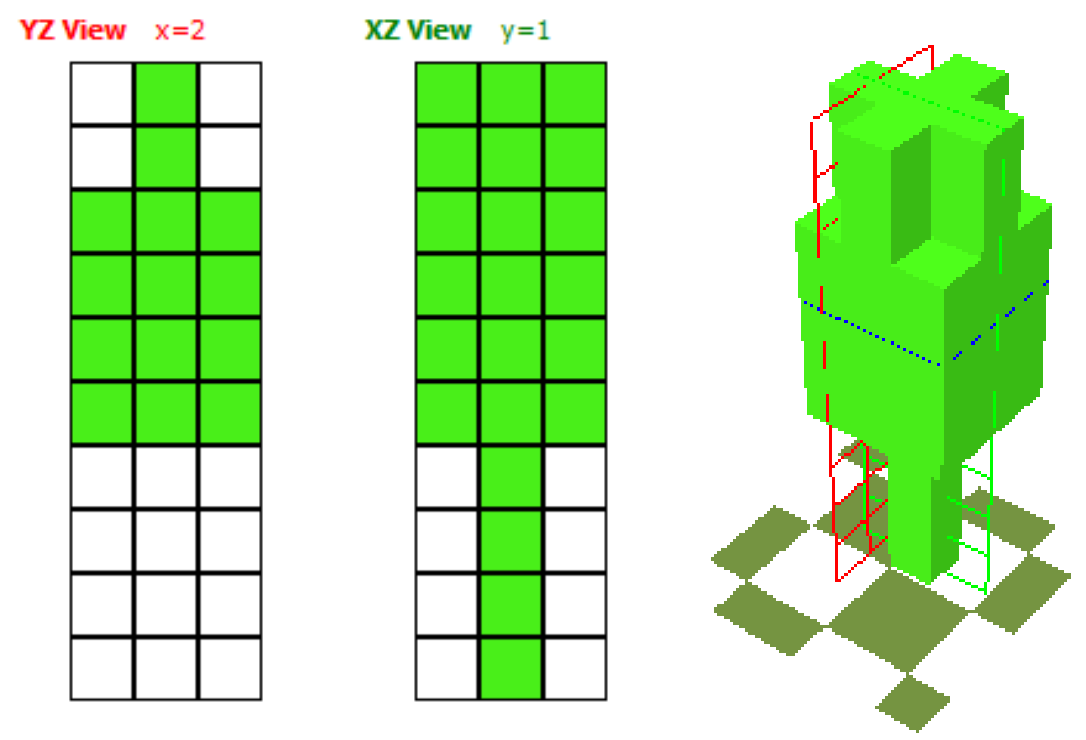

Figure 9 - 10 metre tall tree after being meshed into ENVI-met. Each box represents a grid cell. Note that cells are not scaled to their actual dimensions in this illustration (see section 4.2.10).

Table 7 - Parameters for a heart-shaped deciduous tree with small trunk.

\begin{tabular}{l|c|c|c|c}
\hline & $\begin{array}{c}\text { Leaf area } \\
\text { density (LAD) } \\
{\left[\mathrm{m}^{2} \mathrm{~m}^{-3}\right]}\end{array}$ & $\begin{array}{c}\text { Leaf weight } \\
{\left[\mathrm{g} / \mathrm{m}^{2}\right]}\end{array}$ & $\begin{array}{c}\text { SW reflectivity } \\
(\rho)\end{array}$ & $\begin{array}{c}\text { SW } \\
\text { transmittance } \\
(\tau)\end{array}$ \\
\hline $\begin{array}{l}\text { Heart-shaped deciduous tree } \\
\text { with small trunk }\end{array}$ & 0.3 & 100 & 0.18 & 0.30 \\
\hline
\end{tabular}

\subsubsection{Parameterization of Cool Roofs}

In addition to greening, the UHI Mitigation scenario involves increasing the reflectivity of roofs. Under this scenario, a new albedo of 0.85 was applied to all roofs globally (a 0.65 increase). This is based on values attained for fluid-applied cool roofs and built-up cool roofs (Akbari \& Kolokotsa, 2016). While neither roof type resembles the asphalt shingle roofs prevalent in the study area, it was assumed that future development of cool material technology would enable the houses to be retrofitted with an equivalent albedo.

\subsubsection{Parameterization of Rooftop Photovoltaics}

The Hybrid and Renewables scenarios involve covering all existing roofs with PV panels. Several simplifications were made in the process of modelling this intervention because ENVI-met has no dedicated module for photovoltaics. The first simplification was made with respect to the material properties of PV. As demonstrated by the reviewed literature, electrical efficiency is related to the thermal and optical characteristics of PV. However, in ENVI-met, the only properties that can be 
assigned to materials are thermal conductivity, specific heat, emissivity, shortwave absorptivity, shortwave transmittance and shortwave reflectivity (albedo). To account for the solar conversion property, Taha's (2013) effective albedo method was used. This method involves uprating the shortwave reflectivity of the panels to compensate for the fraction of radiation that is absorbed but not reemitted as heat as demonstrated by the following equation (Taha, 2013):

$$
\alpha_{e f f}=1-\rho-\eta_{\text {ref }}
$$

which is to say that,

$$
A_{e f f}=\rho+\eta_{\text {ref }}
$$

where $\alpha_{e f f}$ is effective shortwave absorptivity, $\rho$ is actual shortwave reflectivity, $\eta_{r e f}$ is the nameplate electrical efficiency and $A_{e f f}$ is the effective albedo. In this way, solar panels could be reasonably depicted using the material properties accepted by ENVI-met. The values selected for these properties are provided in Table 8. It was assumed the solar panels were homogenous materials. Effective albedo was calculated based on a reasonably high efficiency of $18 \%$ (Green et al., 2019) and a typical reflectivity of 12\% (Masson et al., 2014) for monocrystalline silicon PV (Equation 11).

Simplifications were also made in the geometric parameterization of rooftop PV. Like most of the studies in the reviewed literature, solar panels were considered to be flush with the existing flat roofs (Figure 10). Further, panels were assumed to cover $100 \%$ of all roof area. 
Table 8 - Material properties assigned to PV surfaces.

\begin{tabular}{l|c|l}
\hline \multicolumn{1}{c|}{ Property } & Value & \multicolumn{1}{c}{ Reference } \\
\hline Efficiency $\left(\boldsymbol{\eta}_{\text {ref }}\right)$ & 0.18 & Green et al. (2019) \\
\hline Thickness $(\boldsymbol{l})$ & $7 \mathrm{~mm}$ & Tian et al. (2007) \\
\hline Thermal conductivity $(\boldsymbol{k})$ & $7.923 \mathrm{~W} / \mathrm{mK}$ & Tian et al. (2007) \\
\hline Specific heat $\left(\boldsymbol{c}_{\boldsymbol{p}}\right)^{5}$ & $812 \mathrm{~J} / \mathrm{kgK}$ & Tian et al. (2007) \\
\hline Emissivity $(\boldsymbol{\varepsilon})$ & 0.93 & Masson et al. (2014) \\
\hline Shortwave transmittance $(\boldsymbol{\tau})$ & 0.00 & Assumed \\
\hline Shortwave absorptivity $(\boldsymbol{\alpha})$ & 0.70 & Assumed; Equation 11 \\
\hline Shortwave reflectivity $(\boldsymbol{\rho})($ effective albedo) & 0.30 & Equation 11 \\
\hline
\end{tabular}

$$
\begin{gathered}
A_{\text {eff }}=\rho+\eta_{\text {ref }} \\
=0.12+0.18=0.3
\end{gathered}
$$

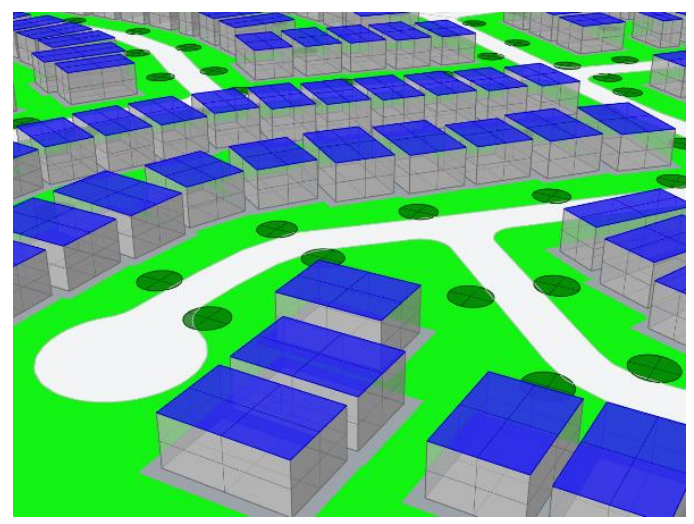

Figure 10 - Close-up of the Renewables scenario in Rhino. Blue surfaces are PV solar panels.

\subsubsection{ENVI-met Settings}

In ENVI-met, spatial resolution strongly influences the model performance. Smaller resolutions may allow for more minute phenomena to be simulated, but at the expense of increased computing time. For the purposes of this study, a horizontal spatial resolution of $3 \mathrm{~m}$ was tested to yield the ideal balance between precision and computing time. Vertical resolution was

\footnotetext{
${ }^{5}$ This value of $c_{p}$ was converted from Tian et al.'s value for heat capacity $\left(\mathrm{J} / \mathrm{m}^{3} \mathrm{k}\right)$ assuming the density of glass was $2500 \mathrm{~kg} / \mathrm{m}^{3}$ (Straube \& Burnett, 2005). Values of $c_{p}$ used by Notton et al. (2005) are similar at 750 $\mathrm{J} / \mathrm{kgK}$ for the glass and $836 \mathrm{~J} / \mathrm{kgK}$ for the silicon inside the PV modules.
} 
configured to be nonlinear: the first cell is spaced $0.5 \mathrm{~m}$ above the ground, then $1 \mathrm{~m}$ for the next 9 cells, above which the spacing 'telescopes' by a factor of 1.1 up to the absolute model height $31.95 \mathrm{~m}$. At this height, vertical resolution is $5.19 \mathrm{~m}$. This approach - of having a finer mesh closer to ground level and a coarser mesh higher in the atmosphere - ensures the model is more accurate at pedestrian height, while minimizing the total number of cells required to reach an adequate model height. A summary of the mesh created is provided in Table 9. A simulation duration of 20 hours commencing at 03:00 was chosen. The first 3 hours of each simulation were treated as spin-up time and was not used towards any analysis.

Table 9 - ENVI-met mesh resolution and extents.

\begin{tabular}{lccc}
\hline & Resolution & Total \# of Cells & Total Extent \\
\hline $\mathbf{X}$ domain & $3 \mathrm{~m}$ & 279 & $837 \mathrm{~m}$ \\
\hline Y domain & $3 \mathrm{~m}$ & 297 & $891 \mathrm{~m}$ \\
\hline $\mathbf{Z}$ domain & $0.5 \mathrm{~m}-5.19 \mathrm{~m}$ & 22 & $32 \mathrm{~m}$ \\
\hline
\end{tabular}

\subsection{PV Efficiency Simulations}

To gain a more precise understanding of the effects of trees on rooftop PV, the PV energy efficiency simulations were performed on a single, typical house in the Brampton study area. The house was modelled as a rectangular prism with the dimensions $18 \mathrm{~m} \times 12 \mathrm{~m} \times 7.5 \mathrm{~m}(\mathrm{~L} \times \mathrm{W} \times \mathrm{H})$ and $100 \%$ rooftop PV coverage. The smaller model area (and hence lessened compute time) of these simulations permitted 14 configurations of the trees surrounding the house to be assessed (Table 10). The configurations are distinguished by tree height, which is either $10 \mathrm{~m}, 15 \mathrm{~m}$ or 25 $\mathrm{m}$; and tree placement relative to the house, which is either North, South, North and South, or East and West. In all cases, trees were only planted along the shorter dimension of the house, approximately 12 m away. 
Table 10 - Overview of scenarios simulated to assess PV energy efficiency.

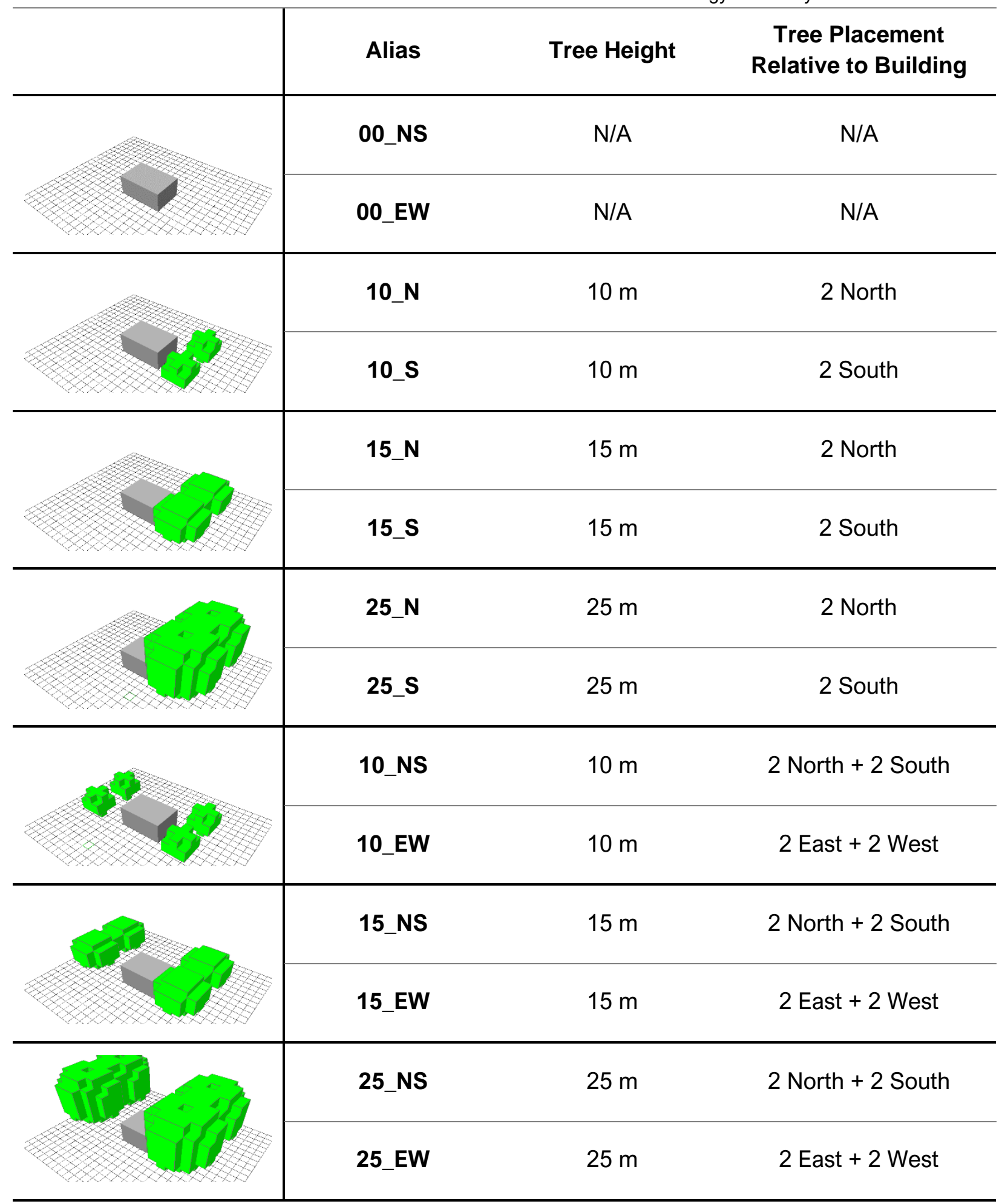




\subsection{Post-processing}

\subsubsection{Calculation of Human Thermal Comfort}

To understand the effect of the scenarios on outdoor thermal comfort, it is necessary to process the 'physical' outputs of ENVI-met into a HTCl. For this study, UTCI was selected because of its adaptative clothing model. Since this study aspires to provide guidance to policymakers, it was decided that a metric in tune with the present buildings industry was most appropriate.

UTCI was calculated from the results of each simulation using BioMet, a post-processing utility packaged with ENVI-met. BioMet can compute several HTCls for the whole model domain or a selection of it. When calculating UTCI, it uses the polynomial approximation of the actual algorithm for computational efficiency (Bröde et al., 2012). The formula only accepts wind speed at 10 metres height, therefore when analyzing pedestrian-level UTCI BioMet applies the logarithmic wind profile to interpolate wind speed downwards (ENVI-met $\mathrm{GmbH}, 2017$ ).

\subsubsection{Calculation of Outdoor Thermal Comfort Autonomy}

In addition to UTCI, it is useful to analyze outdoor thermal comfort in terms of time-integrated metrics such as OTCA. The definition of OTCA according to Nazarian et al. (2019) states that the results should be reflective of a whole year. However, in this case the concept of OTCA was applied to only 17 hours of results.

ENVI-met does not have the ability to calculate OTCA, so a Python script was created to transform the native results. Firstly, the 'Convert EDX to NetCDF' utility packaged with ENVI-met was used to convert the BioMet results into Network Common Data Form (NetCDF). NetCDF is a data format created by Unidata and the University Corporation for Atmospheric Research (UCAR) to store array-orientated scientific data (Unidata, 2019). Next, the Python library netcdf-4python was used to compute OTCA from the BioMet NetCDF files (Unidata, 2019). The script, which is provided in Appendix $\mathrm{H}$, performs the following tasks:

1) Loads the filename of each hourly file into a list

2) Opens each file, queries the UTCI variable (other variables are present in the files) and copies the 3D arrays into a dictionary

3) Creates an empty NumPy ${ }^{6}$ array with the same shape as the $3 \mathrm{D}$ arrays

${ }^{6}$ NumPy is a Python library for operating on multi-dimensional arrays (Oliphant, 2006). 
4) For each item in each 3D array, assigns a ' 1 ' if the value is between 9 and 26 , and a 0 otherwise

5) Adds the resulting 3D arrays to the empty NumPy array

6) Divides each item in the NumPy array by the length of the list in Step 1

7) Writes the NumPy array into a single NetCDF file with the same dimensions as the input files

The result of this procedure is a single 3D array containing decimal values from 0 to 1 , where each value is representative of a fraction of time comfortable. The comfort threshold of $9{ }^{\circ} \mathrm{C}$ to $26^{\circ} \mathrm{C}$ UTCI is based on the official UTCl assessment scale (Figure 11).

\begin{tabular}{|c|l|}
\hline UTCl $\left({ }^{\circ} \mathrm{C}\right)$ & \multicolumn{1}{c}{ Stress category } \\
\hline$>46$ & Extreme heat stress \\
\hline 38 to 46 & Very strong heat stress \\
\hline 32 to 38 & Strong heat stress \\
\hline 26 to 32 & Moderate heat stress \\
\hline 9 to 26 & No thermal stress \\
\hline
\end{tabular}

Figure 11 - UTCl classified into thermal stress categories (Błażejczyk et al., 2010). The 'no thermal stress' category was used as upper and lower bounds for OTCA calculations.

\subsubsection{Calculation of Temperature-Dependent PV Efficiency}

To determine the energy efficiency of rooftop PV in the context of different tree deployments, a linear cell temperature correlation was applied to the ENVI-met results. Four pieces of information were needed to satisfy this correlation: the average air temperature at roof height for each hour of the simulation $\left(T_{a, i}\right)$, the average wind speed at roof height for each hour of the simulation $\left(V_{w, i}\right)$ and the solar radiation intensity on the PV plane (global tilted irradiance) for each hour of the simulation $\left(G_{T, i}\right)$.

First, $T_{a, i}$ and $V_{w, i}$ were determined. Since the house in the single-building simulations was $7.5 \mathrm{~m}$ tall, this was taken as the spatial average of the slice directly above the roof at $z=8 \mathrm{~m}$. Next, $G_{T, i}$ was determined. This occurred in several steps: first, the hourly ENVI-met outputs of direct normal irradiance (DNI) and direct horizontal irradiance (DHI) were extracted from roof height. Next, a list of hourly solar zenith angles $\left(\theta_{z, i}\right)$ for Brampton from July 5 to July 10 was created using the Python library 'pvlib' by Sandia National Laboratories (Holmgren et al., 2018). These three time series were then combined to yield hourly global horizontal irradiance $(\mathrm{GHI})$ as per the equation: 


$$
G H I=D H I+\left(D N I \cdot \cos \left(\theta_{z, i}\right)\right)
$$

Equation 12

Next, the values of GHI were supplied to the pvlib function 'irradiance.get_total_irradiance', which computes the solar radiation intensity arriving at a tilted plane. In this case, the plane was assumed to be South-facing and tilted $44^{\circ}$ relative to horizontal. Finally, $T_{a, i}, V_{w, i}$ and $G_{T, i}$ were fed into Equation 8. The values used for $\beta_{\text {ref }}, T_{r e f}, T_{S O C}$ and $G_{S O C}$ are provided in Table 11. With this information, PV power (W) and energy (Wh) under open-circuit conditions was assessed by assuming a solar panel size. For this study, a solar panel area of $1.7 \mathrm{~m}^{2}$ was assumed, which is typical for a 60-cell consumer model. The Python script used to perform all these actions is provided in Appendix I.

Table 11 - Time-independent inputs for Equation 8.

\begin{tabular}{cccc}
\hline Variable & Value & Justification & Reference \\
\hline $\boldsymbol{\beta}_{\text {ref }}$ & $0.0045^{\circ} \mathrm{C}^{-1}$ & Standard value for crystalline silicon & $\begin{array}{c}\text { Skoplaki \& } \\
\text { Palyvos (2009) }\end{array}$ \\
\hline $\boldsymbol{T}_{\boldsymbol{r} \text { ef }}$ & $25^{\circ} \mathrm{C}$ & $\begin{array}{c}\text { Temperature for which } \eta_{\text {ref }} \text { was obtained; Standard } \\
\text { Testing Conditions (IEC 61215-2:2016) }\end{array}$ & IEC (2016) \\
\hline $\boldsymbol{T}_{\boldsymbol{N O C T}}$ & $45^{\circ} \mathrm{C}$ & $\begin{array}{c}\text { Moderate figure recommended by the Florida Solar } \\
\text { Energy Center }\end{array}$ & FSEC (2010) \\
\hline $\boldsymbol{G}_{\boldsymbol{N} \text { oct }}$ & $800 \mathrm{~W} / \mathrm{m}^{2}$ & $\begin{array}{c}\text { Normal Terrestrial Environment (NTE) in which } \\
\text { Nominal Operating Cell Temperature (NOCT) is } \\
\text { obtained. }\end{array}$ & Stultz (1977) \\
\hline $\boldsymbol{A}_{\text {panel }}$ & $1.7 \mathrm{~m}^{2}$ & Typical for a 60-cell consumer model & \\
\hline
\end{tabular}

\section{RESULTS}

Simulations were run on a $9^{\text {th }}$ generation Intel Core $\mathrm{i} 7-9700 \mathrm{~K}$ processor with 8 cores and a maximum frequency of $4.90 \mathrm{GHz}$. Compute time was approximately 100 hours for each simulation.

\subsection{Validation of Baseline}

To check whether the simulation results were reasonable, hourly air temperatures from four locations in the Baseline model were averaged and compared to the observations at Toronto Pearson International Airport for the corresponding period. The points are at a height of $1.5 \mathrm{~m}^{7}$ and correspond to locations least likely to be influenced by individual buildings or vegetation yet

\footnotetext{
$71.5 \mathrm{~m}$ was the closest grid point to $2 \mathrm{~m}$, which is the measurement height of air temperature at Toronto Pearson International Airport.
} 
still well within the model domain. Overall, the Baseline results of air temperature show a reasonable correlation with the measured data for July 5, 2018 (Figure 12). The coefficient of determination $\left(R^{2}\right)$ was 0.72 . Unexplained variance can be attributed to two facts: first, the weather station is approximately $12 \mathrm{~km}$ from the site and over dissimilar terrain; second, open lateral boundary conditions were used, wherein humidity and wind speed were applied as initial values only. A separate set of simulations were run with closed lateral boundary conditions (simple forcing) and a better fit with the measured data was observed (Appendix J), but these simulations underestimated differences between scenarios and were thus omitted from further analysis. For the purposes of this study, it was deemed more important to quantify relative differences between scenarios rather than to achieve a historically-accurate baseline simulation.

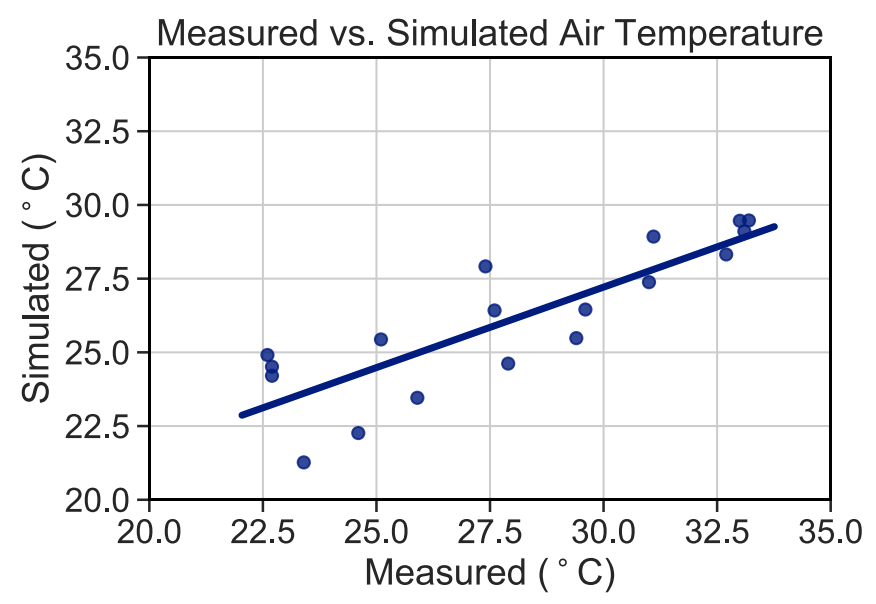

Figure 12 - Air temperature as measured at Toronto Pearson International Airport versus the average of the validation points for the Baseline simulation

\subsection{Outdoor Thermal Comfort}

In this section, the results of the physical variables contributing to thermal comfort (air temperature, humidity, mean radiant temperature and wind speed) are analyzed, then UTCI, then OTCA.

\subsubsection{Physical Variables}

MRT and wind speed have a high degree of spatial variability in urban environments. At any discrete location in a microclimate model, these variables can be drastically influenced by the presence of trees or buildings. To avoid unintentional biases of point observations, time series results were taken as the spatial averages of four regions of the model domain at a height of 1.5 $\mathrm{m}$. The spatial averages were computed as the sum of the values in the region, divided by the 
number of cells in each region. The regions, effectively "slices" of the model mesh, are shown in Figure 13 and correspond to roads and backyards. These areas were deemed worthy of attention because some of the activities they host - walking, bicycling, outdoor dining, gardening - are most threatened by climate change. An equal number of slices orientated parallel versus perpendicular to the South-easterly wind direction were selected in order to eliminate bias towards low or high ventilation areas.

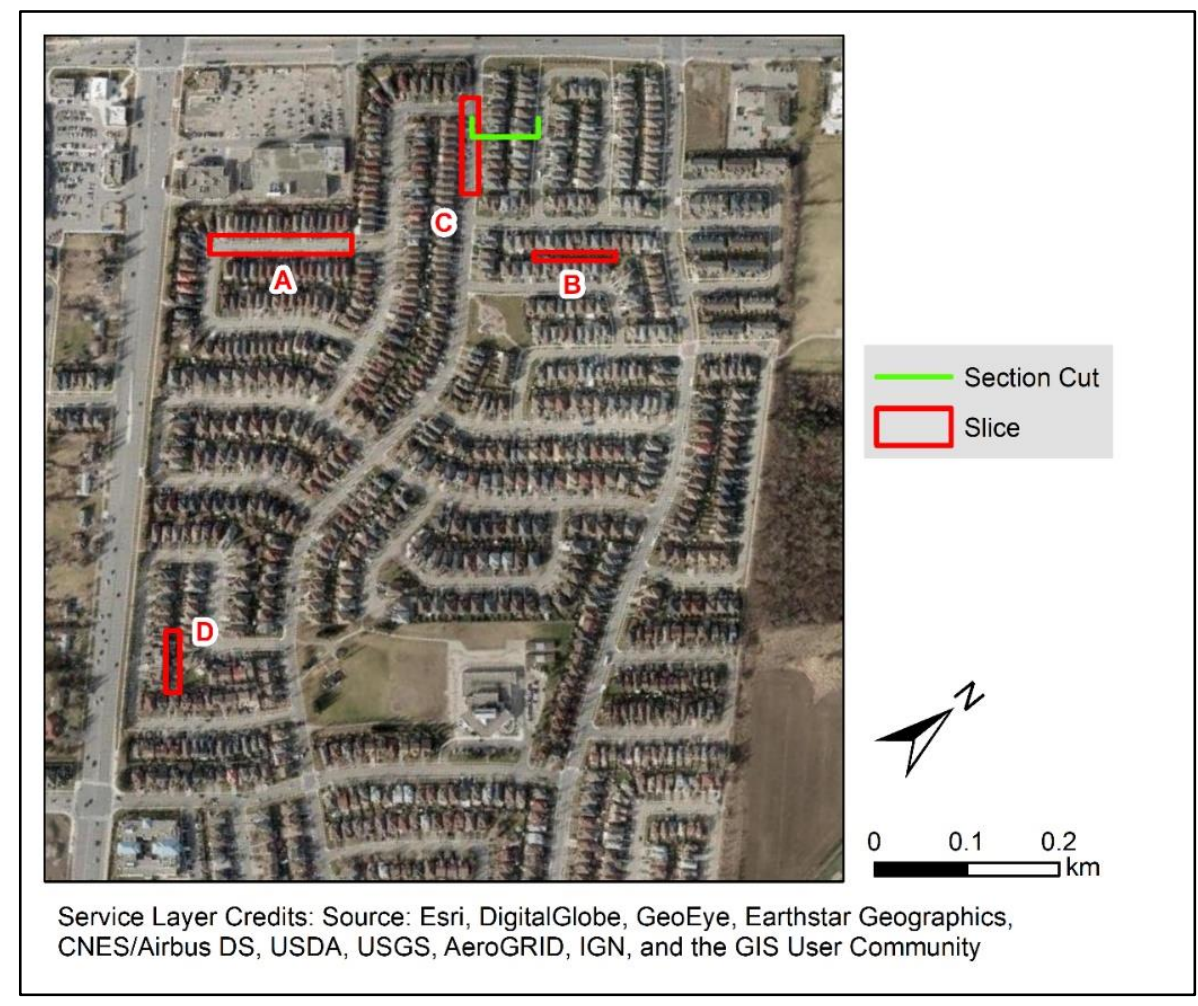

Figure 13 - Slices $(A, B, C, D)$ and the section analyzed.

In general, the UHI Mitigation scenario had the greatest impact on the physical variables. The Hybrid scenario had drastically less of an impact, and the Renewables scenario was virtually indistinguishable from the Baseline simulation in most aspects. Table K-1 shows the daily average air temperature reductions achieved by each scenario. The Renewables scenario had a cooling potential of $0.09{ }^{\circ} \mathrm{C}$, versus $0.1{ }^{\circ} \mathrm{C}$ and $0.44{ }^{\circ} \mathrm{C}$ for the Hybrid and UHI Mitigation scenarios respectively. These reductions were fairly consistent throughout the analysis period, tapering off only slightly in the morning and evening (Figure 14). The vertical distribution of air temperature is shown in Figure 15. It emerges that the Renewables scenario caused significant cooling at roof height, but below $5 \mathrm{~m}$ air temperatures are still above $30^{\circ} \mathrm{C}$. Relative to the other two scenarios, the UHI Mitigation scenario caused extraordinary cooling at all elevations. 

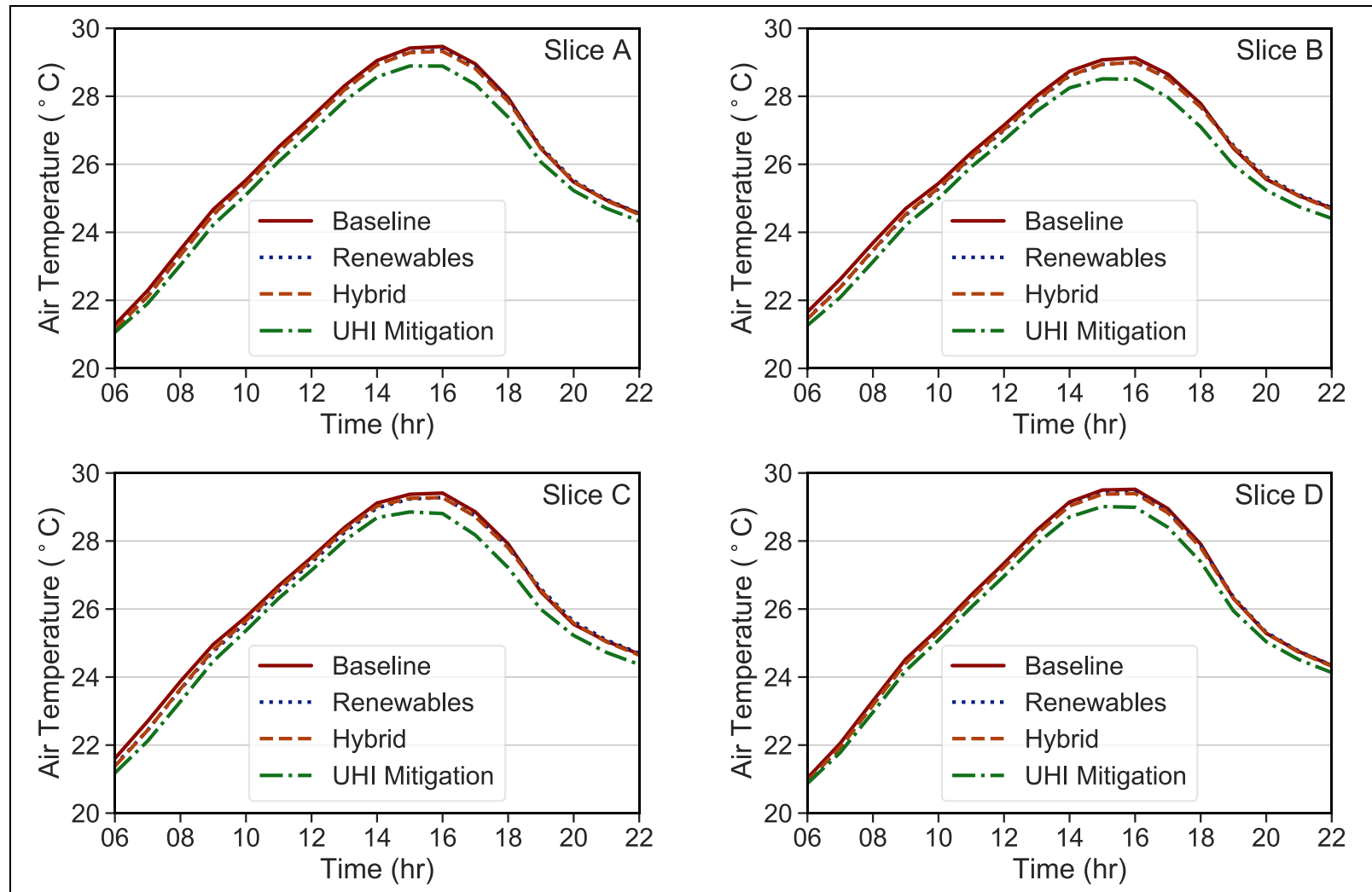

Figure 14 - Spatial average of hourly air temperature for each of the four scenarios, for each slice.

Only small increases in specific humidity were seen for the Hybrid and UHI Mitigation scenarios (Table K-2). Expectedly, the Renewables scenario had no appreciable effect on specific humidity. For all scenarios, peak humidity occurred between noon and 14:00 (Figure 16).

Pedestrian-height MRT was reduced by the addition of trees. On average, decreases of $0.86{ }^{\circ} \mathrm{C}$ and $2.33^{\circ} \mathrm{C}$ were seen for the Hybrid and UHI Mitigation scenarios respectively (Table K-3). In Slice $\mathrm{D}$, an area where more trees happened to be added, the average MRT decrease for the UHI Mitigation scenario was $3.02{ }^{\circ} \mathrm{C}$. Temporally, all slices exhibit a distinct "double top" pattern (Figure 17). The first peak occurred around 9:00, and the second occurred at 16:00. The inflection point occurred at noon and is typically around $5{ }^{\circ} \mathrm{C}$ cooler than the peaks.

Wind speed in each of the slices reflects the wind dampening effect of added trees. On average, the Hybrid and UHI Mitigation scenarios reduced wind speed by $0.07 \mathrm{~m} / \mathrm{s}$ and $0.15 \mathrm{~m} / \mathrm{s}$ respectively (Table K-4). These reductions are mostly constant throughout the day (Figure 18). The Renewables scenario had no appreciable effect on wind speed. 


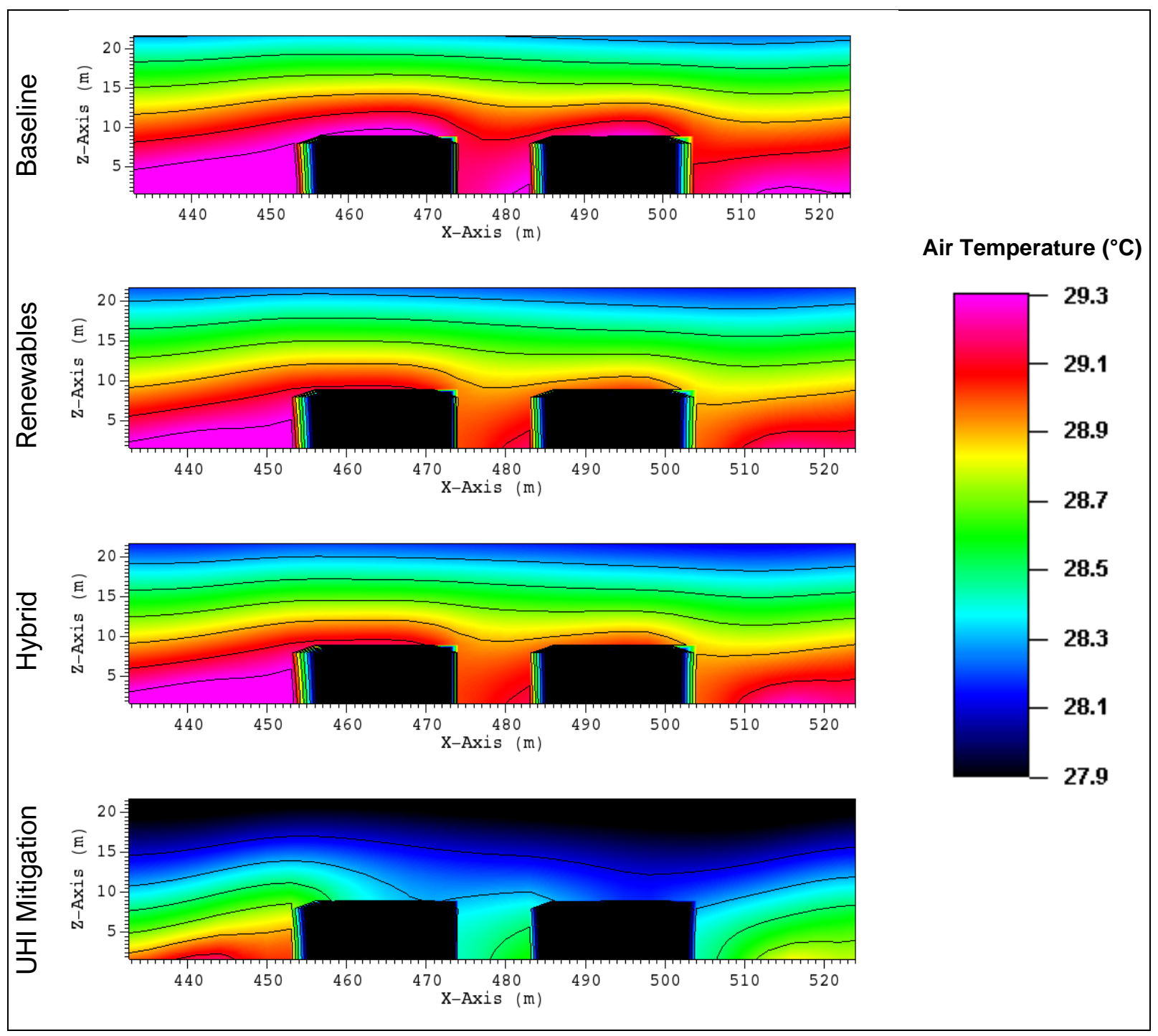

Figure 15 - Air temperature at 15:00, as seen from the section cut in Figure 13. 

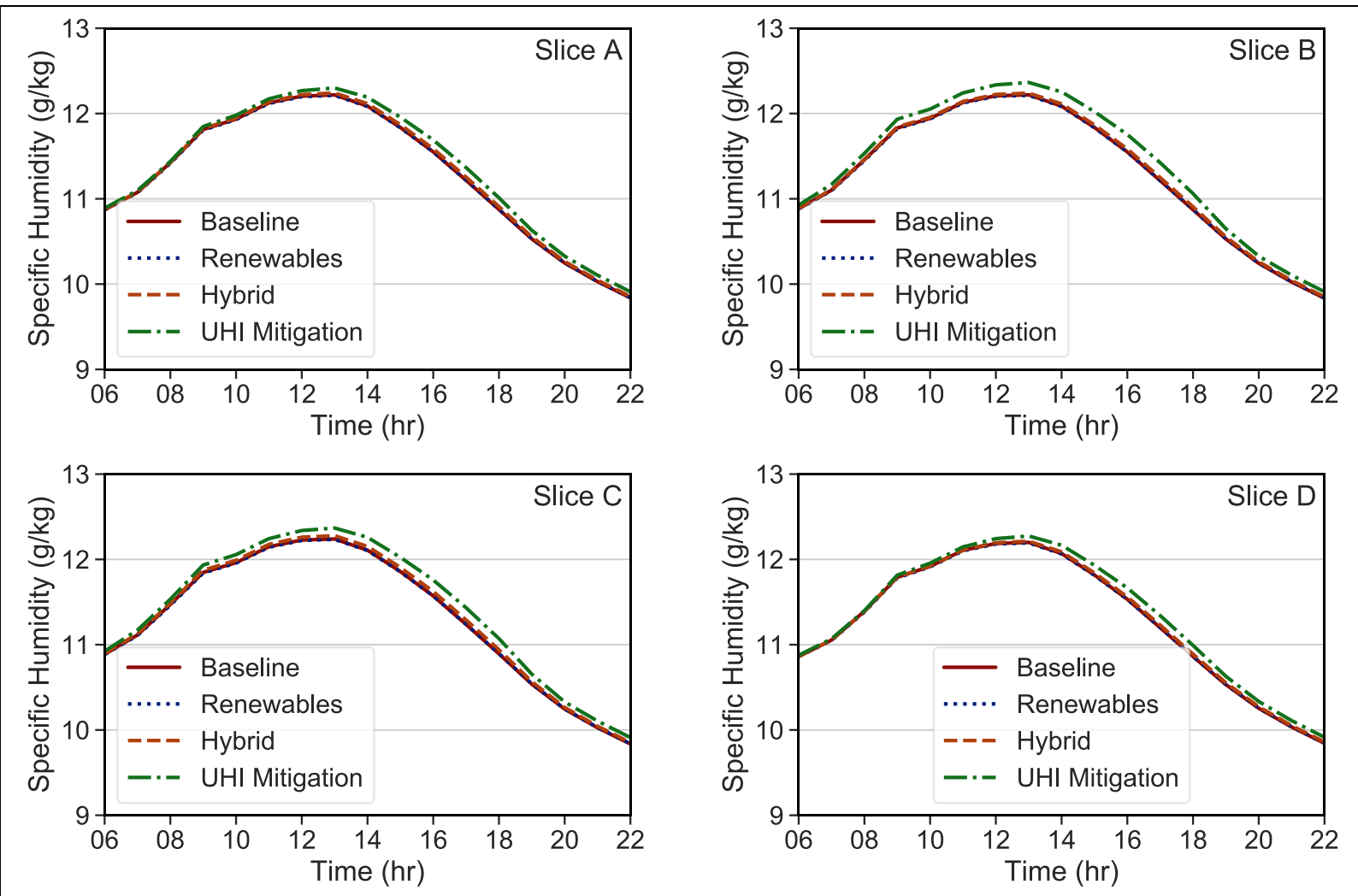

Figure 16 - Spatial average of hourly specific humidity for each of the four scenarios, for each slice.
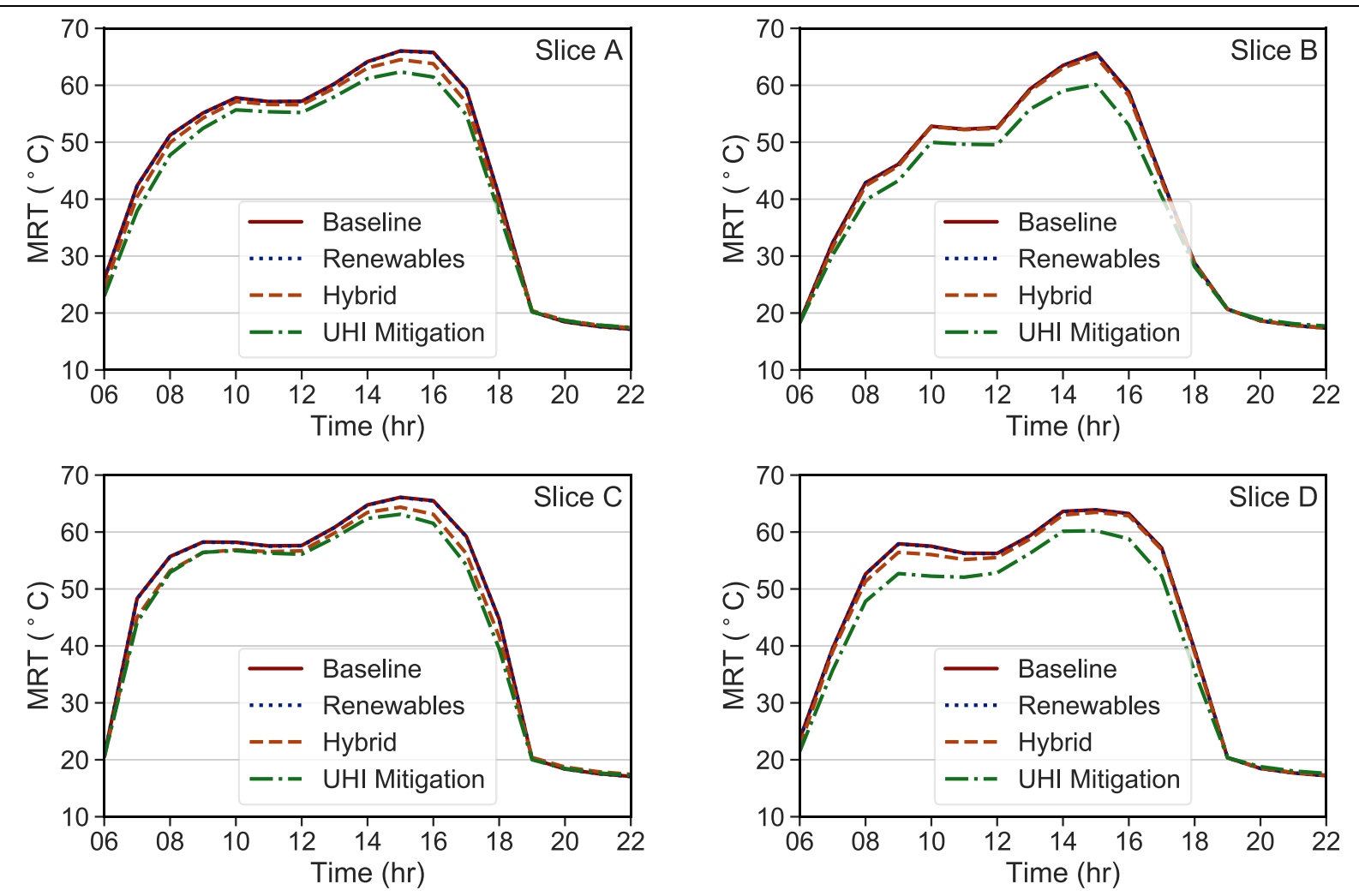

Figure 17 - Spatial average of hourly mean radiant temperature for each of the four scenarios, for each slice. 

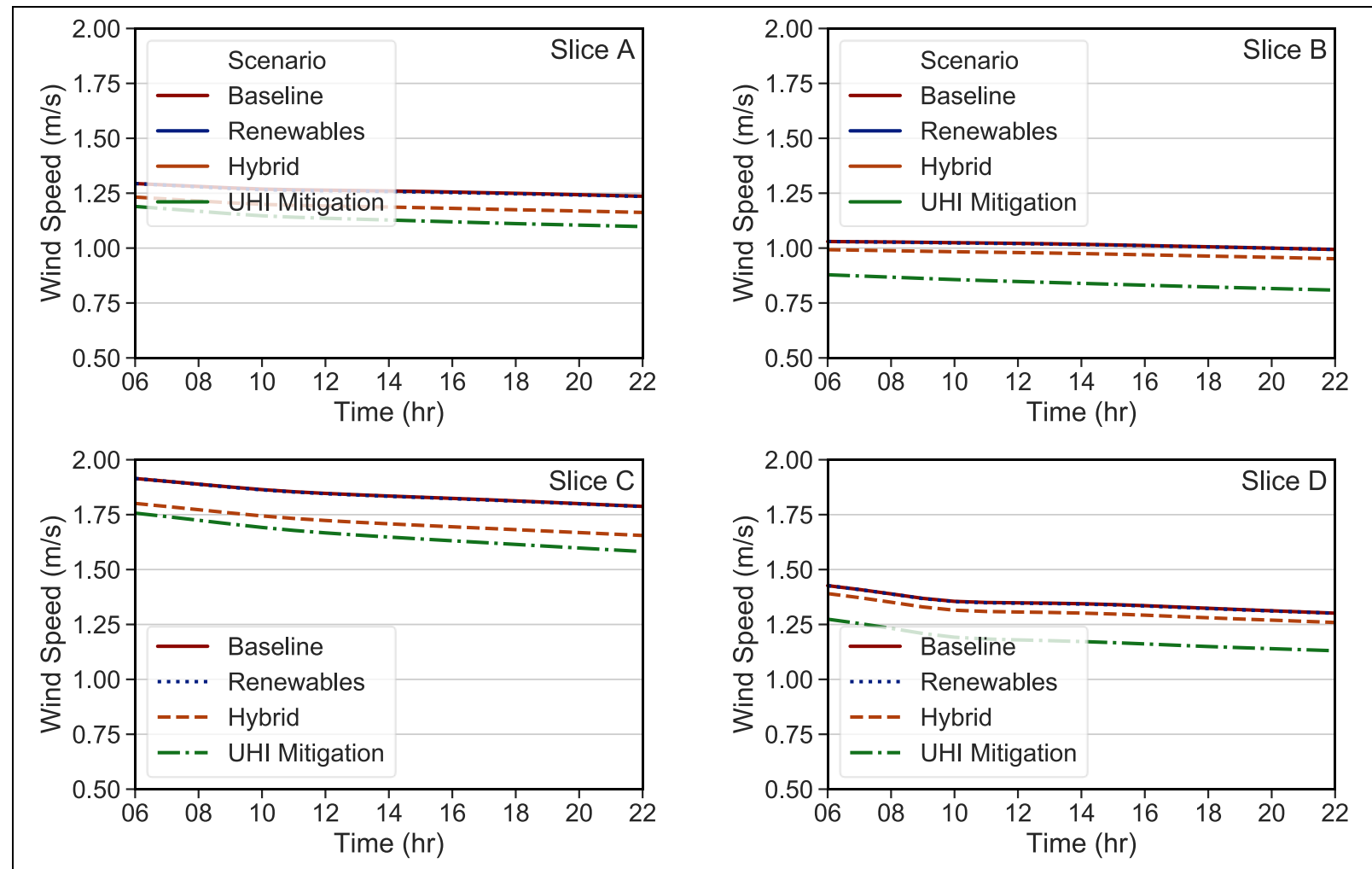

Figure 18 - Spatial average of hourly wind speed for each of the four scenarios, for each slice.

\subsubsection{Universal Thermal Climate Index}

The UTCI results combine the physical variables of air temperature, humidity, MRT and wind speed to give a comprehensive assessment of outdoor thermal comfort. Throughout most of the day, the baseline UTCl at $1.5 \mathrm{~m}$ height was above $32^{\circ} \mathrm{C}$, which is the lower threshold for strong heat stress $\left(32-38{ }^{\circ} \mathrm{C}\right)$. While all scenarios lowered the daily mean UTCI (Table 12), reductions were not enough to change the heat stress category, except around 14:00 to 18:00 when the UHI Mitigation scenario brought Slices A and B down from the very strong heat stress category (38$42^{\circ} \mathrm{C}$ ) and back into the strong heat stress category (Figure 19). The average reductions across all slices were $0.07{ }^{\circ} \mathrm{C}, 0.12{ }^{\circ} \mathrm{C}$ and $0.54{ }^{\circ} \mathrm{C}$ UTCI for the Renewables, Hybrid and UHI Mitigation scenarios respectively.

Table $12 \mathrm{~b}$ shows the absolute maximum UTCI deltas for each scenario. Cooling by the Renewables scenario remains small, at up to $0.20^{\circ} \mathrm{C}$. Cooling up to $5.90^{\circ} \mathrm{C}$ was achieved for the UHI Mitigation scenario, and up to $5.35^{\circ} \mathrm{C}$ for the Hybrid scenario. It is important to note these numbers are representative of a single cell in the model domain at a specific time. Heat maps of UTCI at 12:00 and 15:00 show that these maximums were achieved directly beneath newly-added trees (Figure 20). These heat maps also show that very strong heat stress $\left(\mathrm{UTCl} \geq 38{ }^{\circ} \mathrm{C}\right.$ ) was 
most persistent in streets and backyards orientated perpendicular to the South-easterly wind direction, where convective heat removal is limited and longwave emission from building materials is high. Areas rendered white have no value of UTCI because their $10 \mathrm{~m}$ wind speed was less than $0.5 \mathrm{~m} / \mathrm{s}$, which is incompatible with the UTCl formula.
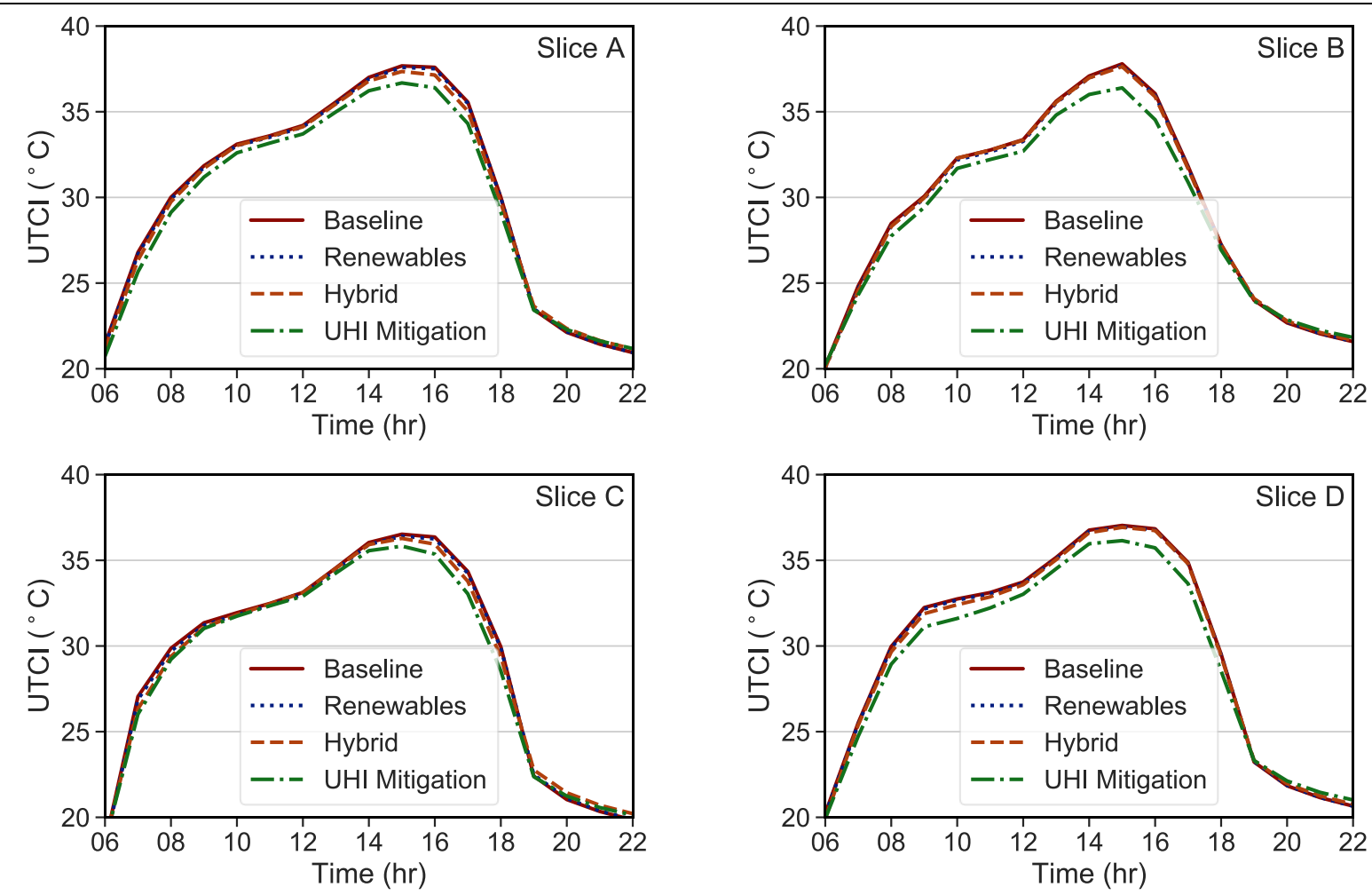

Figure 19 - Spatial average of UTCI for each of the four scenarios, for each slice.

Table 12 - Spatial average (a) and maximum (b) UTCI deltas (relative to the baseline simulation) for the whole analysis period.

\begin{tabular}{|c|c|c|c|c|c|c|}
\hline \multirow[b]{2}{*}{ Scenario } & \multicolumn{3}{|c|}{$\begin{array}{l}\left.\text { a) Average UTCI Delta (UTCl baseline }-\mathrm{UTCl}_{\text {scenario }}\right) \\
{\left[{ }^{\circ} \mathrm{C}\right]}\end{array}$} & \multicolumn{3}{|c|}{$\begin{array}{l}\text { b) Maximum UTCI Delta (UTCl baseline - } \\
\text { UTClscenario) }\left[{ }^{\circ} \mathrm{C}\right]\end{array}$} \\
\hline & 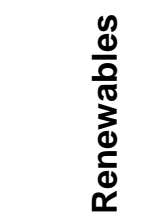 & 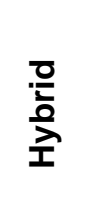 & 폭 & 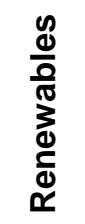 & $\begin{array}{l}\text { 은 } \\
\text { 홎 }\end{array}$ & 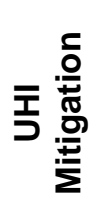 \\
\hline Slice A & 0.06 & 0.15 & 0.58 & 0.17 & 5.32 & 5.33 \\
\hline Slice B & 0.07 & 0.06 & 0.54 & 0.17 & 5.35 & 5.05 \\
\hline Slice C & 0.08 & 0.12 & 0.41 & 0.20 & 5.07 & 5.28 \\
\hline Slice D & 0.05 & 0.12 & 0.63 & 0.11 & 4.56 & 5.90 \\
\hline All Slices & 0.07 & 0.12 & 0.54 & 0.20 & 5.35 & 5.90 \\
\hline
\end{tabular}




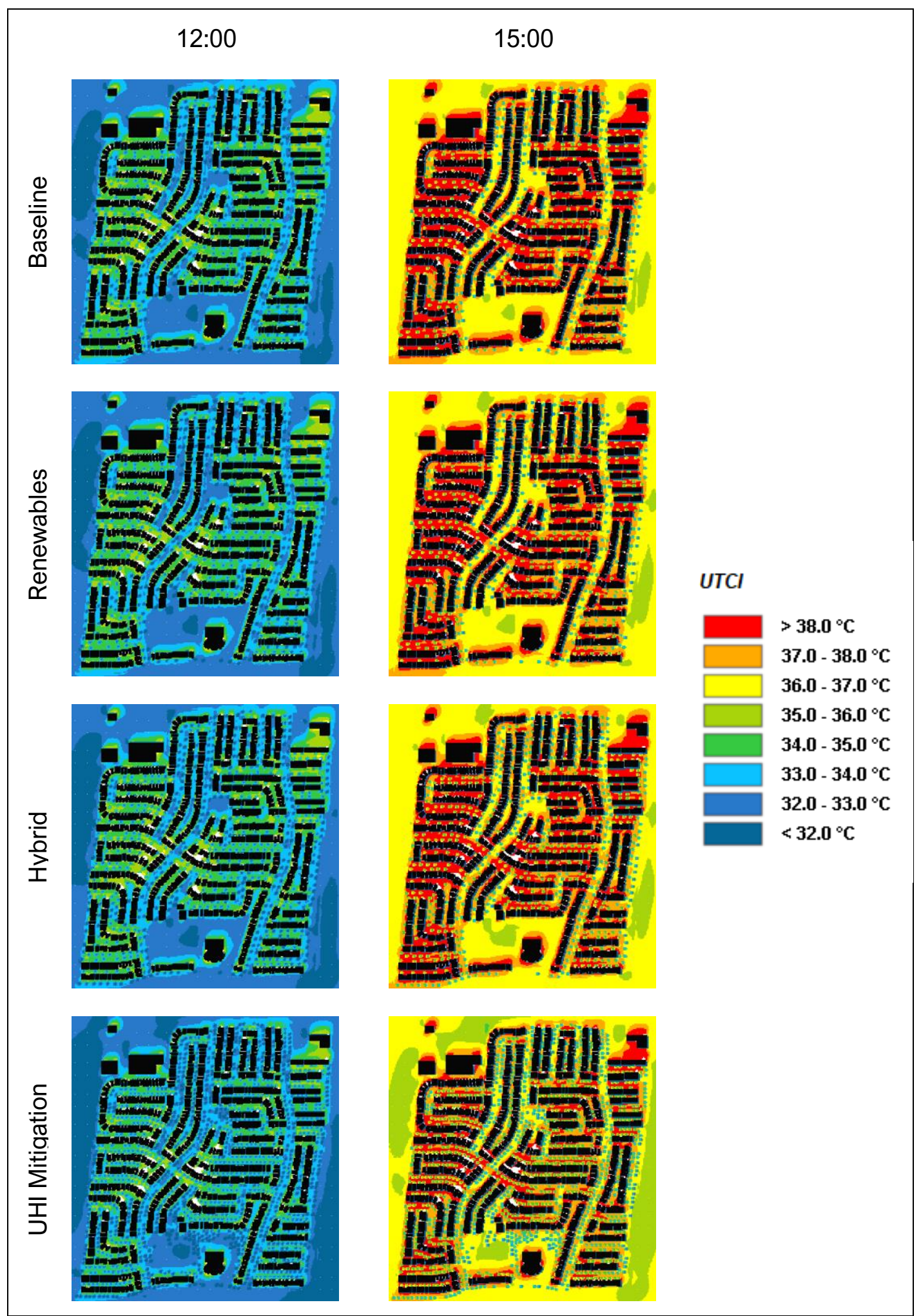

Figure $20-\mathrm{UTCl}$ heatmaps at 12:00 and 15:00. 


\subsubsection{Outdoor Thermal Comfort Autonomy}

OTCA is the most aggregate human thermal comfort metric used in this study. It integrates results for every hour in the analysis period (6:00 to 22:00) to provide an overall understanding of the experience created by the space during a heat wave. Figure 21 shows the OTCA heat maps. There is little to distinguish the scenarios because all of them quickly exceeded the comfort threshold of $26^{\circ} \mathrm{C}$ UTCl early in the morning and did not drop below it until late in the evening. Accordingly, OTCA is less than $40 \%$ almost everywhere in all scenarios. Slight increases in OTCA (5 to $10 \%$ ) are visible under trees.

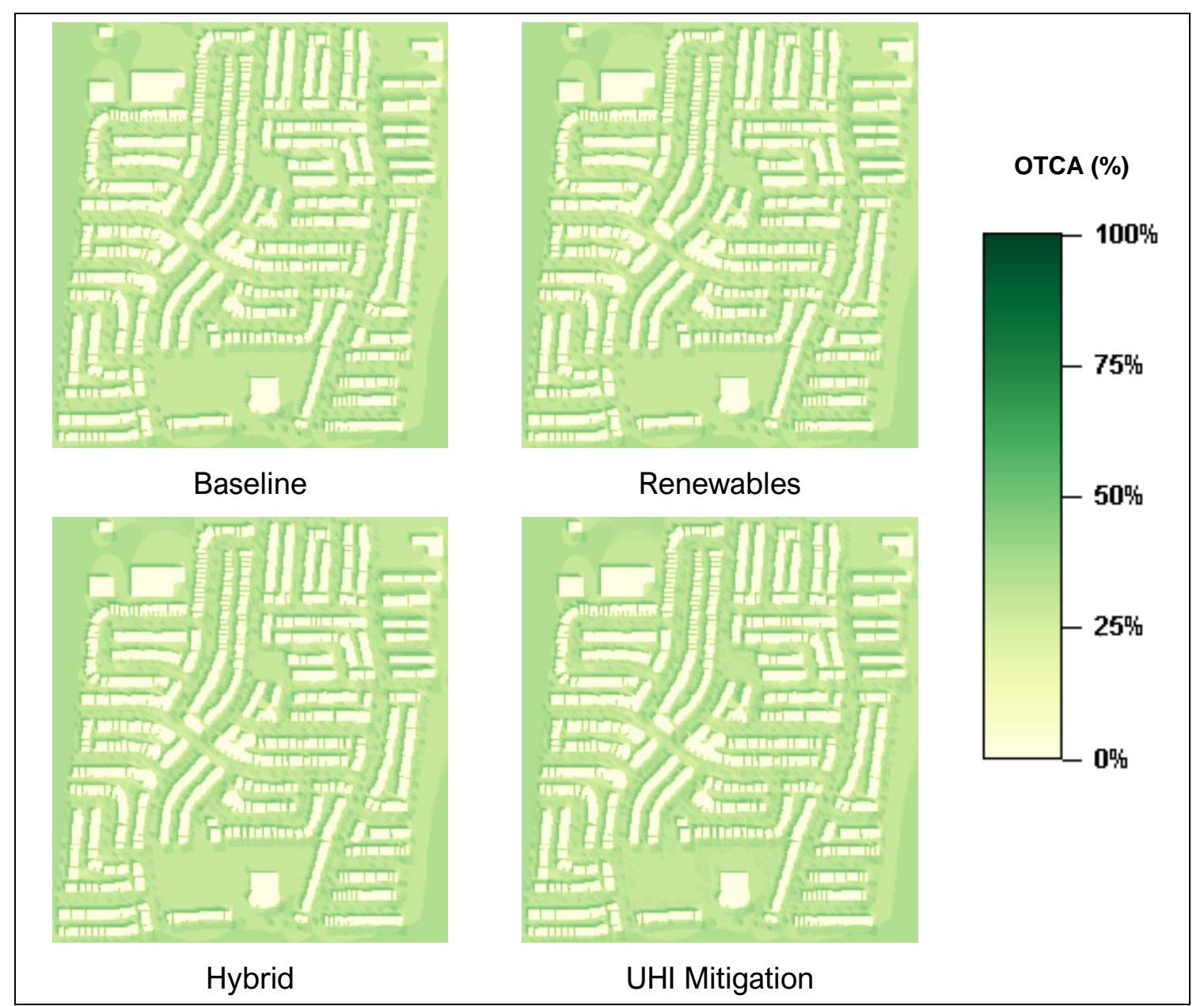

Figure 21 - OTCA heatmaps for each scenario, considering an analysis period from 6:00 to 20:00 and a comfort criterion of $9{ }^{\circ} \mathrm{C}<\mathrm{UTCl}<26^{\circ} \mathrm{C}$.

The Spatial OTCA (the percentage of space comfortable more than $50 \%$ of the time) for all scenarios is virtually zero percent (Table 13). Spatial OTCA was also calculated for the percentage of space comfortable more than $25 \%$ of the time. This yields greater differentiation between 
scenarios. For example, the UHI Mitigation scenario adds $1.84 \%$ Spatial OTCA relative to the Baseline. Interestingly, the Hybrid scenario, despite having fewer trees, has a slightly higher Spatial OTCA (+0.42\%) versus the UHI Mitigation scenario.

Table 13 - Spatial OTCA for each scenario, assuming an analysis period from 6:00 to 20:00, a comfort criterion of $9{ }^{\circ} \mathrm{C}<\mathrm{UTCl}<26^{\circ} \mathrm{C}$.

\begin{tabular}{ccccc}
\hline & \multicolumn{4}{c}{ Spatial Outdoor Thermal Comfort Autonomy [\%] } \\
\hline Scenario & Baseline & Renewables & Hybrid & UHI Mitigation \\
\hline $\mathbf{5 0 \%}$ & 0.03 & 0.03 & 0.03 & 0.03 \\
\hline $\mathbf{2 5 \%}$ & 68.50 & 68.80 & 70.76 & 70.34 \\
\hline
\end{tabular}

\subsection{Energy Efficiency of Rooftop PV}

\subsubsection{Temperature-Dependent Efficiency}

The temperature-dependent solar conversion efficiency of PV was calculated for the 14 singlebuilding simulations. The results successfully reflect the three environmental parameters used in the cell temperature correlation by Skoplaki \& Palyvos (2009). In general, PV would be most efficient ( 18.2\%) at night, when rooftop air temperatures were lower than that of STC and global tilted irradiance was not contributing to increased cell temperatures. As the sun tracked South and higher in the sky, tilt irradiance and air temperature increased causing efficiency to drop as low as $16.2 \%$. Variation among scenarios was most apparent in the daytime, during which $15 \mathrm{~m}$ trees caused the greatest drop in efficiency and a lack of trees produced the smallest drop in efficiency. In addition, trees planted South (Figure 22) or North and South of the house were more detrimental to efficiency than trees planted East and West of the house (Figure 23). Trees planted North of the house had no appreciable effect on efficiency (Figure 22). The time-averaged efficiency (for the 96-hour study period) does not vary substantially across scenarios (Table 14).

Results of the meteorological variables used to compute PV cell temperature - air temperature, wind speed and global tilted irradiance - are shown in 0 - N In general, taller trees produced lower rooftop air temperatures. In all configurations, the spatially-averaged air temperature over the roof at $14: 00$ was $1.1^{\circ} \mathrm{C}-1.8^{\circ} \mathrm{C}$ cooler with $25 \mathrm{~m}$ tall trees versus no trees at all. Rooftop wind speeds varied significantly when trees were planted South or North and South of the house. In these configurations, $15 \mathrm{~m}$ and $25 \mathrm{~m}$ trees reduced the spatially averaged wind speed by approximately $1 \mathrm{~m} / \mathrm{s}$. 


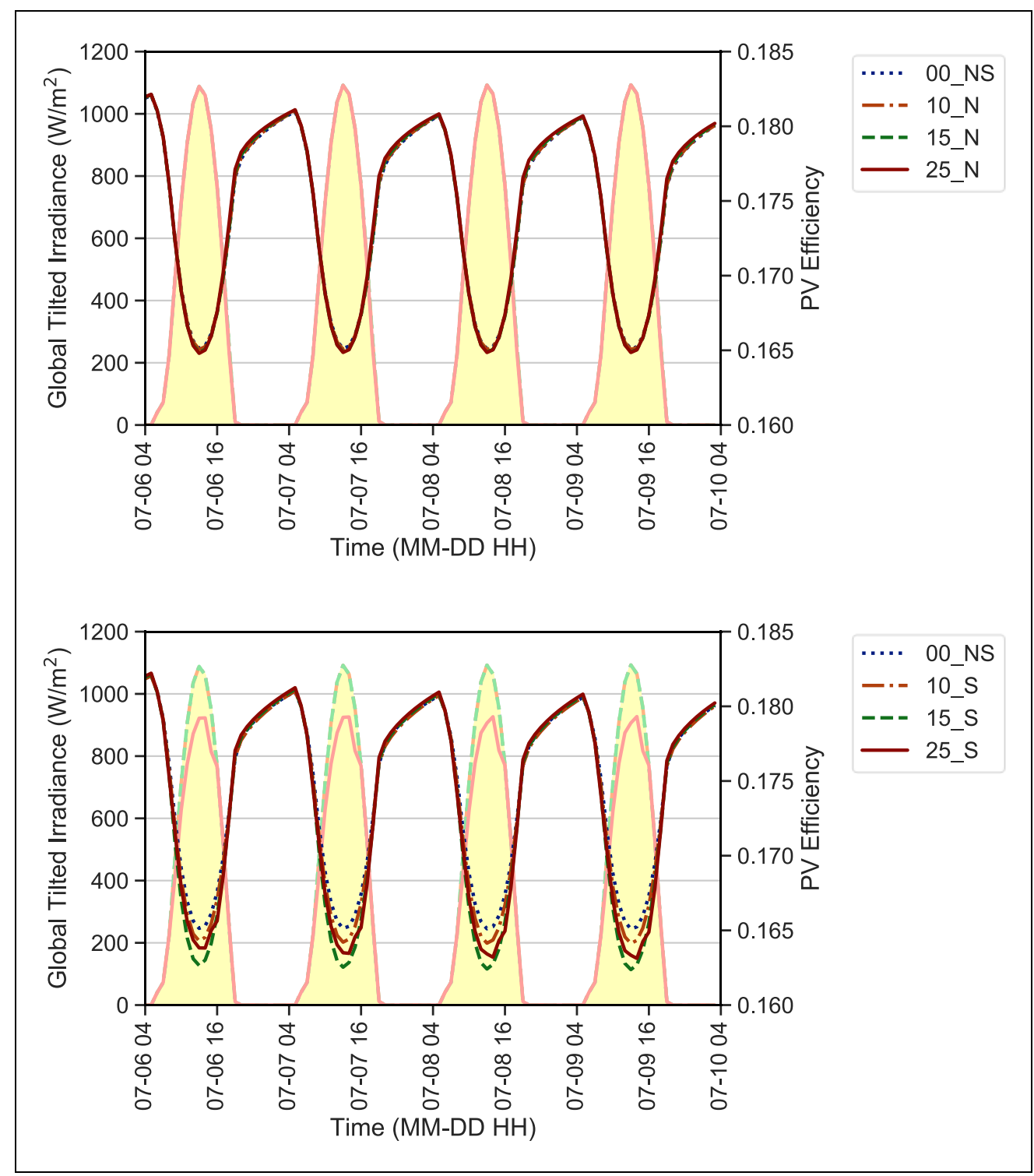

Figure 22 - Solar conversion efficiency with no trees (00_NS), with trees planted to the North (above), and with trees planted to the South (below). Areas shaded yellow indicate global tilted irradiance. Values are spatially-averaged over the rooftop area. 


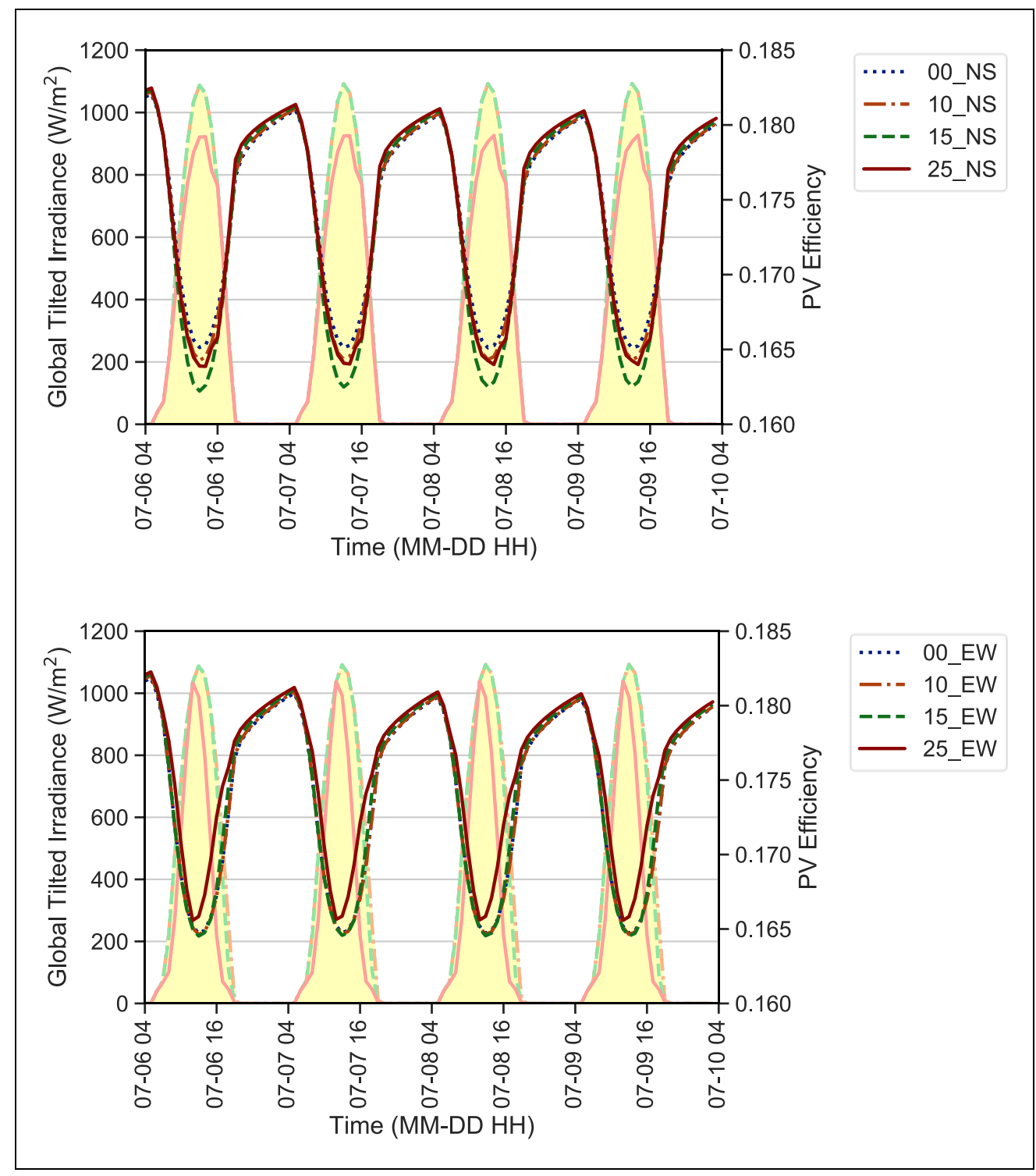

Figure 23 - Solar conversion efficiency with no trees (00_NS/00_EW), with trees planted to the North and South (above), and with trees planted to the East and West (below). Areas shaded yellow indicate global tilted irradiance. Values are spatially-averaged over the rooftop area. 
Table 14 - PV efficiency spatially and temporally averaged over the rooftop area and 4-day analysis period.

\begin{tabular}{|c|c|c|c|c|c|}
\hline \multicolumn{6}{|c|}{ Average PV Efficiency } \\
\hline & & \multicolumn{4}{|c|}{ Tree Placement } \\
\hline & & $\mathbf{N}$ & $\mathbf{S}$ & NS & EW \\
\hline \multirow{4}{*}{ 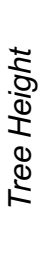 } & No trees & & & 0.1743 & 0.1741 \\
\hline & $10 \mathrm{~m}$ & 0.1743 & 0.1740 & 0.1741 & 0.1741 \\
\hline & $15 \mathrm{~m}$ & 0.1743 & 0.1735 & 0.1736 & 0.1743 \\
\hline & $25 \mathrm{~m}$ & 0.1744 & 0.1737 & 0.1742 & 0.1755 \\
\hline
\end{tabular}

\subsubsection{Power and Energy Output}

Power output was calculated assuming a solar panel area of $1.7 \mathrm{~m}^{2}$. The results successfully capture the shading caused by different tree configurations. Without trees, the peak power output was approximately $300 \mathrm{~W}$. With the addition of $25 \mathrm{~m}$ tall trees South (Figure 24) or North and South (Figure 25) of the house, the peak power output was reduced to approximately $250 \mathrm{~W}$. With the addition of $25 \mathrm{~m}$ tall trees East and West of the house, $300 \mathrm{~W}$ was achieved midday but power declined more rapidly in the afternoon and evening (Figure 25).

The cumulative effect of these differences is expressed by the average daily energy generated during the 96-hour analysis period (Figure 26). Without trees, the solar panel produced between $2351 \mathrm{Wh}$ and $2356 \mathrm{Wh}$ per day. With the addition of $25 \mathrm{~m}$ trees to the South or North and South of the house, $\sim 2065 \mathrm{Wh}$ was produced per day. The most detrimental configuration was $25 \mathrm{~m}$ trees East and West of the house (25_EW), which resulted in only $1605 \mathrm{Wh}$ being produced per day. Configurations involving trees planted North of the house had no discernible effect on power or energy output (Figure 24). Further, trees smaller than $25 \mathrm{~m}$ had limited influence regardless of orientation. 


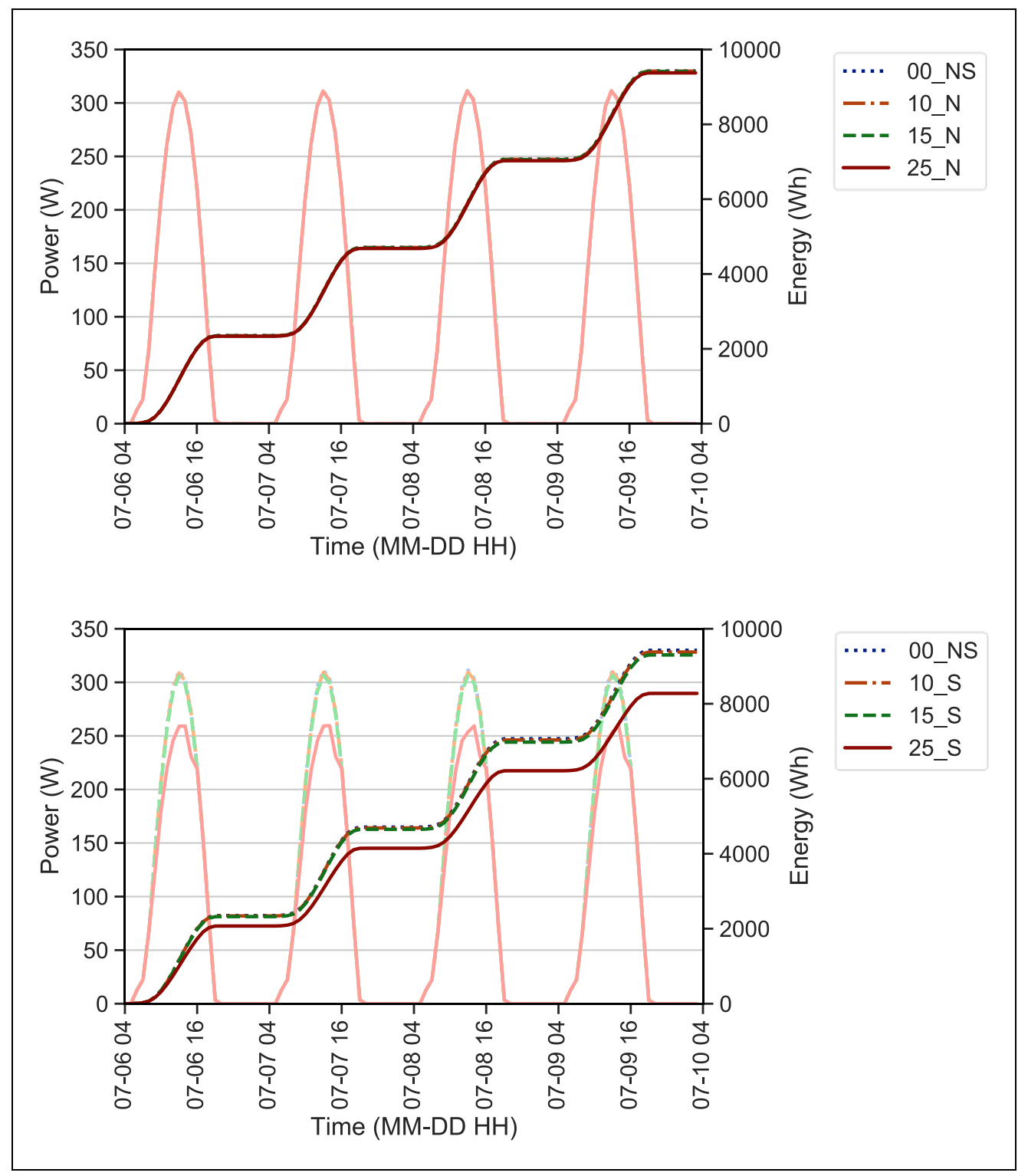

Figure 24 - PV power and energy output with no trees (00_NS), with trees planted to the North (above), and with trees planted to the South (below). 


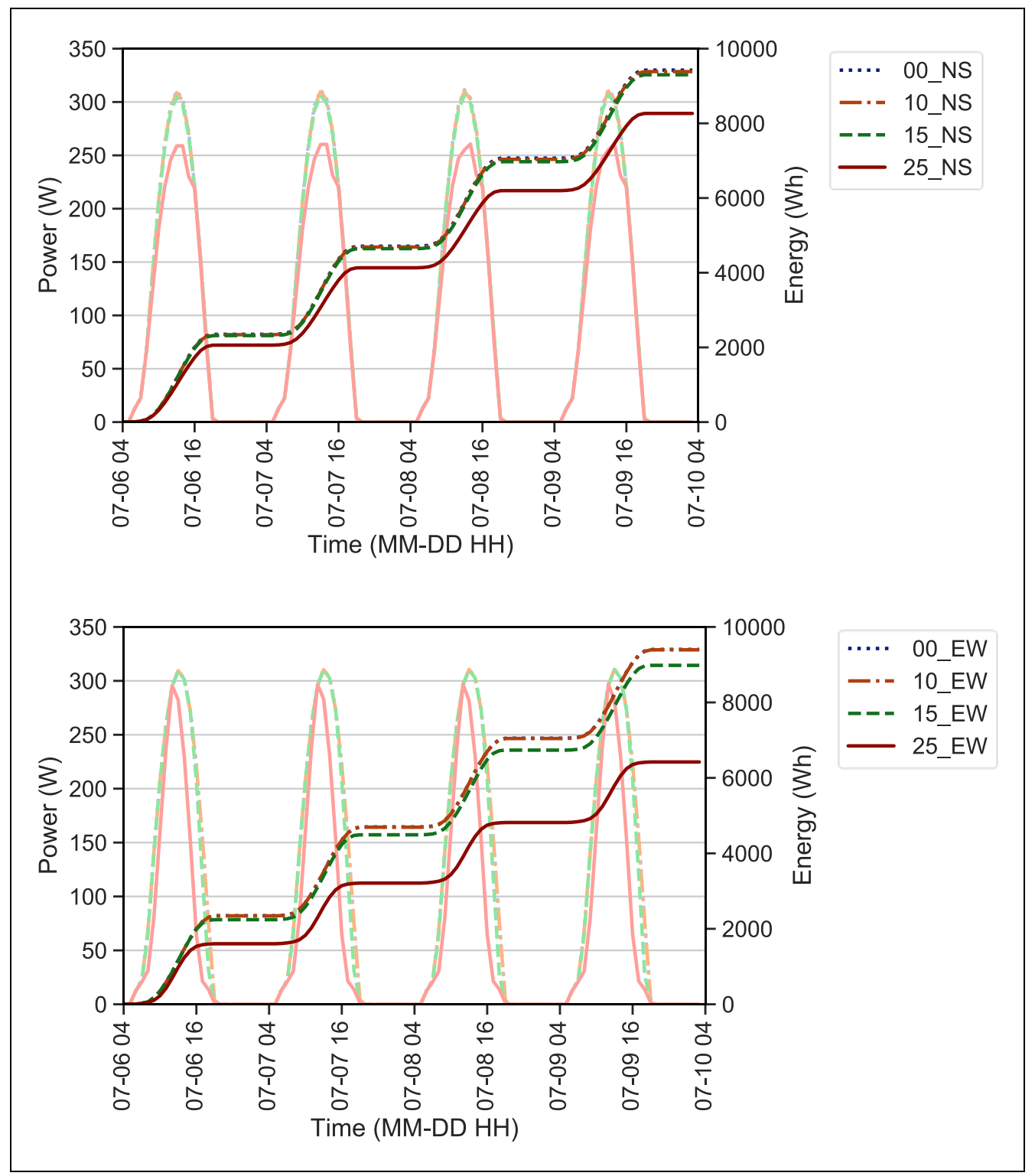

Figure 25 - PV power and energy output with no trees (00_NS/00_EW), with trees planted to the North and South (above), and with trees planted to the East and West (below). 


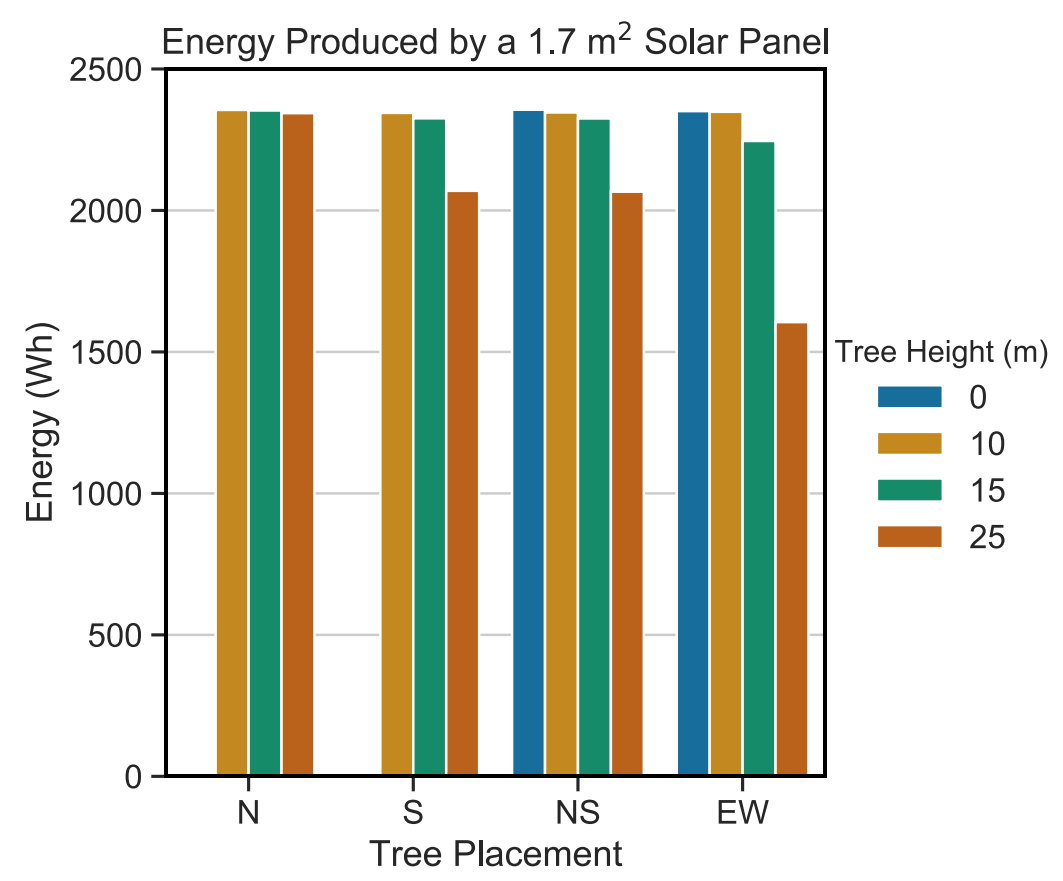

Figure 26 - Average energy produced per day for each of the 14 scenarios.

\section{DISCUSSION}

\subsection{Effect of the Interventions on Outdoor Thermal Comfort}

Overall, it is apparent that UTCl equivalent temperatures can be significantly warmer than air temperatures, thus demonstrating the relevance of multivariate assessments of outdoor thermal comfort. Comparing the results of the scenarios showed that a policy dedicated to UHI Mitigation could cause cooling of up to $5.9^{\circ} \mathrm{C} \mathrm{UTCl} \mathrm{under} \mathrm{newly} \mathrm{added} \mathrm{trees.} \mathrm{Of} \mathrm{course,} \mathrm{this} \mathrm{is} \mathrm{an} \mathrm{absolute}$ maximum reflective of a point in time and point in space. In fact, when the results are averaged across four regions of the model domain and 17 hours, the UHI Mitigation scenario claims cooling of $0.54{ }^{\circ} \mathrm{C} \mathrm{UTCl}$ and negligible change to OTCA. As a reminder, this scenario involved adding 619 $10 \mathrm{~m}$ tall trees and converting $100 \%$ of roofs to cool roofs (albedo 0.85 ). Given the intensity of these interventions, the average cooling achieved is modest. One explanation for the modest cooling might be the leaf area density (LAD) used for the neighbourhood-scale simulations, which, at $0.3 \mathrm{~m}^{2} \mathrm{~m}^{-3}$, is characteristic of a sparser tree (Stadt \& Lieffers, 2000). This is significant because in ENVI-met, LAD is a factor controlling evaporative cooling, such that a denser tree will exert more of a cooling influence (Appendix D).

The results also showed that adding $18 \%$ efficient PV to $100 \%$ of all roofs would have limited effects at pedestrian height. The average air temperature reduction for the Renewables scenario 
was $0.09{ }^{\circ} \mathrm{C}$, which is in line with previously reported values of $0.05{ }^{\circ} \mathrm{C}$ to $0.3{ }^{\circ} \mathrm{C}$ (Taha, 2013; Masson et al., 2014). Cooling occurred because the PV roofs were given a shortwave reflectivity $10 \%$ greater than the baseline asphalt roofs in order to account for their solar conversion property. With more shortwave radiation reflected (and less absorbed), the PV roofs remained cooler and offered less sensible heat to be removed into the air. This led to significant air temperature reductions at roof height but limited change below $5 \mathrm{~m}$ (Figure 15), which is a limitation of all rooftop interventions ( $\mathrm{Ng}$ et al., 2012; Santamouris et al., 2018). In fact, when pedestrian-height UTCI is considered, the effective cooling was even less, only $0.07{ }^{\circ} \mathrm{C}$. This is because the remaining ingredients to human thermal comfort - humidity, radiant temperature and wind speed - were wholly unaffected at pedestrian height. This analysis, in terms of a comprehensive $\mathrm{HTCl}$, was missing from previous studies. It refutes claims that rooftop PV could be regarded as an UHI Mitigation strategy (Masson et al., 2014). It should be acknowledged, however, that this study assumed a nameplate efficiency of $18 \%$. Previous studies reporting large amounts of cooling assumed more generous efficiencies up to 60\% (Ma et al., 2018).

The addition of trees in the Hybrid scenario caused only slight cooling relative to the Renewables scenario. The Hybrid scenario symbolized a policy aiming to balance renewable energy production with urban heat mitigation by still having $100 \%$ rooftop PV deployment, but in conjunction with $50 \%$ of the street and backyard trees added by the UHI Mitigation scenario. It was assumed this was the maximum tree coverage that could be added without shading the PV. Under this configuration, the average UTCl cooling increased from $0.07^{\circ} \mathrm{C}$ (Renewables) to 0.12 ${ }^{\circ} \mathrm{C}$ (Hybrid). Considering the UHI Mitigation scenario achieved cooling of $0.54{ }^{\circ} \mathrm{C}$, this improvement is trivial. One explanation is that the cooling caused by urban forestry does not scale linearly - in other words, half the tree canopy coverage does not equal half the cooling effect. In any case, it was demonstrated that partial implementations of UHI mitigation strategies are significantly less effective than full-fledged implementations.

A pattern observed in all scenarios was the greater prevalence of heat stress in streets orientated perpendicular to the wind versus streets orientated parallel to the wind. This can be explained by lower wind speeds in the former, as visible in Figure 18 (slice A and B). In terms of the UTCI algorithm, lower wind speeds means less potential for convective cooling, and subsequently more heat storage in the human body. It can thus be hypothesized that UHI mitigation policies might be more effective if they were intensified around areas of consistently poorer ventilation rather than being applied globally. 
Another pattern present in all scenarios was the "double-top" of the MRT time plots. This pattern is seen in studies by Taleghani et al. (2016), Berardi (2016) and Ghaffarianhoseini et al. (2015) but is seldom remarked upon. It is most likely a product of ENVI-met's calculation of MRT, which uses a projected area factor $\left(f_{p}\right)$ to account for the geometry of an upright-standing human. That factor is calculated dynamically relative to the sun's altitude $(\varnothing)$ by the following function (Bruse, 1999)

$$
f_{p}=0.3345-0.00272 \emptyset
$$

Equation 13

which is a linear approximation of tabular values from VDI Standard 3787 (VDI, 1996). This factor is used to diminish the influence of direct solar radiation as solar altitude increases (and less of the human body is exposed to the incident radiation), thus explaining the "dip" in MRT at solar noon. This information suggests that vertical surfaces, such as walls and solid fences, contribute to thermal comfort because they cast shadows when solar radiation is most detrimental to the human heat balance - at low solar altitudes.

The calculation of Spatial OTCA produced an unexpected result when a $25 \%$ time threshold was considered. Under this configuration, the Hybrid scenario was observed to be $0.42 \%$ more comfortable than the UHI Mitigation scenario, which contradicts results showing that the daily average UTCI was lower for the UHI Mitigation scenario. One explanation for this could be the fact that Spatial OTCA takes into account the whole study area at $1.5 \mathrm{~m}$, while UTCl was only extracted from specific regions at $1.5 \mathrm{~m}$. It is possible that outside of these regions there were hours when the Hybrid scenario was comfortable and the UHI Mitigation scenario was not.

\subsection{Effect of the Interventions on PV Energy Efficiency}

The results of the single-building simulations showed that on a hot, cloudless summer day, a roofmounted monocrystalline silicon solar panel could lose $10 \%$ of its nameplate efficiency in the early afternoon. This loss was caused by increased PV cell temperature due to solar radiation, local air temperature and local wind speed. The 14 tree configurations showed that rooftop PV would retain most of its efficiency with no trees surrounding the house. Although the trees reduced rooftop air temperatures, they also reduced local wind speeds thereby contributing to higher cell temperatures. An exception to this pattern was with trees planted North of the house. Since Southerly winds were simulated, trees planted North of the house had less of an impact on rooftop wind speed and thus PV efficiency. 
The results of PV power and 4-day energy output were highly influenced by shading. $25 \mathrm{~m}$ tall trees caused the poorest performance with a 32\% loss in energy output in the East and West configuration. Applications of $10 \mathrm{~m}$ and $15 \mathrm{~m}$ tall trees were much less harmful to PV output despite still being taller than the roof. This can be explained by the July 5 sun path, which had a small zenith angle throughout the day thus limiting shading caused by shorter objects. Moreover, when the $10 \mathrm{~m}$ and $15 \mathrm{~m}$ tall trees did block the roof from solar radiation, the sun was at an East or West azimuth and thus not much radiation was arriving at the South facing PV anyways. An obvious but important result was the unchanged performance of the rooftop PV when trees were planted North of the house. Under this configuration, the 4-day energy output changed no more than $0.5 \%$ when trees of any height were added. This suggests that an urban policy can balance renewable energy production and UHI mitigation by planting larger trees North of buildings.

\subsection{Limitations}

A handful of clauses limit the validity of this study. Firstly, the representation of solar panels in ENVI-met was drastically simplified. They were assumed to be part of the roof assembly and level with the horizon. As pointed out by Pham et al. (2019), this fails to account for convective heat transfer on the bottom side of the panels which may lead to an underestimation of the sensible heat removed into the air. Moreover, many simplifications were made during the calulcation of PV energy efficiency. Even though cell temperature was estimated using a well-cited formula incorporating air temperature, wind speed and radiation, the cells were assumed to possess no thermal storage. Further, there are other factors influencing solar conversion efficiency such as the spectrum of incident radiation and the sun angle dependent reflectivity of modules (Bücher, 1997; Zachariou \& Protogeropoulos, 2010). Also, even though the formula for cell temperature accounts for wind speed, it does not account for turbulent mixing of air. Experiments by Ogaili \& Sailor (2016) suggest that turbulent mixing of air by rooftop vegetation reduce PV cell temperatures and thereby improve efficiency. If such an effect is achieved by trees too, it is not represented in this study. Lastly, the method for determining PV power and energy output overestimated performance under partial shading. In reality, the power lost due to shading is greater than proportional to the amount of shade on a solar panel (Deline, 2010). 


\section{CONCLUSIONS}

Street trees, cool roofs and rooftop PV all make positive strides towards urban resilience. However, there are trade-offs to consider when deploying these interventions. Rooftop PV substitutes what could be a surface of comparatively higher solar absorptance, thereby hampering UHI mitigation. Street trees shade PV, limiting their energy output. The purpose of this study was

to quantify trade-offs between an urban policy dedicated to UHI mitigation and one dedicated to renewable energy production via rooftop $\mathrm{PV}$.

To assess the effects in terms of outdoor thermal comfort, three versions of a neighbourhood in Brampton were simulated using the microclimate analysis tool ENVI-met. Each version had a different quantity of tree canopy coverage and either cool roofs or PV roofs. Overall, a neighbourhood-wide deployment of rooftop PV was shown to cause cooling of $0.07{ }^{\circ} \mathrm{C} \mathrm{UTCl}$ at pedestrian height. Meanwhile, a scenario dedicated to street trees and cool roofs caused cooling of around $0.54{ }^{\circ} \mathrm{C}$ UTCl. To assess the effects in terms of PV energy efficiency, 14 single-building microclimate simulations were performed. It was found that trees can substantially reduce air temperatures above a two-storey building, but not enough to improve the solar conversion efficiency of rooftop PV. In fact, one configuration of $25 \mathrm{~m}$ tall trees caused a $32 \%$ loss of energy in a 4-day period. On the other hand, $10 \mathrm{~m}$ and $15 \mathrm{~m}$ trees were shown to be relatively harmless to rooftop PV performance.

It should be reminded that these conclusions are specific to the study area in Brampton, Ontario. Although every effort was made to select a generic neighbourhood and meteorological boundary condition, slightly different contexts may have responded differently to the interventions. Moreover, a highly simplified parameterization of rooftop PV was used. Future studies can improve accuracy by parameterizing rooftop $\mathrm{PV}$ as standalone tilted surfaces while still analyzing neighbourhood-scale effects. Also, there is a need for more precise PV cell temperature models which consider turbulent airflow. 


\section{Appendix A}

\section{Results of Studies Simulating UHI Mitigation Strategies}

This table is not intended to be a comprehensive account of each author's results. Rather, only the figures most emphasized by the authors are included. Cells in red indicate the intervention caused warming.

Table A-1 - Main results of studies involving macro- or microclimate simulations of UHI mitigation strategies.

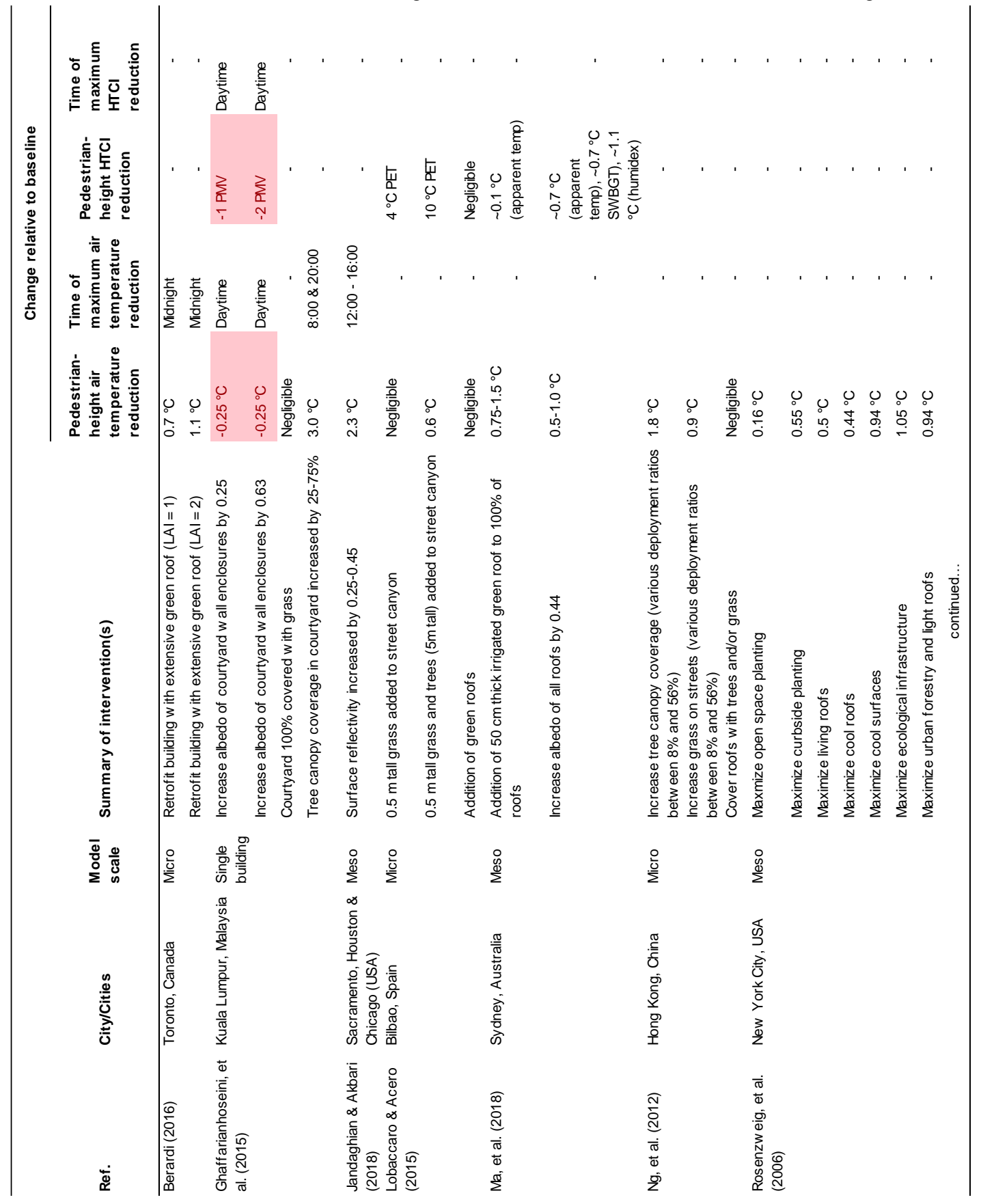




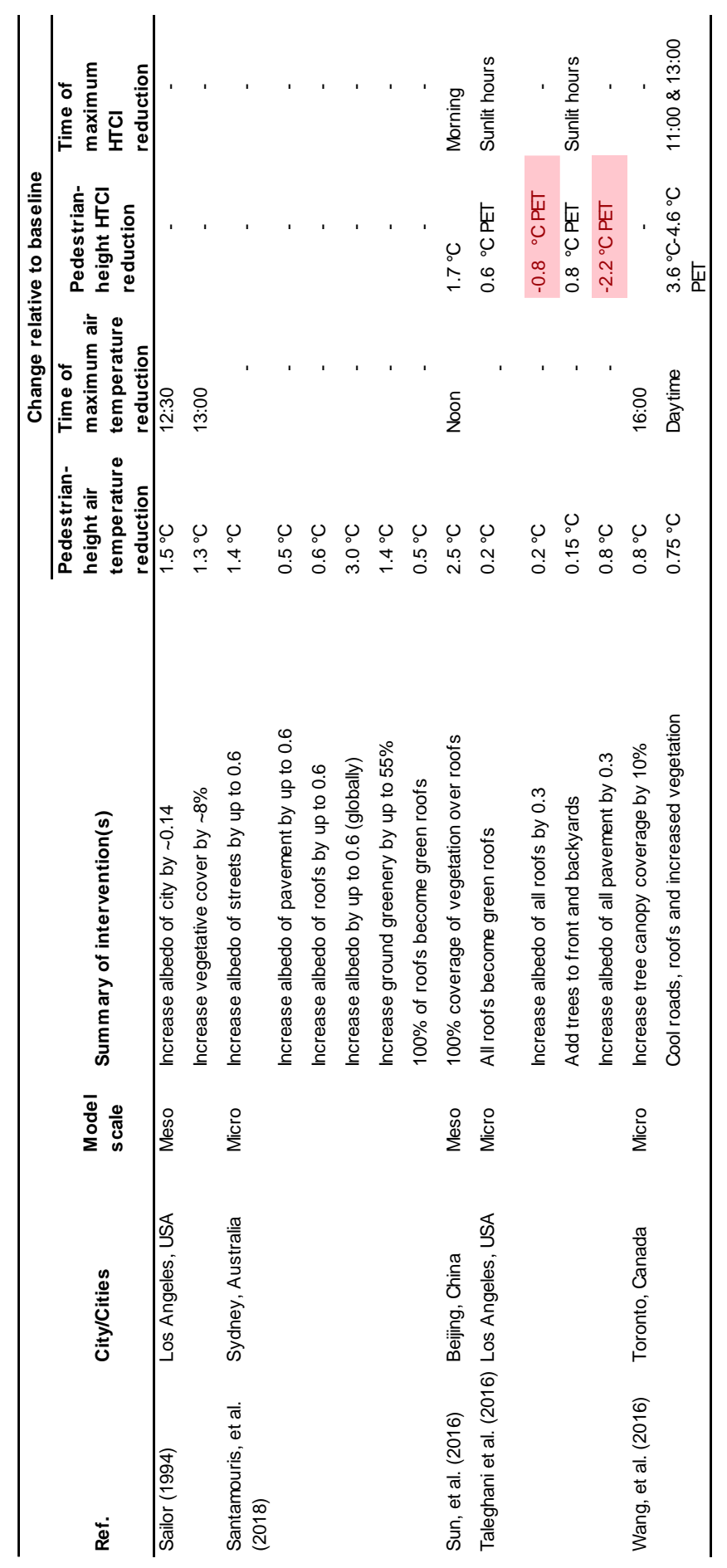




\section{Appendix B}

\section{Results of Studies Simulating Microclimate Effects of Rooftop PV}

This table is not intended to be a comprehensive account of each author's results. Rather, only the figures most emphasized by the authors are included. * indicates air temperature was taken at $5 \mathrm{~m}$ height.

Table B-1 - Main results of studies involving macro- or microclimate simulations of rooftop PV

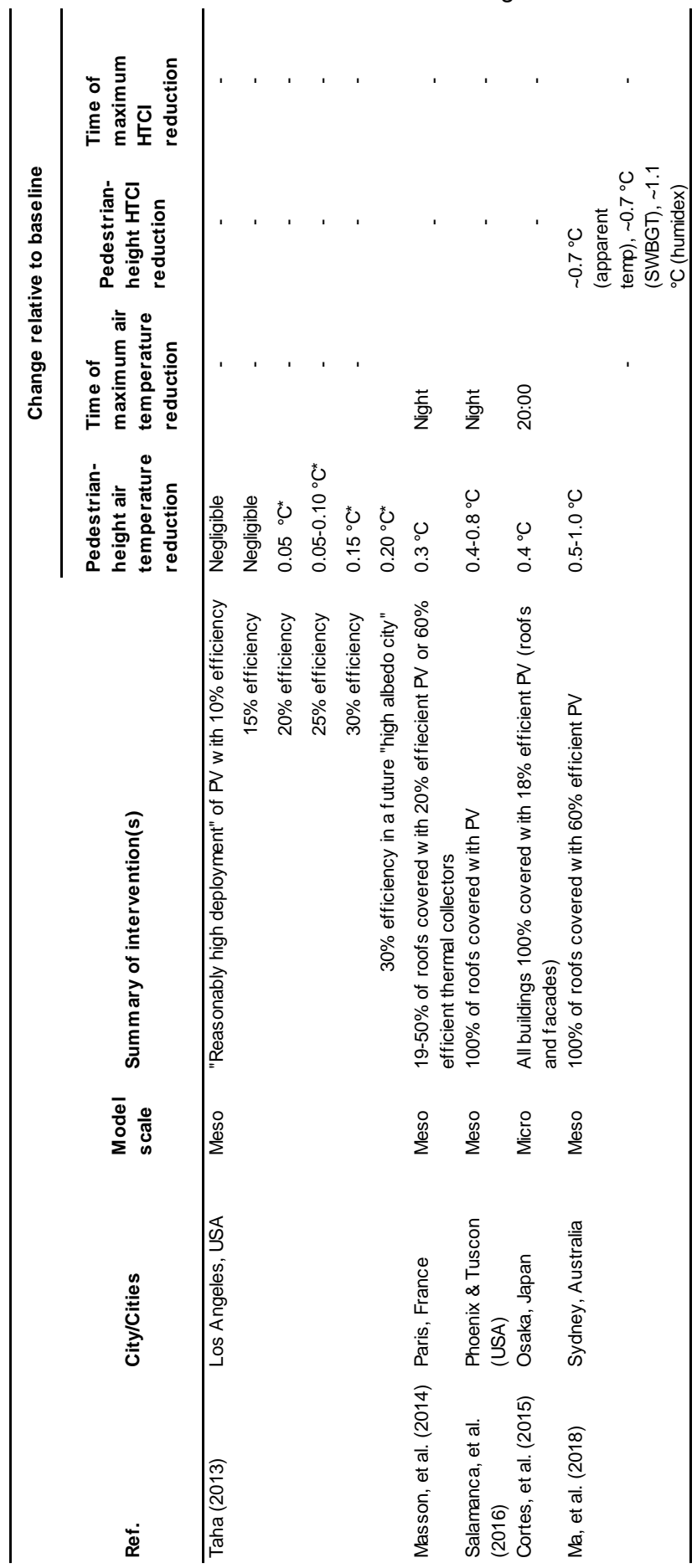




\section{Appendix C}

Mesoscale and Microscale Atmospheric Models

As computational resources have become more abundant, the resolution and specificity of simulations has increased. Presently, there is a divide between mesoscale atmospheric models serving horizontal study areas in the range of $50 \mathrm{~km} \times 50 \mathrm{~km}$ (i.e. Weather Research and Forecasting), and microclimate models serving areas $1 \mathrm{~km} \times 1 \mathrm{~km}$ and smaller (i.e. ENVI-met). A benefit of microscale models is that, because of their high spatial resolution, static inputs such as buildings, topography and vegetation require little parameterization and can be depicted explicitly (Simon et al., 2018). This level of specificity has led to new discoveries. For example, Ali-Toudert \& Mayer (2006) simulated different urban canyon geometries and orientations and found that a height-to-width ratio equal to or greater than 2 is most effective at reducing MRT at pedestrian height in Algeria. MRT is highly dependent on sky view factor, which is determined by the explicit geometry of buildings. Thus, it is useful to be able to model urban morphologies explicitly. On the other hand, mesoscale models have access to more accurate meteorological boundary condition data. For example, WRF simulations can be nested inside gridded continental data synthesized from rawinsondes, aircraft, satellites and weather stations (Mesinger et al., 2006). This enables the simulation to capture effects from large-scale meteorological processes. ENVI-met simulations, meanwhile, are forced by idealized conditions or weather station data. Another benefit of mesoscale models is that, by merit of the physical model extents, they permit direct examination of UHI intensity, which is the difference in $2 \mathrm{~m}$ air temperature between city centre and surrounding cropland. 


\section{Appendix D}

\section{Equations Governing ENVI-met Plant Behaviour}

\section{Wind Dampening}

$$
S_{u(i)}=\frac{\overline{\partial p^{\prime}}}{\partial x}=c_{d, f} L A D(z) \cdot W \cdot u_{i}
$$

Equation D-1

where $S_{\boldsymbol{u}(\boldsymbol{i})}$ is the local windspeed 'sink' along the X-axis for a given cell, $\frac{\overline{\partial p \prime}}{\partial x}$ is an internal force in the Navier-Stokes equation, $\boldsymbol{c}_{\boldsymbol{d}, \boldsymbol{f}}$ is a fixed mechanical drag coefficient, $\boldsymbol{L A D}(\mathbf{z})$ is leaf area density at height $\mathrm{z}, \mathrm{W}$ is the mean wind speed in all directions at height $z$, and $\boldsymbol{u}_{\boldsymbol{i}}$ is the $u$ component of the wind vectors for a given cell.

\begin{tabular}{|c|c|}
\hline \multicolumn{2}{|l|}{ Shading } \\
\hline$\sigma_{s w, d i r}(z)=\exp \left(F \cdot L A I^{*}(z)\right)$ & Equation D-2 \\
\hline$\sigma_{s w, d i f}(z)=\exp \left(F \cdot L A I\left(z, z_{p}\right)\right)$ & Equation D-3 \\
\hline \multicolumn{2}{|c|}{$\begin{array}{l}\text { where } \boldsymbol{\sigma} \text { is a radiation reduction coefficient at height } \boldsymbol{z}, \boldsymbol{L A I} \text { is the one-dimensional vertical leaf area index of the } \\
\text { plant from height } \boldsymbol{z} \text { to the top of the plant and } \boldsymbol{F} \text { is an orientation-dependent leaf extinction coefficient. }\end{array}$} \\
\hline \multicolumn{2}{|c|}{$\boldsymbol{L} \boldsymbol{A} \boldsymbol{I}^{*}$ is the three-dimensional leaf area index which is dependent on the incident angle of the sun's rays. } \\
\hline \multicolumn{2}{|l|}{ Humidification } \\
\hline$J_{f, e v a p}=r_{a}^{-1} \Delta q \delta_{c} f_{w}+r_{a}^{-1}\left(1-\delta_{c}\right) \Delta q$ & Equation D-4 \\
\hline$J_{f, t r a n s}=\delta_{c}\left(r_{a}+r_{s}\right)^{-1}\left(1-\delta_{c}\right) \Delta q$ & Equation D-5 \\
\hline$Q_{q}(z)=L A D(z)\left(J_{f, \text { evapo }}+J_{f, \text { trans }}\right)$ & Equation D-6 \\
\hline \multicolumn{2}{|c|}{$\begin{array}{l}\text { where } \boldsymbol{J}_{\boldsymbol{f} \text {,evap }} \text { is evaporation flux between a leaf and the air, } \boldsymbol{J}_{f, \text { trans }} \text { is transpiration flux, } \boldsymbol{Q}_{\boldsymbol{q}}(\mathbf{z}) \text { is the source/sink factor } \\
\text { for vegetation at height } \boldsymbol{z}, \boldsymbol{r}_{\boldsymbol{a}} \text { is the aerodynamic resistance of the leaf, } \Delta \boldsymbol{q} \text { is humidity difference between the leaf } \\
\text { and the air, } \boldsymbol{\delta}_{\boldsymbol{c}} \text { is a coefficient determining whether evaporation is possible, } \boldsymbol{f}_{\boldsymbol{w}} \text { is the fraction of wet leaves in a grid } \\
\text { cell, and } \boldsymbol{r}_{\boldsymbol{s}} \text { is the stomatal resistance of the vegetation. }\end{array}$} \\
\hline
\end{tabular}

\section{Evaporative Cooling ${ }^{8}$}

$\begin{array}{cc}J_{f, h}=1.1 r_{a}^{-1}\left(T_{f}-T_{a}\right) & \text { Equation D-7 } \\ Q_{h}(z)=L A D(z) J_{f, h} & \text { Equation D-8 }\end{array}$

where $\boldsymbol{J}_{\boldsymbol{f}, \boldsymbol{h}}$ is sensible heat flux between a leaf and the air, $\boldsymbol{T}_{\boldsymbol{f}}$ is leaf temperature, $\boldsymbol{T}_{\boldsymbol{a}}$ is air temperature, and $\boldsymbol{Q}_{\boldsymbol{h}}(\mathbf{z})$ is the source/sink factor for vegetation at height $z$.

${ }^{8}$ Occurs through the decrease of $T_{f}$ through the repartition of sensible heat into latent heat. 


\section{Appendix E}

\section{Results from the Greenbelt Simulations}

Three additional simulations of the Brampton study area were performed for a project entitled "Examining the Role of Green Infrastructure and the Greenbelt's Urban River Valleys in Building Resilience to Climate Change and the Impacts of Extreme Heat", which was delivered to the Friends of the Greenbelt Foundation, Ontario. In this project, the scenarios "Baseline", "Scenario 1" and "Scenario 2" corresponded to the scenarios "Baseline", "Hybrid" and "UHI Mitigation", respectively, in the present MRP. The only differences were that all trees were parameterized with a LAD of $1.5 \mathrm{~m}^{2} \mathrm{~m}^{-3}$, and all rooftops were asphalt (across all scenarios). A selection of tables and figures from the project are shown below.

Table E-1 - Air temperature reductions achieved relative to the Baseline simulation.

\begin{tabular}{c|ccc}
\hline & $\begin{array}{c}\text { Spatially Averaged } \\
\text { Cooling at 17:00 }\left({ }^{\circ} \mathbf{C}\right)\end{array}$ & $\begin{array}{c}\text { Maximum Cooling, } \\
\text { all hours }\left({ }^{\circ} \mathbf{C}\right)\end{array}$ & $\begin{array}{c}\text { Time of Maximum } \\
\text { Cooling }\end{array}$ \\
\hline Scenario 1 & 0.11 & 0.39 & $18: 00$ \\
\hline Scenario 2 & 0.46 & 1.51 & $18: 00$ \\
\hline
\end{tabular}

Table E-2 - Perceived temperature (UTCI) reductions achieved relative to the Baseline simulation.

\begin{tabular}{c|ccc}
\hline & $\begin{array}{c}\text { Spatially Averaged } \\
\text { Cooling at 17:00 }\left({ }^{\circ} \mathbf{C}\right. \\
\text { UTCI) }\end{array}$ & $\begin{array}{c}\text { Maximum Cooling, } \\
\text { all hours }\left({ }^{\circ} \mathbf{C} \text { UTCI) }\right.\end{array}$ & $\begin{array}{c}\text { Time of Maximum } \\
\text { Cooling }\end{array}$ \\
\hline Scenario 1 & 0.28 & 11.06 & $07: 00$ \\
\hline Scenario 2 & 1.12 & 9.7 & $07: 00$ \\
\hline
\end{tabular}



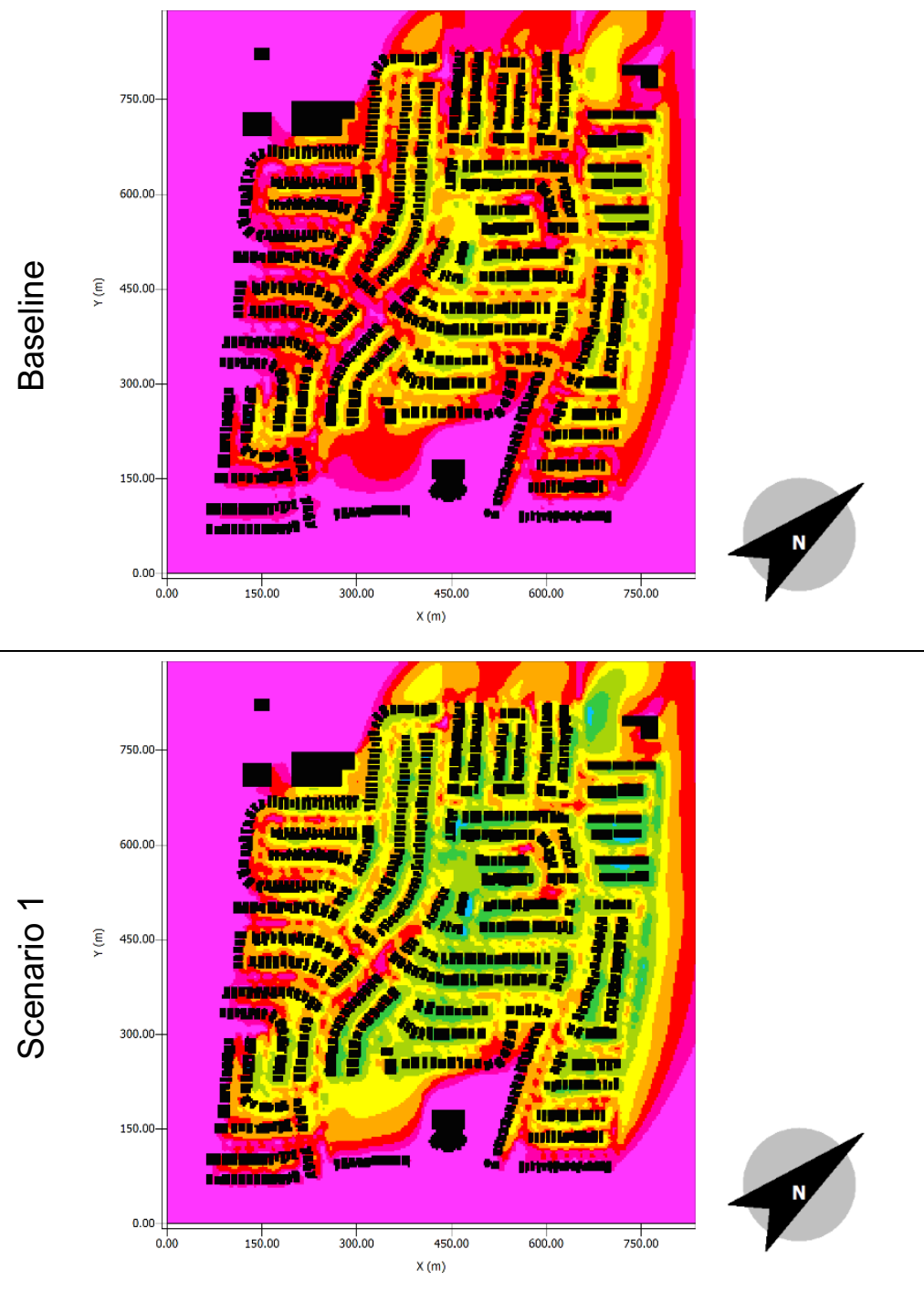

\section{Air Temperature}

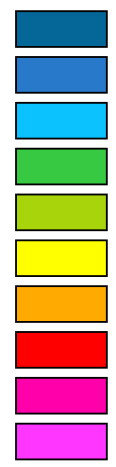

below $28.1^{\circ} \mathrm{C}$

28.1 to $28.2^{\circ} \mathrm{C}$

28.2 to $28.3^{\circ} \mathrm{C}$

28.3 to $28.4^{\circ} \mathrm{C}$

28.4 to $28.5^{\circ} \mathrm{C}$

28.5 to $28.6^{\circ} \mathrm{C}$

28.6 to $28.7^{\circ} \mathrm{C}$

28.7 to $28.8^{\circ} \mathrm{C}$

28.8 to $28.9^{\circ} \mathrm{C}$ above $28.9^{\circ} \mathrm{C}$
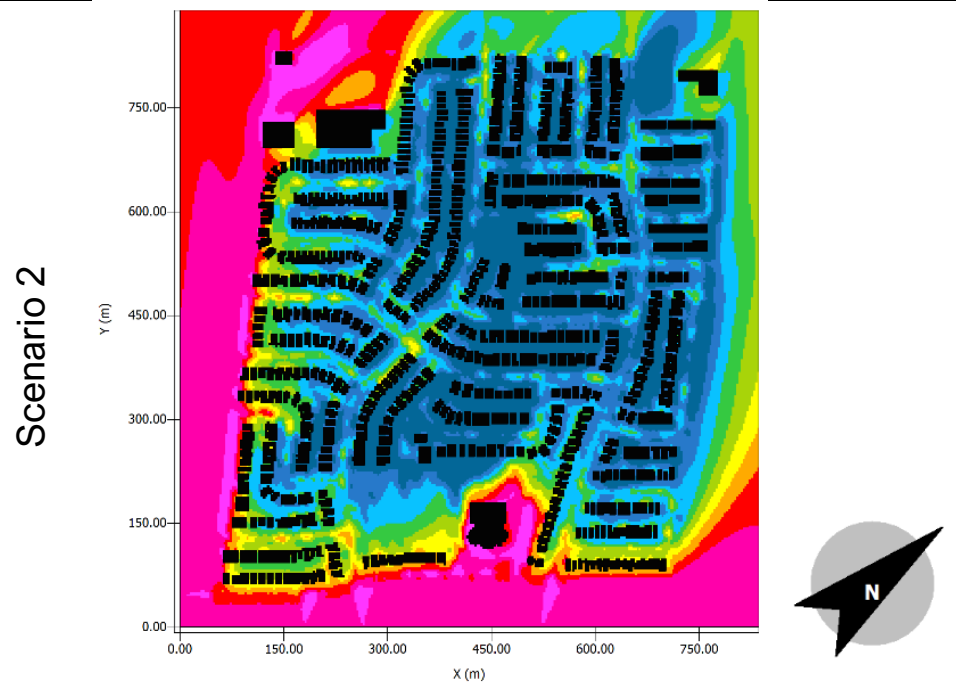

Figure E-3 - Air temperature at $1.5 \mathrm{~m}$ height at 17:00, for each of the three scenarios. 

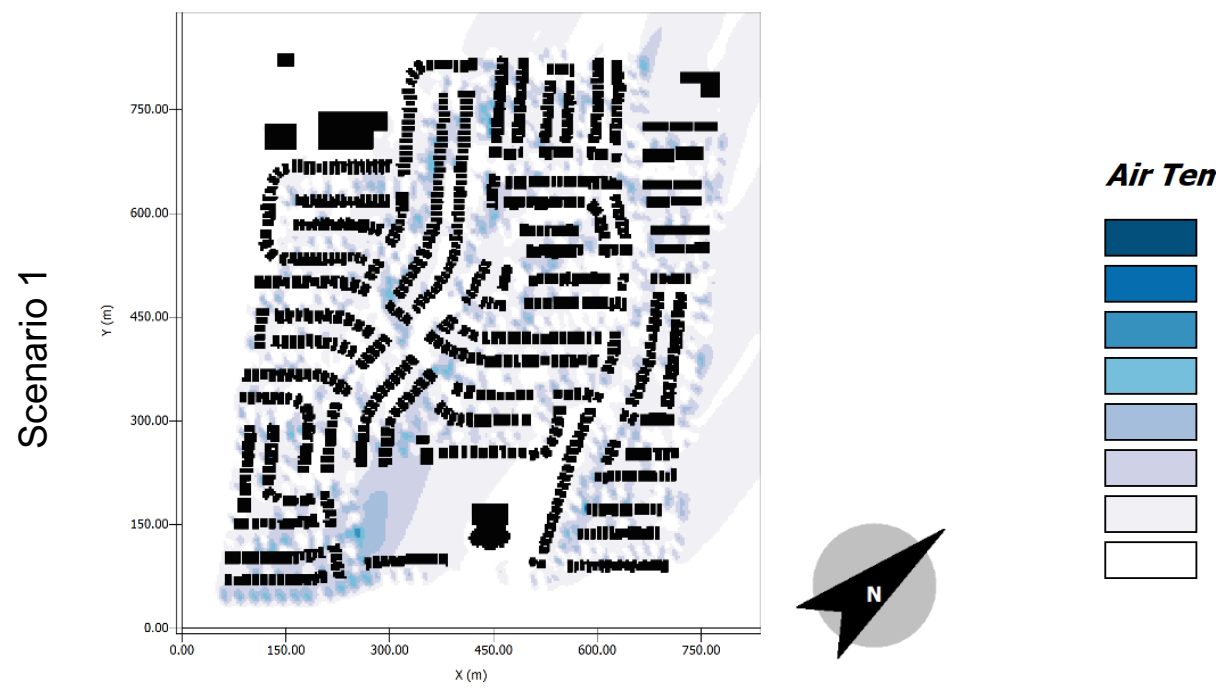

\section{Temperature Difference}

below $-0.40^{\circ} \mathrm{C}$

-0.40 to $-0.35^{\circ} \mathrm{C}$

-0.35 to $-0.30^{\circ} \mathrm{C}$

-0.30 to $-0.25^{\circ} \mathrm{C}$

-0.25 to $-0.20^{\circ} \mathrm{C}$

-0.20 to $-0.15^{\circ} \mathrm{C}$

-0.15 to $-0.10^{\circ} \mathrm{C}$

above $-0.10^{\circ} \mathrm{C}$

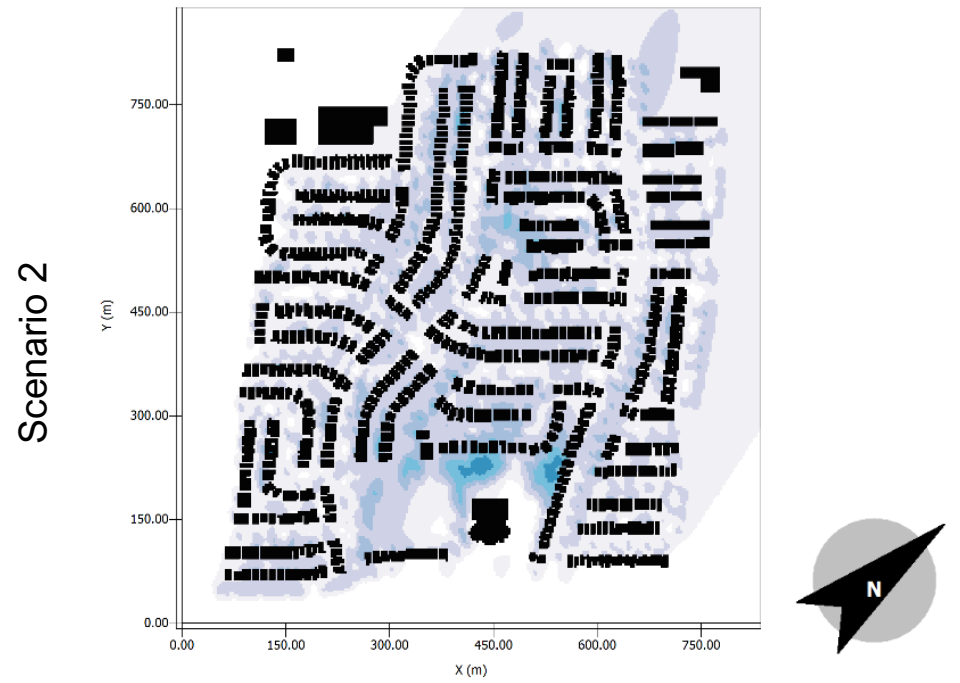

Air Temperature Difference

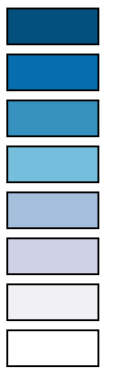

below $-1.0^{\circ} \mathrm{C}$

-1.0 to $-0.9^{\circ} \mathrm{C}$

-0.9 to $-0.8^{\circ} \mathrm{C}$

-0.8 to $-0.7^{\circ} \mathrm{C}$

-0.7 to $-0.6^{\circ} \mathrm{C}$

-0.6 to $-0.5^{\circ} \mathrm{C}$

-0.5 to $-0.4^{\circ} \mathrm{C}$

above $-0.4^{\circ} \mathrm{C}$

Figure E-4 - $1.5 \mathrm{~m}$ air temperature reductions relative to the baseline scenario, at 17:00

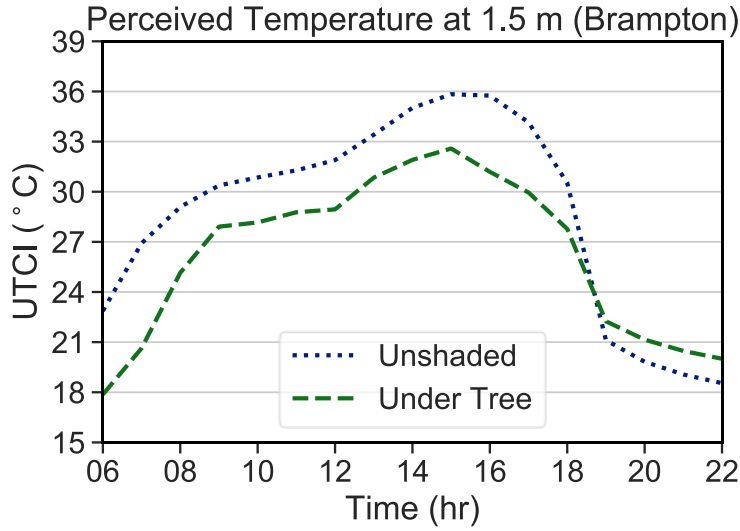

Figure E-5 - Hourly UTCl at $1.5 \mathrm{~m}$, at unshaded and tree-shaded locations in the model domains of the Baseline simulation and Scenario 2, respectively. 

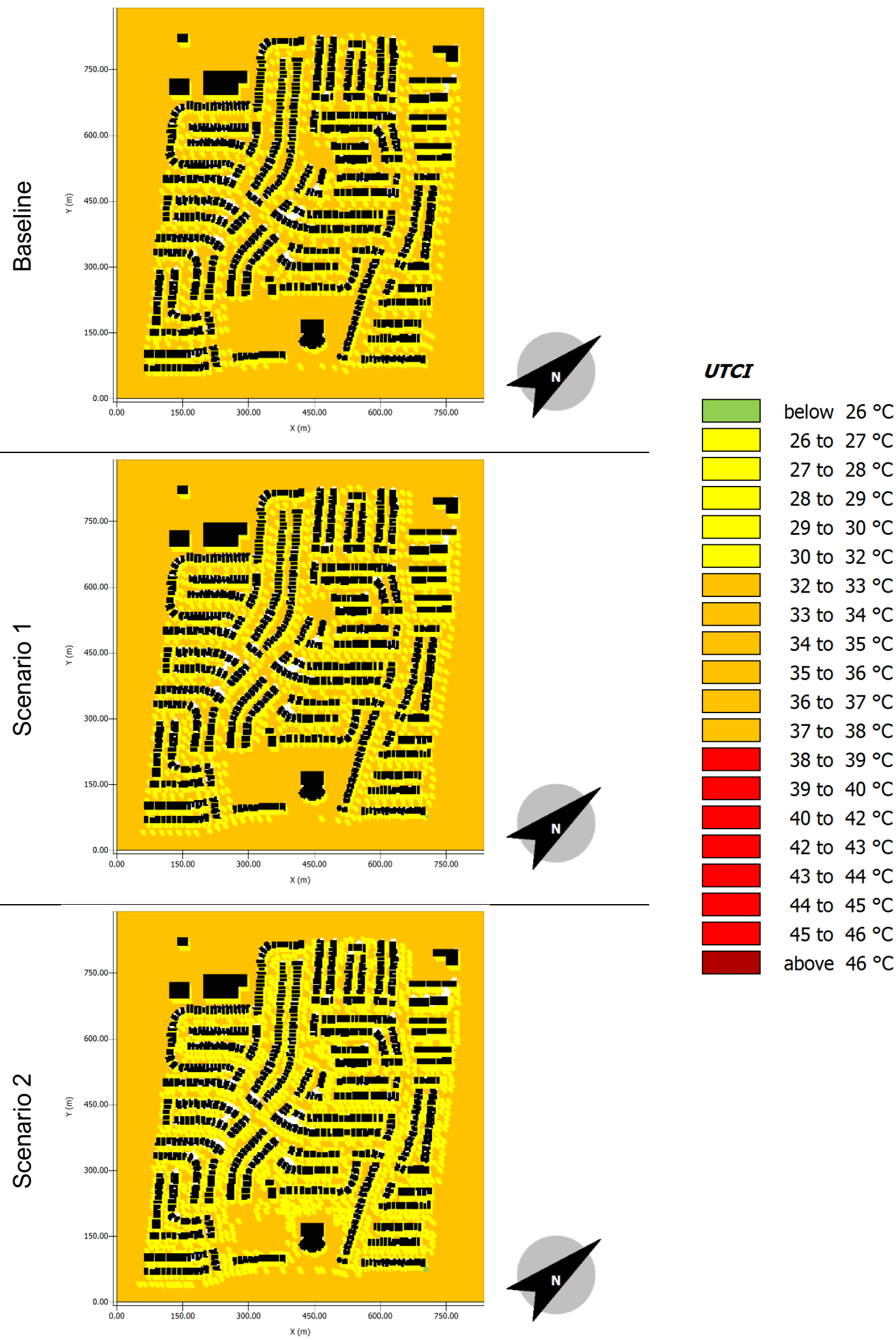

Figure E-6 - UTCI at $1.5 \mathrm{~m}$ height at 17:00, for each of the three scenarios. 


\section{Appendix F}

Alternate Study Areas

The following study areas were shortlisted for analysis. \#3 was ultimately used for a related study commissioned by the Ontario Greenbelt Foundation.

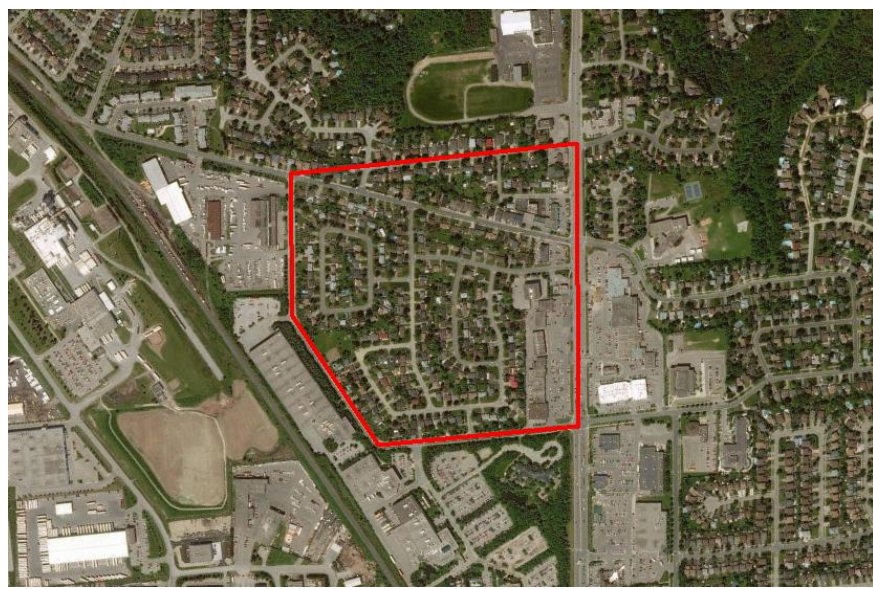

\section{\#1 Bolton, Ontario}

Reasons for rejecting:

Older neighbourhood with mature trees. Not much potential for greening.

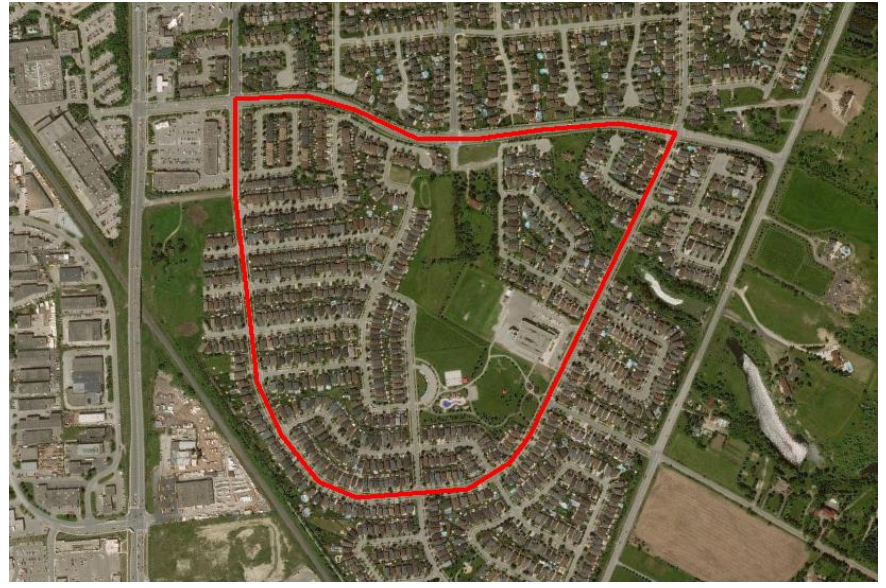

\section{\#2 Bolton, Ontario}

Reasons for rejecting:

Irregular shape would lead to wasted space in the model domain. Sloped topography could lead to site-specific phenomena.

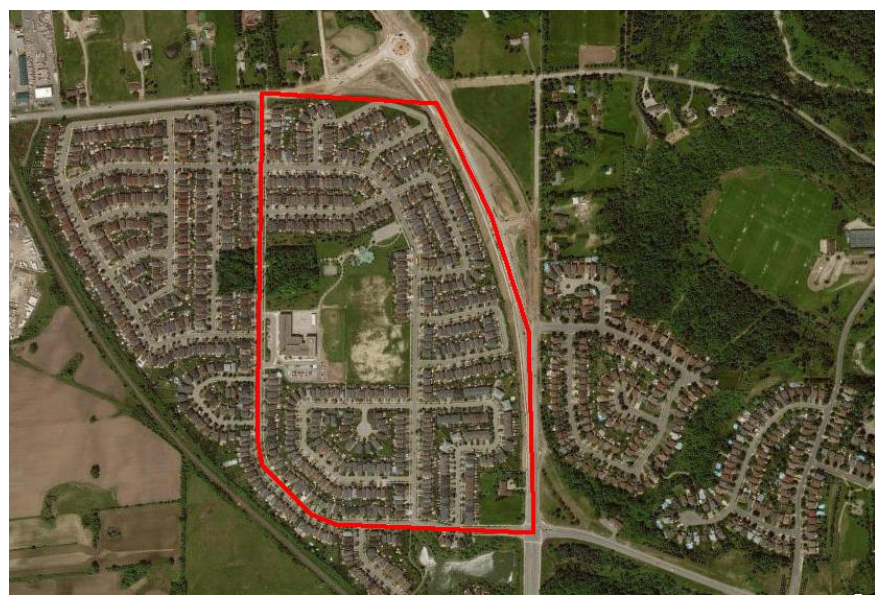

\section{\#3 Bolton, Ontario}

Reasons for rejecting:

Patch of forest at the edge could lead to boundary effects and/or numerical instability of the model. 


\section{Appendix G}

Grasshopper Script Used to Digitize the Study Area

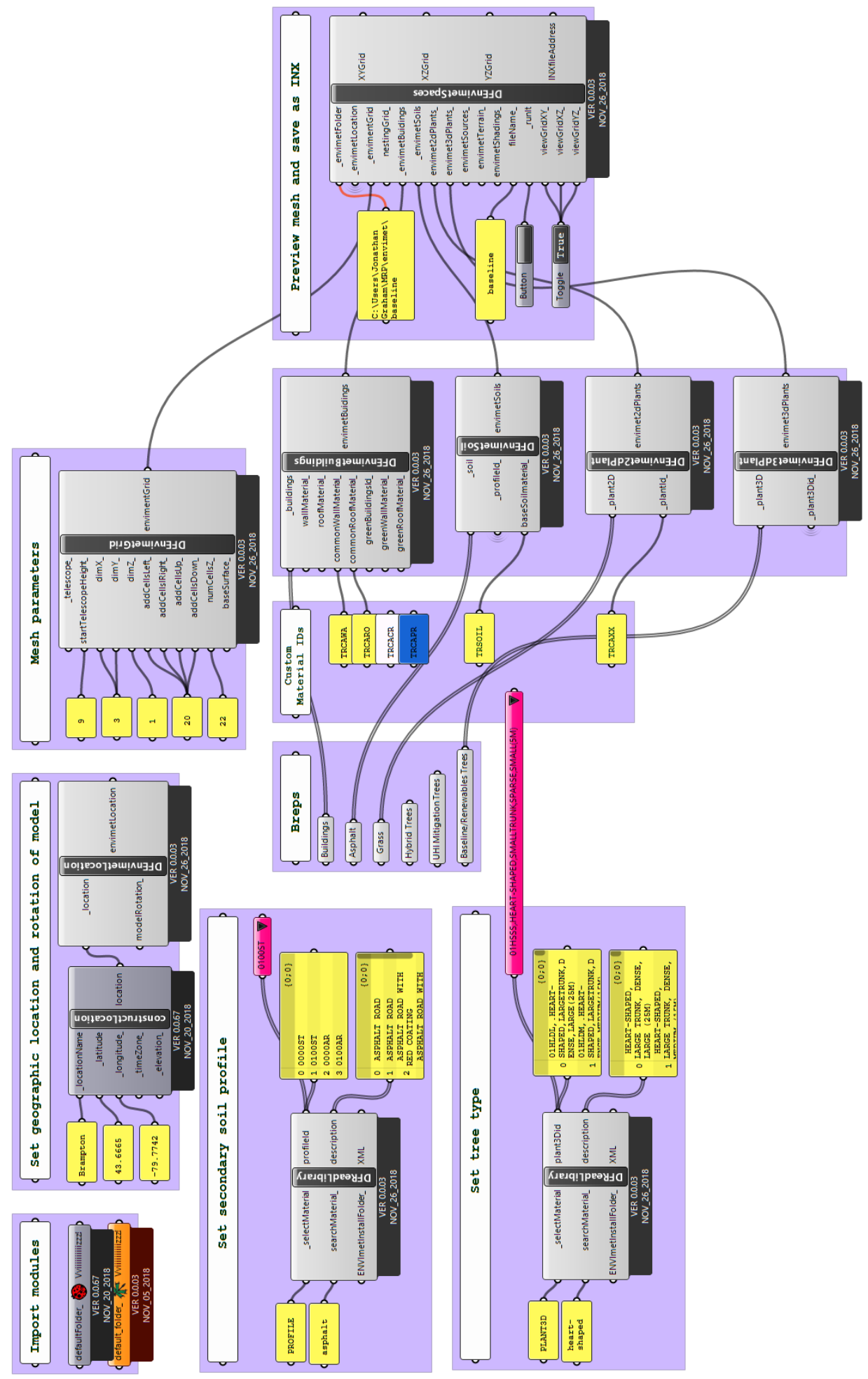




\section{Appendix $\mathrm{H}$}

\section{Python Script for Calculation of OTCA}

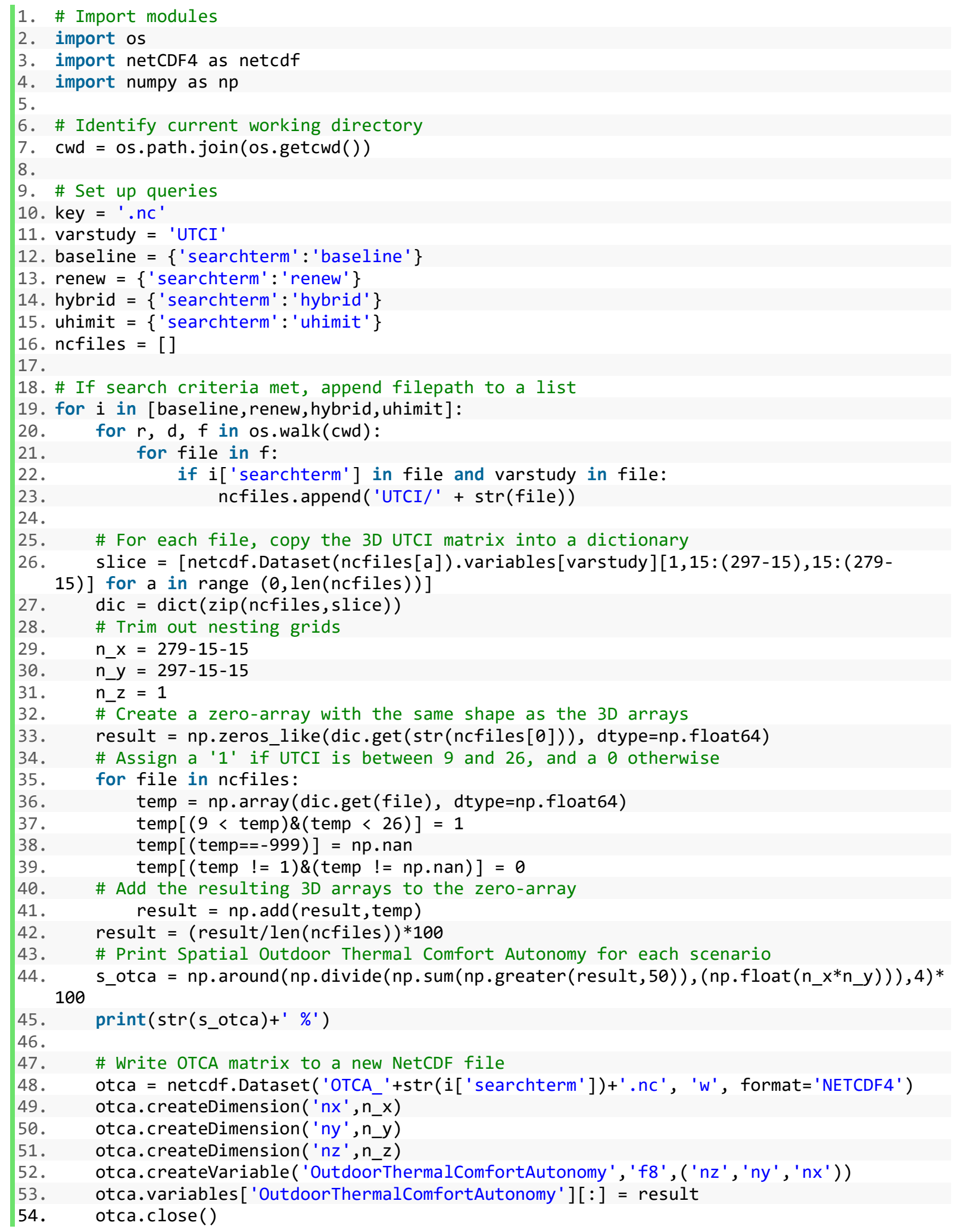




\section{Appendix I}

\section{Python Script for Calculation of PV Energy Efficiency}

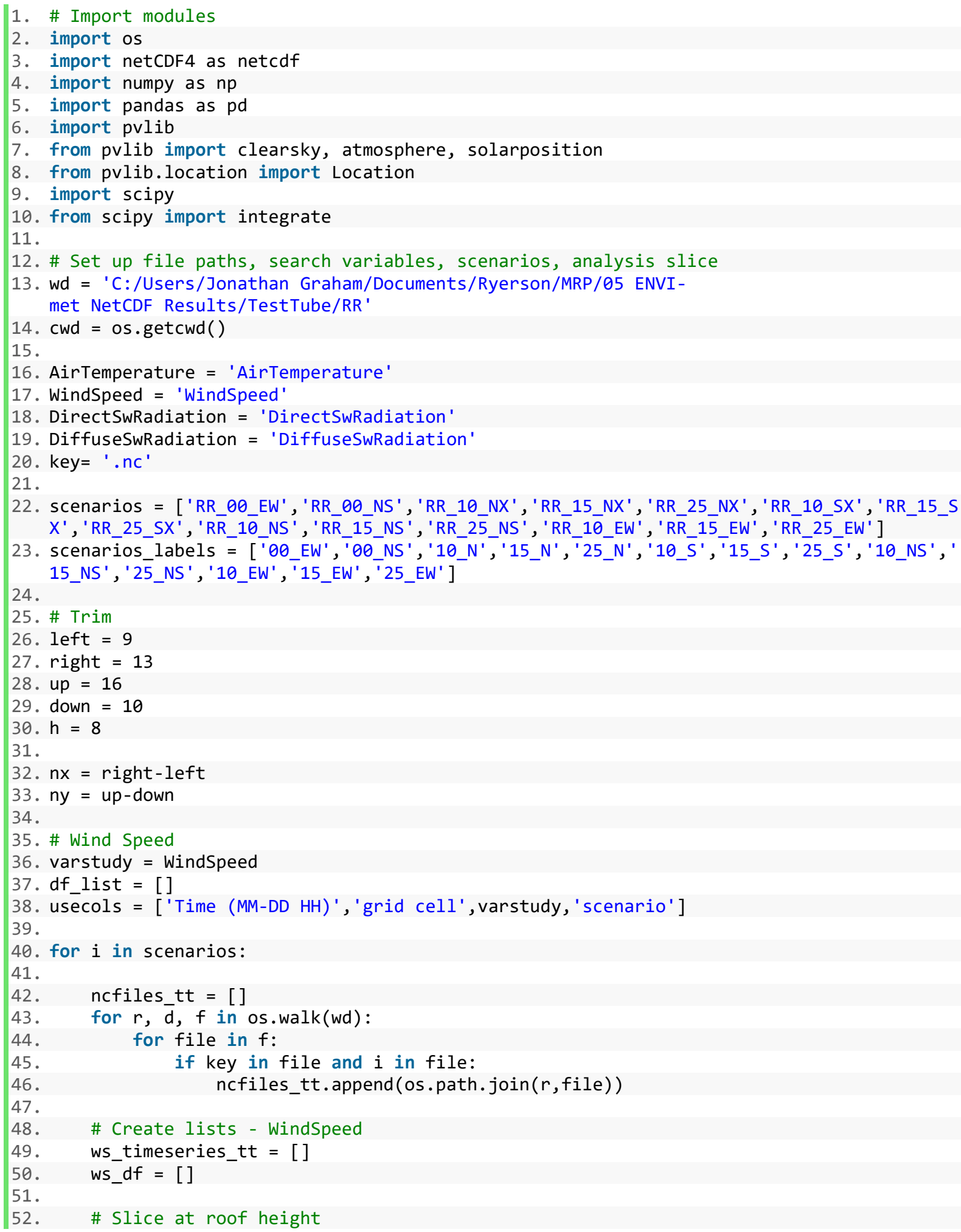




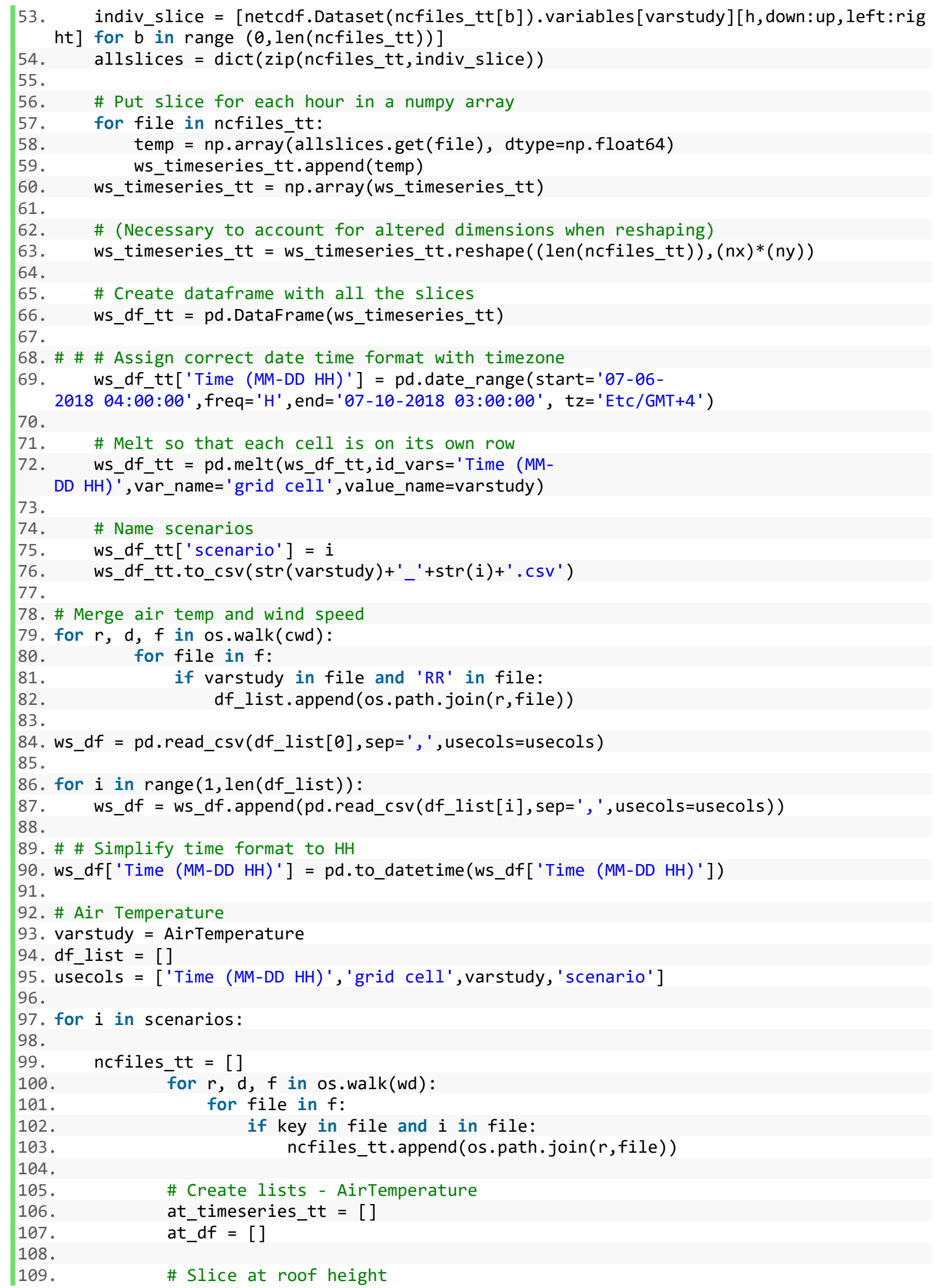




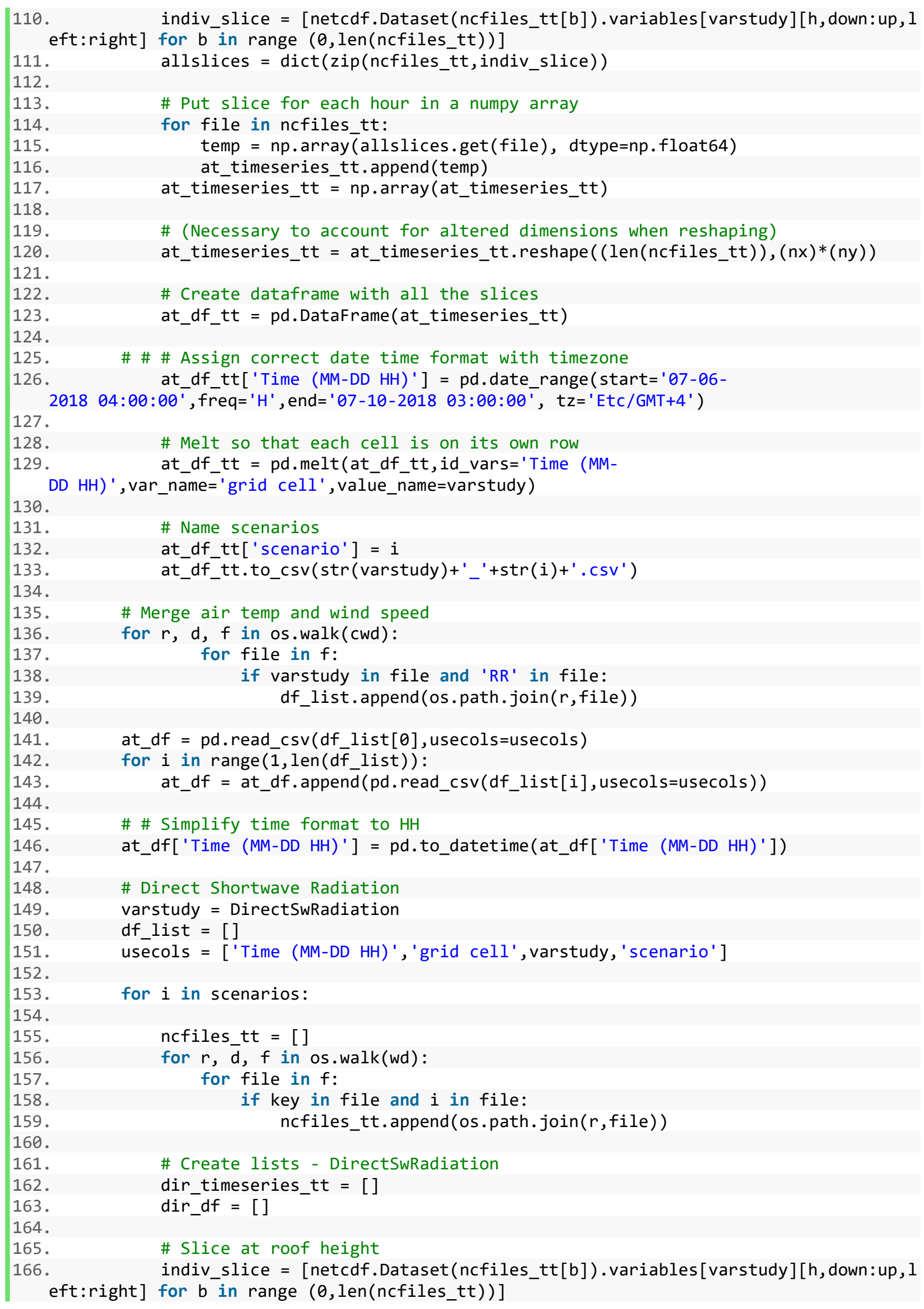




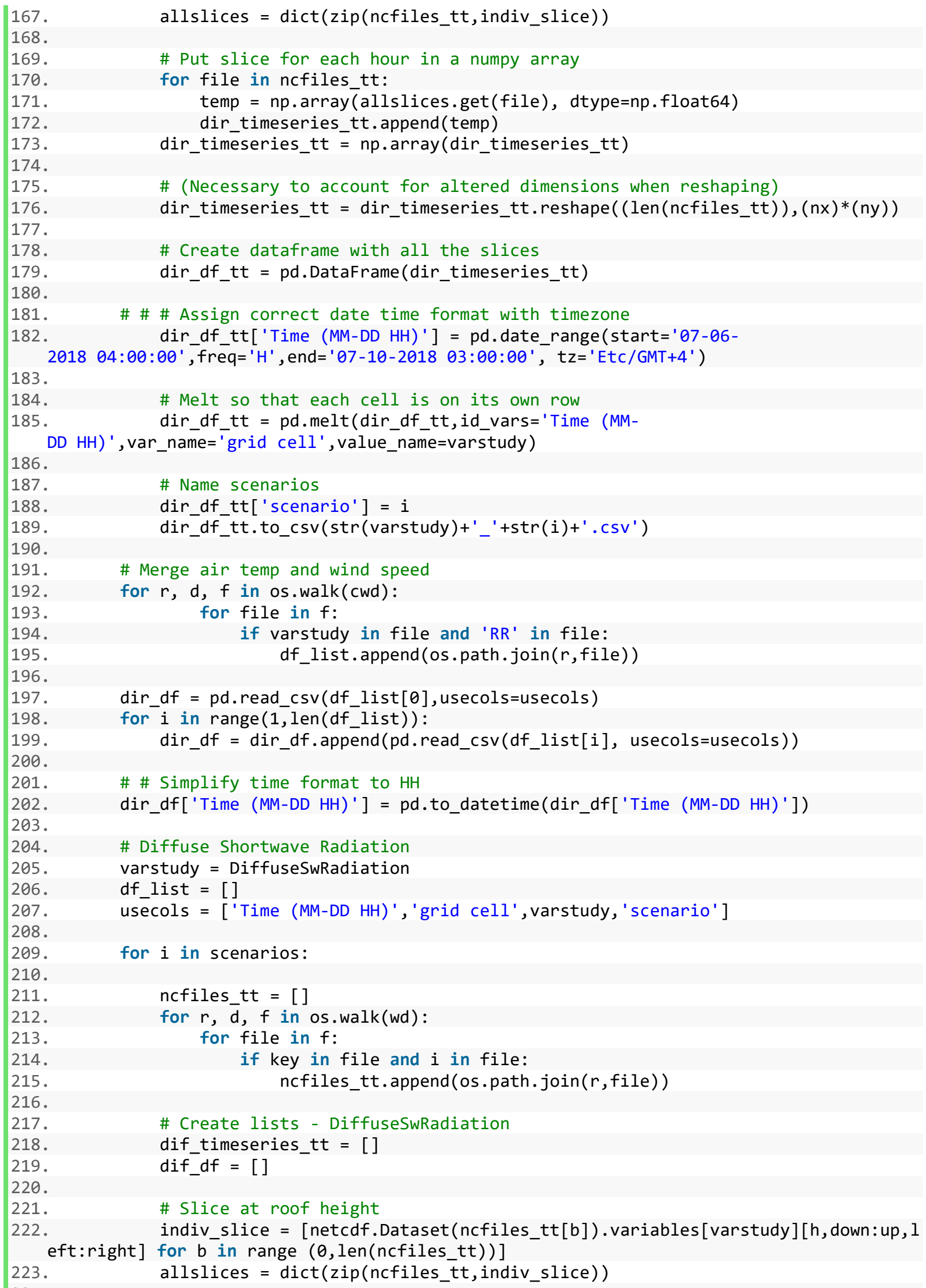




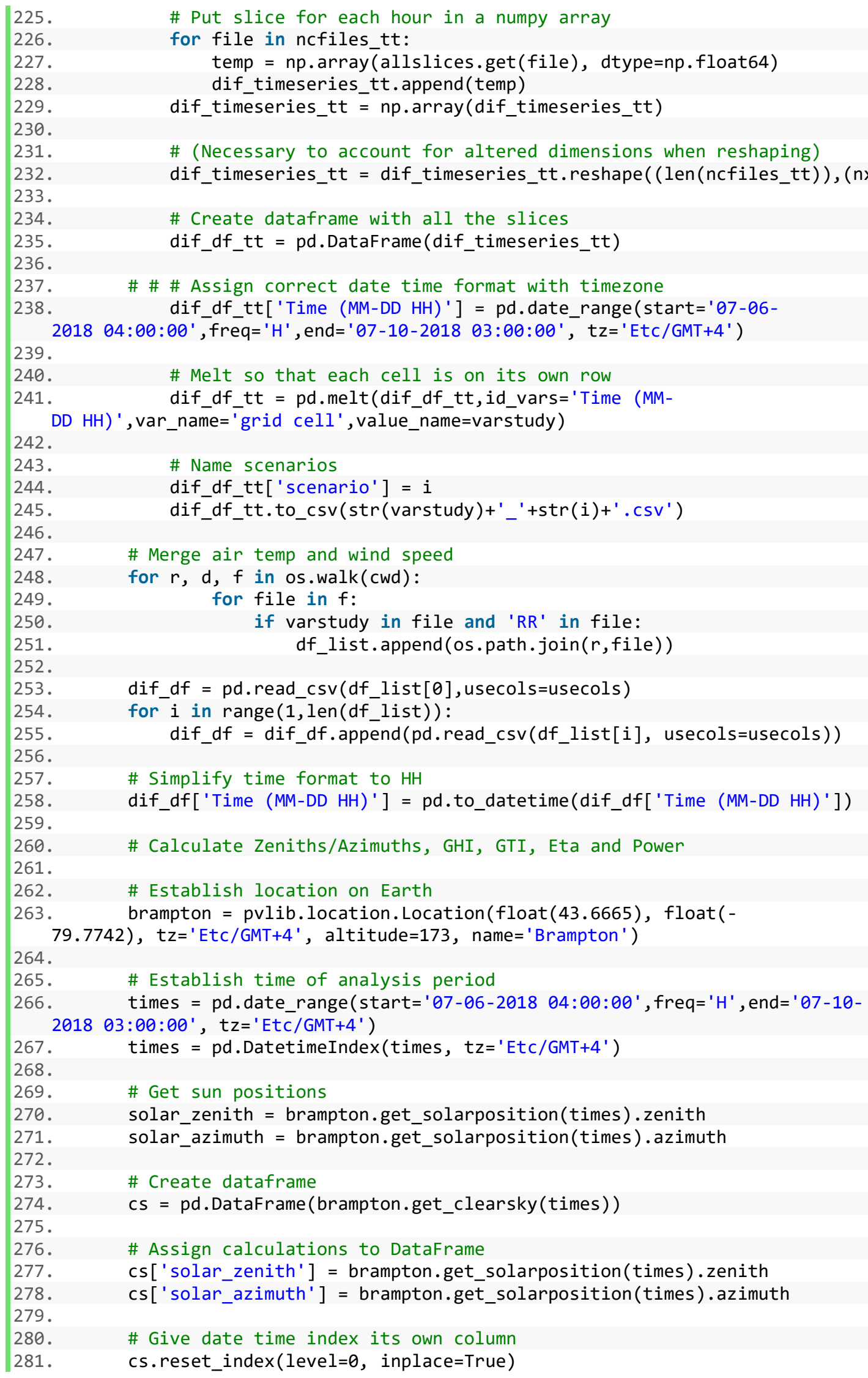




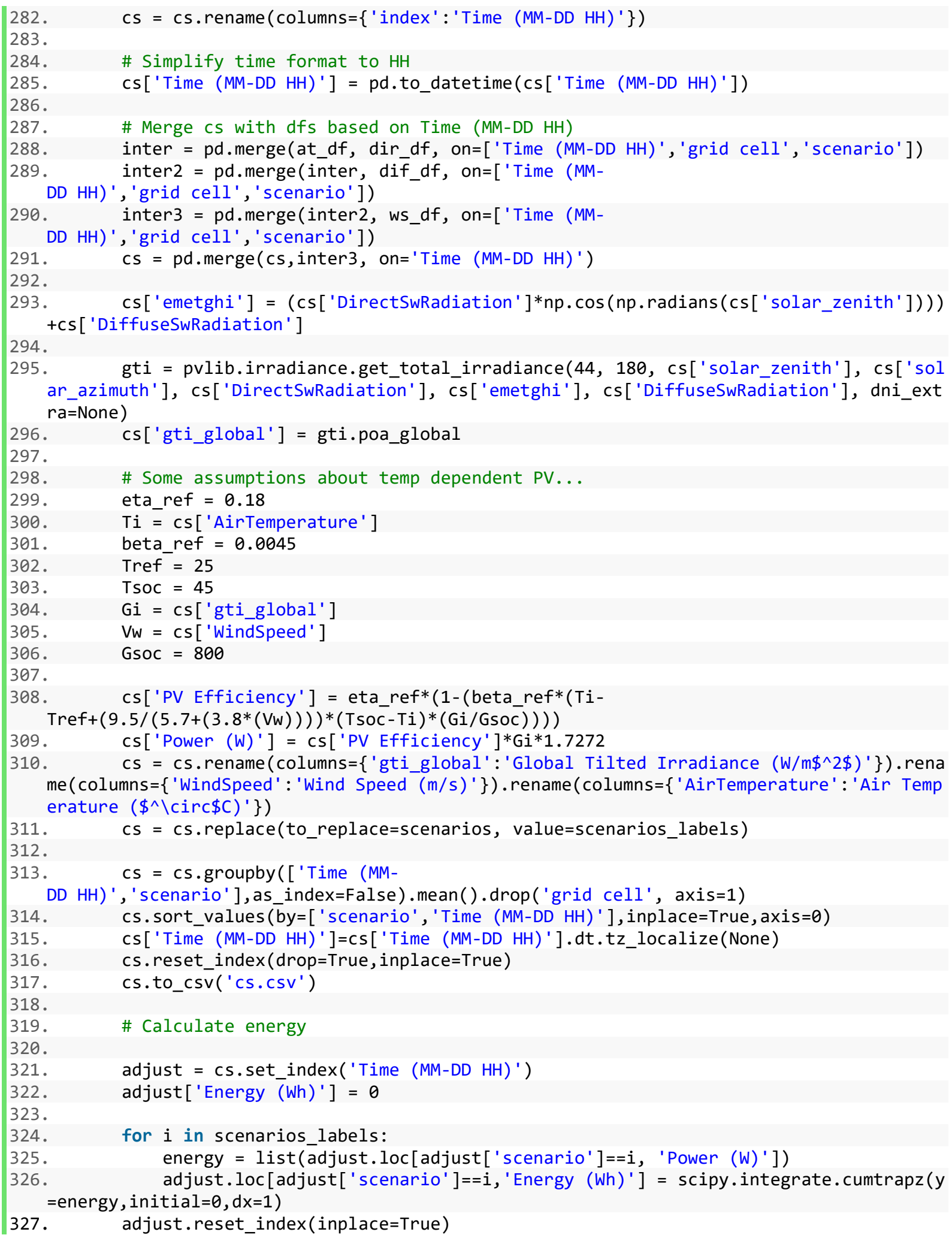




\section{Appendix $\mathrm{J}$}

\section{Validation of Alternate Baseline Simulation}

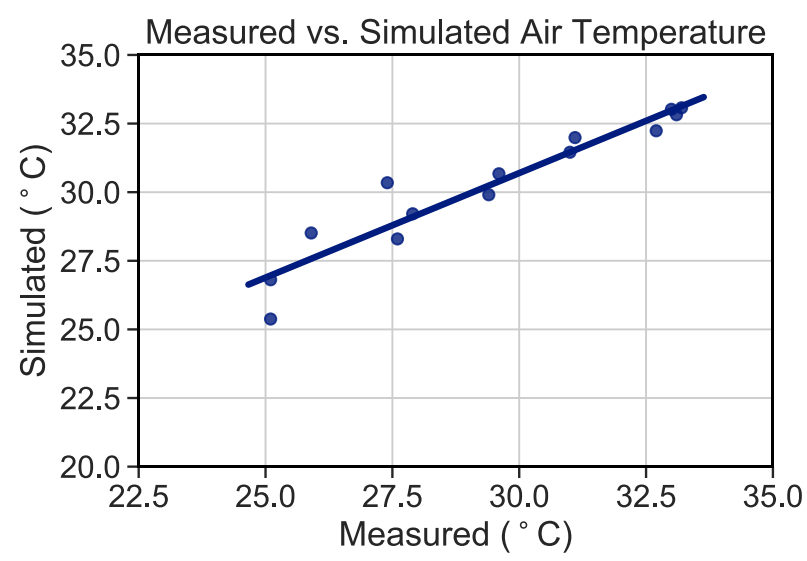

Air temperature as measured at Toronto Pearson International Airport versus an omitted version of the Baseline simulation. The coefficient of determination $\left(R^{2}\right)$ was 0.90 . 


\section{Appendix K}

Tabular Summaries of Physical Meteorological Results

Table K-1 - Spatial average air temperature delta (relative to the baseline simulation) for the whole analysis period.

Average Air Temperature Delta $\left(\mathrm{T}_{\text {baseline }}-\mathrm{T}_{\text {scenario }}\right)\left[{ }^{\circ} \mathrm{C}\right]$

\begin{tabular}{lccc}
\hline Scenario & Renewables & Hybrid & UHI Mitigation \\
\hline Slice A & 0.09 & 0.10 & 0.42 \\
\hline Slice B & 0.11 & 0.11 & 0.48 \\
\hline Slice C & 0.11 & 0.11 & 0.47 \\
\hline Slice D & 0.07 & 0.09 & 0.36 \\
\hline \hline All Slices & 0.09 & 0.10 & 0.44
\end{tabular}

Table K-2 - Spatial average specific humidity delta (relative to the baseline simulation) for the whole analysis period.

Average Specific Humidity Delta ( $\left.\boldsymbol{\omega}_{\text {baseline }}-\boldsymbol{\omega}_{\text {scenario }}\right)[\mathrm{g} / \mathrm{kg}]$

\begin{tabular}{lccc}
\hline Scenario & Renewables & Hybrid & UHI Mitigation \\
\hline Slice A & 0 & -0.02 & -0.08 \\
\hline Slice B & 0 & -0.02 & -0.12 \\
\hline Slice C & 0 & -0.03 & -0.11 \\
\hline Slice D & 0 & -0.01 & -0.07 \\
\hline \hline All Slices & 0 & -0.02 & -0.09 \\
\hline
\end{tabular}

Table K-3 - Spatial average MRT delta (relative to the baseline simulation) for the whole analysis period.

\begin{tabular}{lccc}
\hline & \multicolumn{3}{c}{ Average MRT Delta $\left(\mathrm{MRT}_{\text {baseline }}-\mathrm{MRT}_{\text {scenario }}\right)\left[{ }^{\circ} \mathrm{C}\right]$} \\
\hline Scenario & Renewables & Hybrid & UHI Mitigation \\
\hline Slice A & 0.03 & 0.93 & 2.32 \\
\hline Slice B & 0.04 & 0.28 & 2.31 \\
\hline Slice C & 0.03 & 1.31 & 2.03 \\
\hline Slice D & 0.03 & 0.62 & 3.02 \\
\hline \hline All Slices & 0.03 & 0.86 & 2.33
\end{tabular}


Table K-4 - Spatial average wind speed delta (relative to the baseline simulation) for the whole analysis period.

\begin{tabular}{lccc} 
& \multicolumn{2}{c}{ Average Wind Speed Delta $\left(\mathrm{T}_{\text {baseline }}-\mathrm{T}_{\text {scenario }}\right)[\mathrm{m} / \mathrm{s}]$} \\
\hline Scenario & Renewables & Hybrid & UHI Mitigation \\
\hline Slice A & 0 & 0.07 & 0.13 \\
\hline Slice B & 0 & 0.04 & 0.17 \\
\hline Slice C & 0 & 0.13 & 0.18 \\
\hline Slice D & 0 & 0.04 & 0.17 \\
\hline \hline All Slices & 0 & 0.07 & 0.15 \\
\hline
\end{tabular}




\section{Appendix L}

Air Temperatures Contributing to PV Cell Temperature Calculations
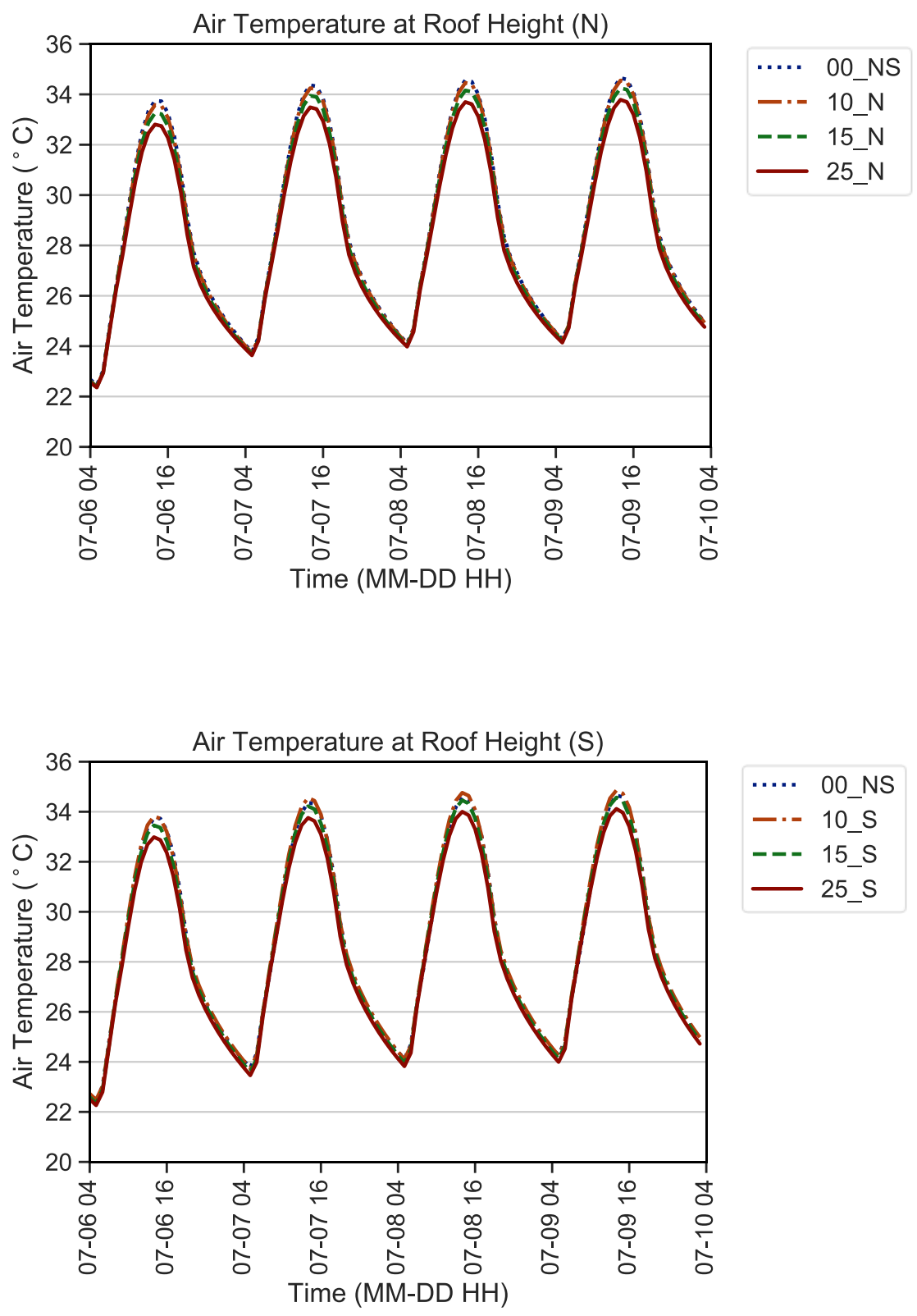

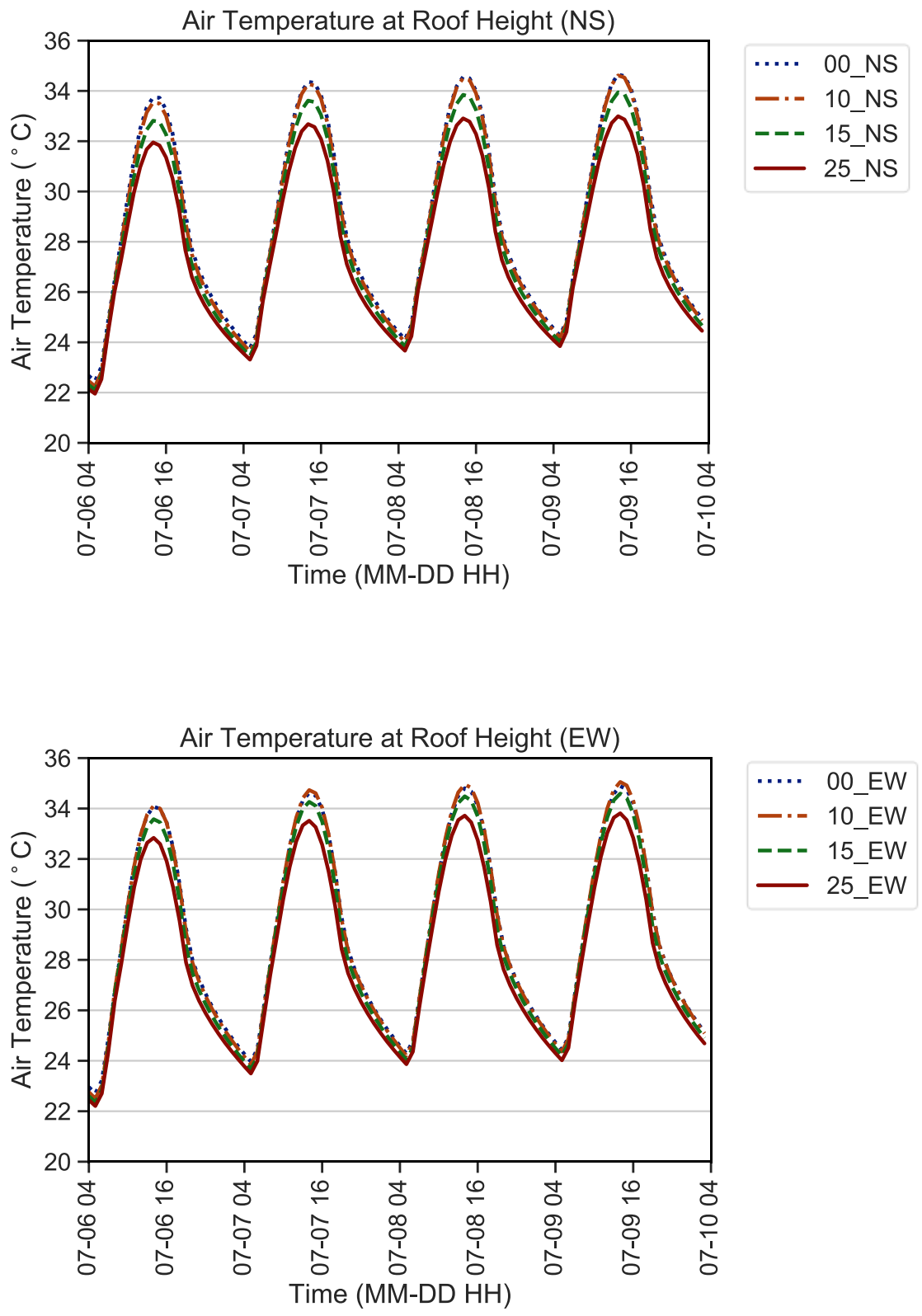


\section{Appendix M}

Wind Speeds Contributing to PV Cell Temperature Calculations
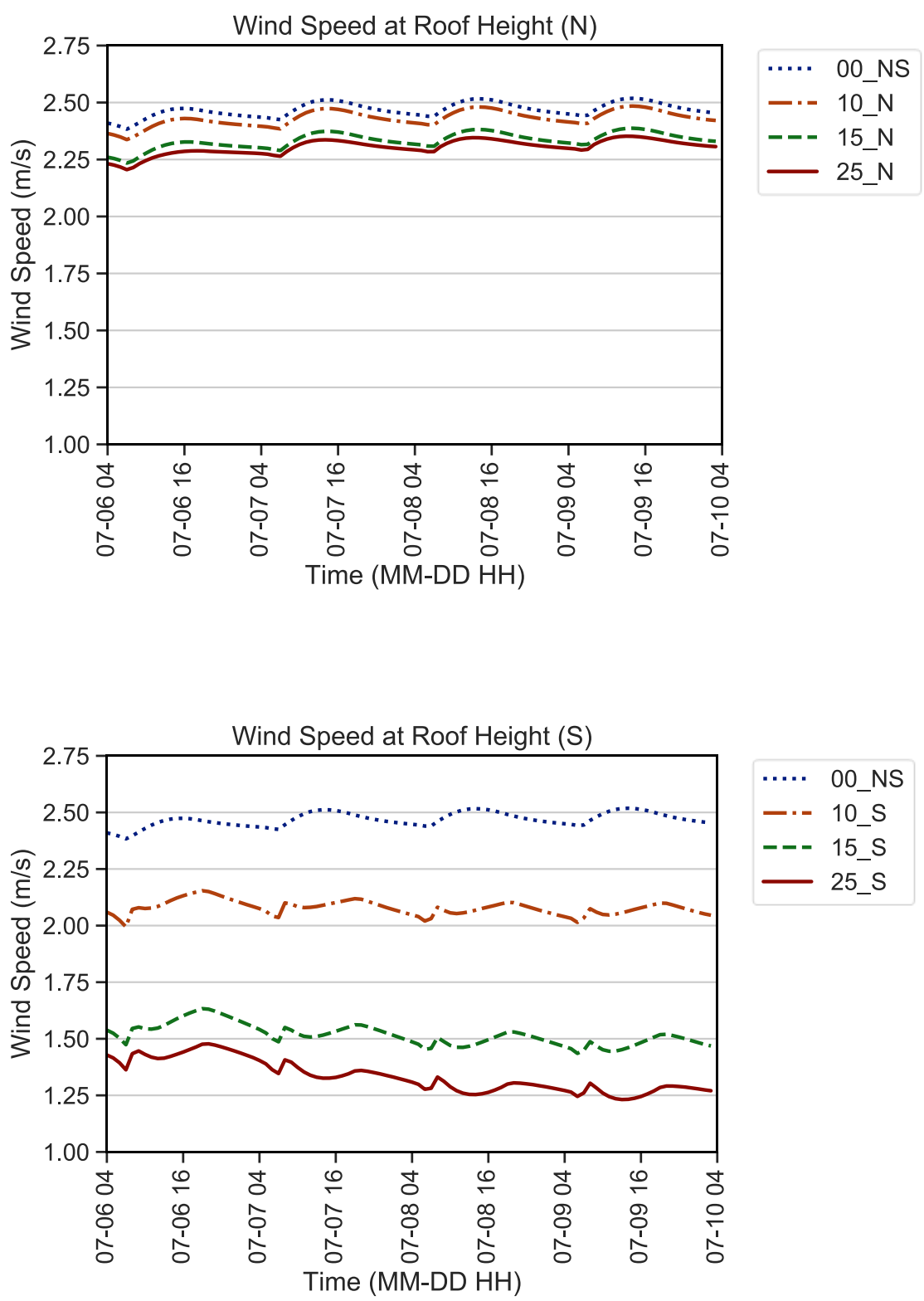

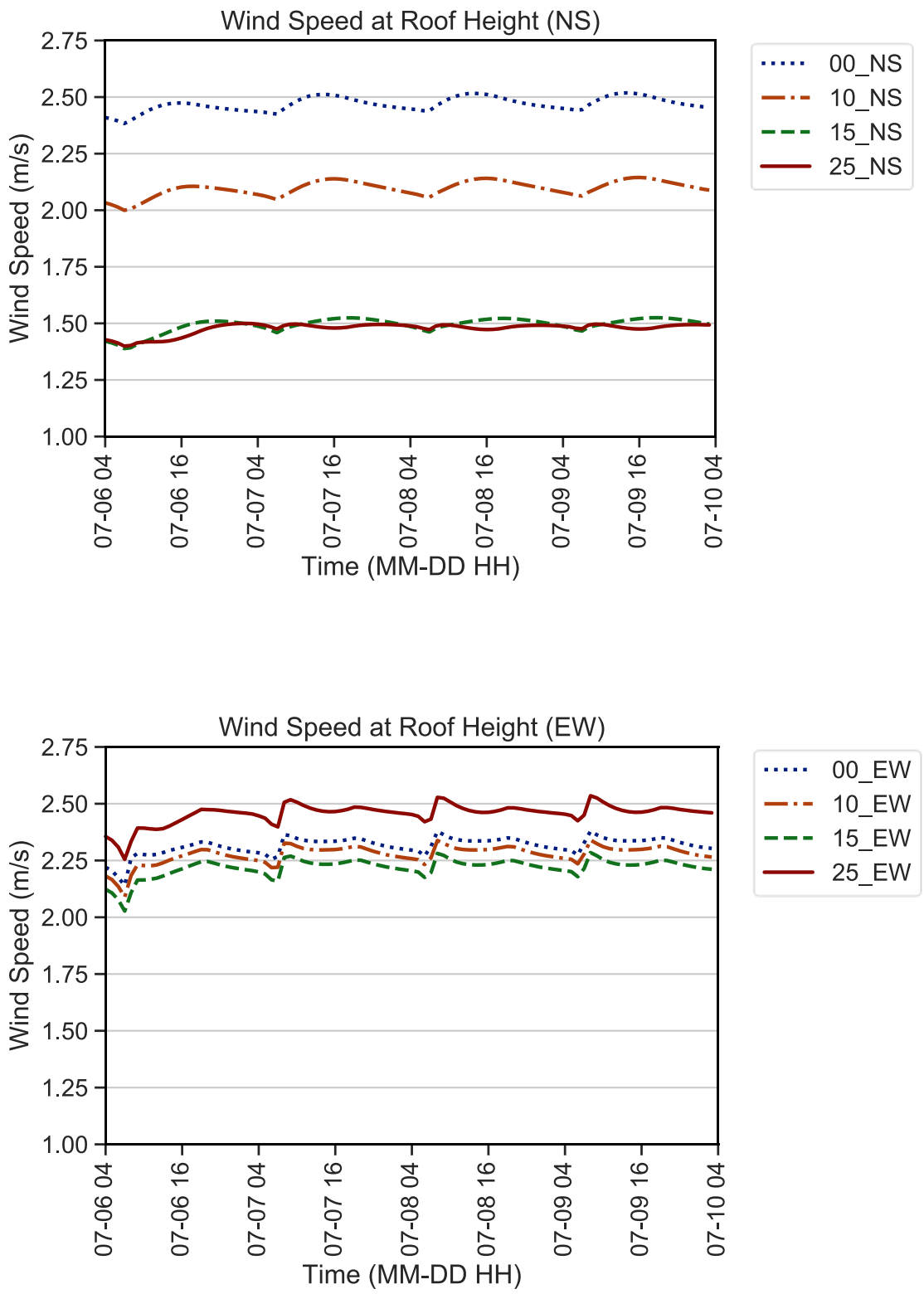


\section{Appendix N}

Global Tilted Irradiance Values Contributing to PV Cell Temperature
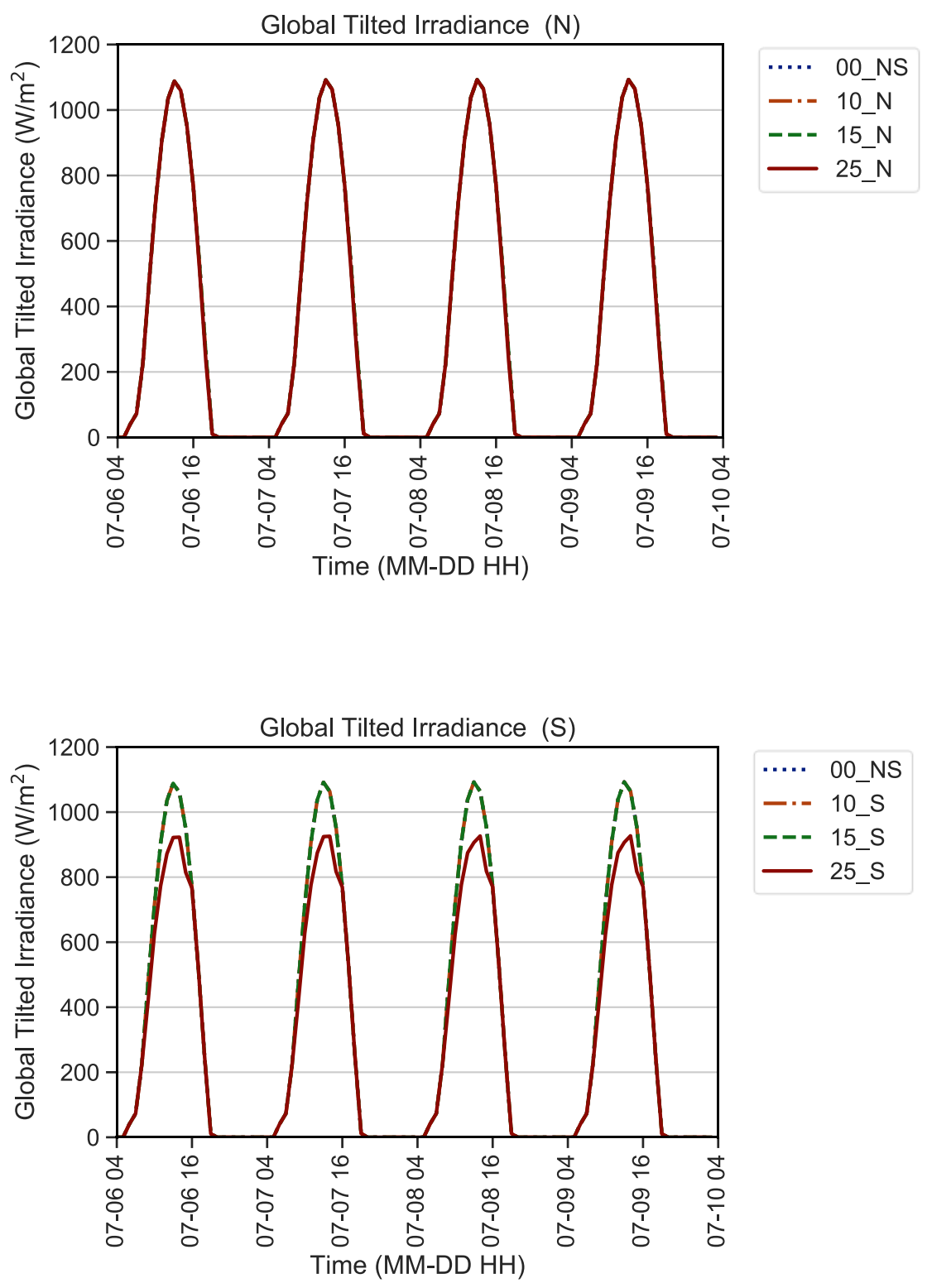

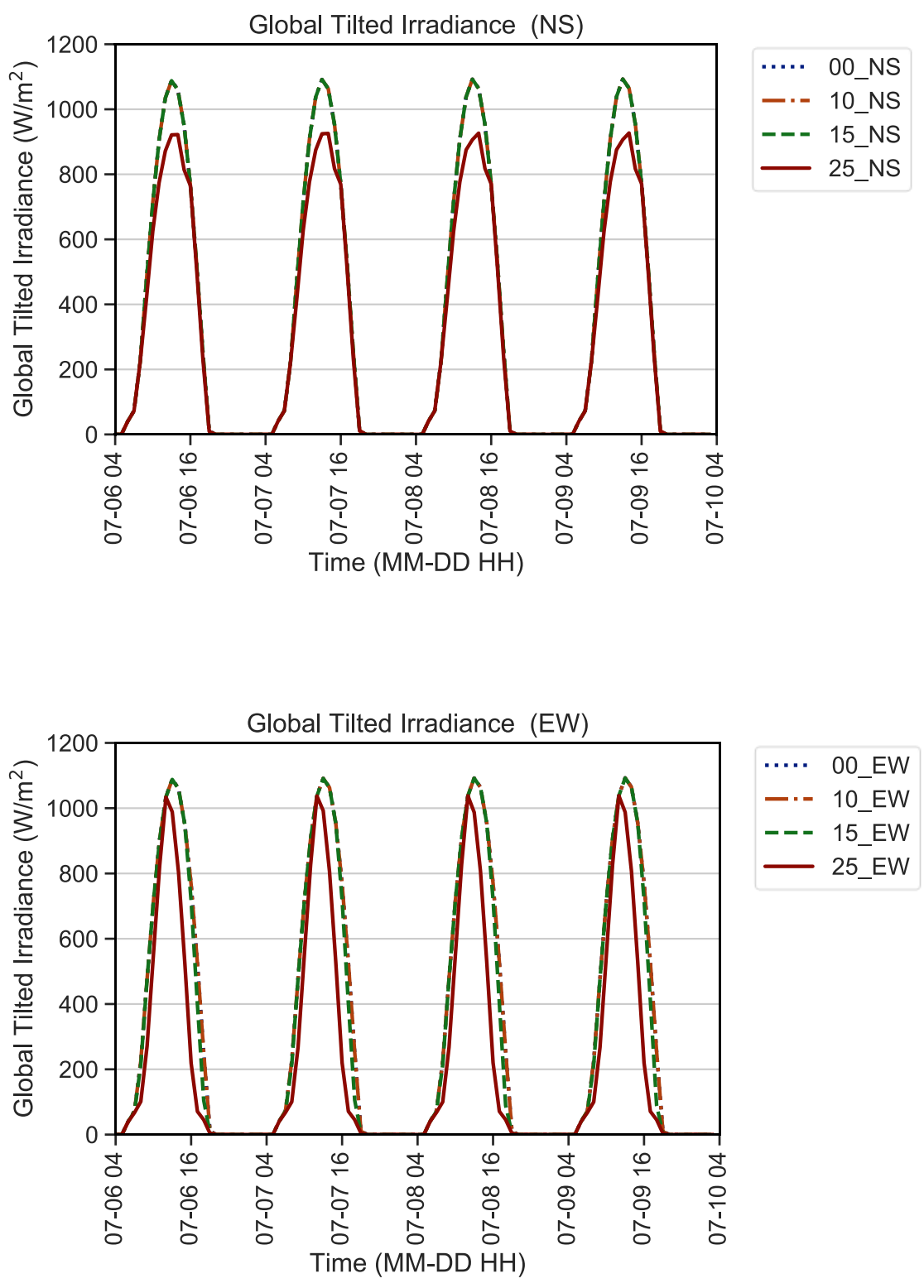


\section{REFERENCES}

Akbari, H., \& Kolokotsa, D. (2016). Three decades of urban heat islands and mitigation technologies. Energy and Buildings, 133, 834-842.

Akbari, H., Rosenfeld, A. H., \& Taha, H. (1990). Summer heat islands, urban trees and white surfaces. Atlanta, GA: Lawrence Berkeley Laboratory.

Ali-Toudert, F., \& Mayer, H. (2006). Numerical study on the effects of aspect ratio and orientation of an urban street canyon on outdoor thermal comfort in hot and dry climate. Building and Environment, 41(2), 94-108.

ASHRAE. (2017a). ANSI/ASHRAE Standard 55-2017: Thermal Environmental Conditions for Human Occupancy.

ASHRAE. (2017b). ASHRAE Handbook—Fundamentals. ASHRAE.

ASHRAE. (2019). ANSI/ASHRAE/IES Standard 90.1-2019: Energy Standard for Buildings Except Low-Rise Residential Buildings. ASHRAE.

Berardi, U. (2016). The outdoor microclimate benefits and energy saving resulting from green roof retrofits. Energy and Buildings, 121, 217-229.

Berardi, U., \& Wang, Y. (2016). The effect of a denser city over the urban microclimate: The case of Toronto. Sustainability, 8(8), 1-11.

Błażejczyk, K., Bröde, P., Fiala, D., \& Havenith, G. (2010). New index for assessment of heat stress in man. Przeglad Geograficzny, 49-71.

Bröde, P., Fiala, D., Błażejczyk, K., Holmér, I., Jendritzky, G., Kampmann, B., . . Havenith, G. (2012). Deriving the operational procedure for the Universal Thermal Climate Index (UTCI). International Journal of Biometeorology, 56(3), 481-494.

Bruse, M. (1999). Die Auswirkungen kleinskaliger Umweltgestaltung auf das Mikroklima. Bochum, Germany: Ruhr-Universität Bochum.

Bruse, M., \& Fleer, H. (1998). Simulating surface-plant-air interactions inside urban environments. Environmental Modelling \& Software, 13, 373-384.

Bücher, Klaus. (1997). Site dependence of the energy collection of PV modules. Solar Energy Materials and Solar Cells, 47, 85-94. 
Canan, F., Golasi, I., Ciancio, V., Coppi, M., \& Salata, F. (2019). Outdoor thermal comfort conditions during summer in a cold semi-arid climate. A transversal field survey in Central Anatolia (Turkey). Building and Environment, 148, 212-224.

Chen, L., \& Ng, E. (2012). Outdoor thermal comfort and outdoor activities: A review of research in the past decade. Cities, 29(2), 118-125.

City of Brampton. (2013). 200 Series Standard Drawings. Brampton, Ontario, Canada. Retrieved from https://www.brampton.ca/en/residents/Roads/engineering-construction/Pages/200series.aspx

City of Brampton. (2018). Building Footprints. Brampton. Retrieved from http://geohub.brampton.ca/datasets/6cfdf355719a452ba445ca35cb0bbd88_0

City of Brampton. (2019). Streets (Centreline). Brampton, Ontario. Retrieved from http://geohub.brampton.ca/datasets/3994641ff22d450eaa3435ed74812358_1

City of Toronto. (2018). Checklist - Toronto Green Standards Version 3.0: Low Rise Residential Development. Toronto: City of Toronto.

City of Toronto. (2019). Toronto's First Resilience Strategy. Toronto: City of Toronto.

Cortes, A., Murashita, Y., Matsuo, T., Kondo, A., Shimadera, H., \& Inoue, Y. (2015). Numerical evaluation of the effect of photovoltaic cell installation on urban thermal environment. Sustainable Cities and Society, 19, 250-258.

Deline, C. (2010, September 23). Characterizing Shading Losses on Partially Shaded PV Systems. Albuquerque: National Renewable Energy Laboratory. Retrieved January 12, 2020, from https://energy.sandia.gov/wpcontent/gallery/uploads/Deline_NREL_ShadeModeling.pdf

Duffie, J. A., \& Beckman, W. A. (2013). Solar Engineering of Thermal Processes (4th ed.). New Jersey: John Wiley \& Sons.

Durisch, W., Urban, I., \& Smestad, G. (1996). Characterisation of solar cells and modules under actual operating conditions. World Renewable Energy Congress.

ENVI-met GmbH. (2017). Biomet_utci. Retrieved January 12, 2020, from http://www.envimet.info/doku.php?id=apps:biomet_utci 
Environment \& Climate Change Canada. (2013). Spring and Summer weather hazards. Retrieved January 12, 2020, from https://www.ec.gc.ca/meteo-weather/meteoweather/default.asp

Environment \& Climate Change Canada. (2019). Canadian climate normals 1981-2010.

Erell, E., Pearlmutter, D., \& Williamson, T. (2011). Urban Microclimate: Designing the Spaces Between Buildings. New York: Earthscan.

Fabbri, K., Di Nunzio, A., Gaspari, J., Antonini, E., \& Boeri, A. (2017). Outdoor comfort: the ENVIBUG tool to evaluate PMV values output comfort point by point. Energy Procedia, 111, 510-519.

Fanger, P. (1972). Thermal comfort. New York: McGraw Hill Book Company.

FSEC. (2010). FSEC Standard 202-10: Test Method for Photovoltaic Module Power Rating. Florida: Florida Solar Energy Center.

Ghaffarianhoseini, A., Berardi, U., \& Ghaffarianhoseini, A. (2015). Thermal performance characteristics of unshaded courtyards in hot and humid climates. Building and Environment, 87, 154-168.

Green, M. A., Dunlop, E. D., Levi, D. H., Hohl-Ebinger, J., \& Yoshita, M. (2019). Solar cell efficiency tables (version 54). Progress in Photovoltaics, 27(7), 565-575.

Henning Larsen. (2019). Engineering. Retrieved January 12, 2020, from https://henninglarsen.com/en/services/engineering

Holmgren, W. F., Hansen, C. W., \& Mikofski, M. A. (2018). pvlib python: a python package for modeling solar energy systems. Journal of Open Source Software, 3(29), 884.

Höppe, P. (1999). The physiological equivalent temperature - a universal index for the biometeorological assessment of the thermal environment. International Journal of Biometeorology, 43(2), 71-75.

IEC. (2016). IEC 61215-2:2016: Terrestrial photovoltaic (PV) modules - Design qualification and type approval - Part 2: Test procedures. IEC-IECEE.

Jandaghian, Z., \& Akbari, H. (2018). The effect of increasing surface albedo on urban climate and air quality: A detailed study for Sacramento, Houston, and Chicago. Climate, 6(19), 21. 
Jendritzky, G., de Dear, R., \& Havenith, G. (2012). UTCl—Why another thermal index? International Journal of Biometeorology, 56(3), 421-428.

Kummert, M., \& Robert, A. (2012). Designing net-zero energy buildings for the future climate, not for the past. Building an Environment, 55, 150-158.

Labouret, A., \& Villoz, M. (2003). Solar Photovoltaic Energy. London: The UK Institution of Engineering and Technology.

Lobaccaro, G., \& Acero, J. A. (2015). Comparative analysis of green actions to improve outdoor thermal comfort inside typical urban street canyons. Urban Climate, 14, 251-267.

Ma, S., Pitman, A., Yang, J., Carouge, C., Evans, J. P., Hart, M., \& Green, D. (2018). Evaluating the Effectiveness of Mitigation Options on Heat Stress for Sydney, Australia. Journal of Applied Meterology and Climatology, 57, 209-220.

Masson, V., Bonhomme, M., Salagnac, J.-I., Briottet, X., \& Lemonsu, A. (2014). Solar panels reduce both global warming and urban heat island. Frontiers in Environmental Science, 2(14), 1-10.

Matzarakis, A. (2018). RayMan Pro: A tool for applied climatology. Retrieved January 12, 2020, from https://www.urbanclimate.net/rayman/RayManManual.pdf

Mesinger, F., DiMego, G., Kalnay, E., Mitchell, K., Shafran, P. C., \& Ebisuzaki, W. (2006). North American Regional Reanalysis.

Naboni, E., Meloni, M., Coccolo, S., Kaempf, J., \& Scartezzini, J.-L. (2017). An overview of simulation tools for predicting the mean radiant temperature in an outdoor urban space. Energy Procedia, 122, 1111-1116.

Nazarian, N., Acero, J. A., \& Norford, L. (2019). Outdoor thermal comfort autonomy: Performance metrics for climate-conscious urban design. Building and Environment, 155(March), 145-160.

Ng, E., Chen, L., Wang, Y., \& Yuan, C. (2012). A study on the cooling effects of greening in a high-density city: An experience from Hong Kong. Building and Environment, 47, 256271.

Notton, G., Cristofari, M., Mattei, M., \& Poggi, P. (2005). Modelling of a double-glass photovoltaic module using finite differences. Applied Thermal Engineering, 25, 2854-2877. 
NREL. (2019, May 29). Reference Air Mass 1.5 Spectra. Retrieved January 12, 2020, from https://www.nrel.gov/grid/solar-resource/spectra-am1.5.html

Ogaili, H., \& Sailor, D. J. (2016). Measuring the effect of vegetated roofs on the performance of photovoltaic panels in a combined system. Journal of Solar Energy Engineering, 138(6), $1-8$.

Oliphant, T. E. (2006). A guide to NumPy. USA: Trelgol Publishing.

Parker, J. H. (1982). Landscaping to reduce the energy used in cooling buildings. Journal of Forestry, 81(2), 82-105.

Petela, R. (2010). Engineering thermodynamics of thermal radiation for solar power utilization. New York: McGraw-Hill.

Pham, J. V., Baniassadi, A., Brown, K. E., Heusinger, J., \& Sailor, D. J. (2019). Comparing the photovoltaic and reflective shade surfaces in the urban environment: Effects on surface sensible heat flux and pedestrian thermal comfort. Urban Climate, 29.

Reinhart, C. F., Mardaljevic, J., \& Rogers, Z. (2006). Dynamic daylight performance metrics for sustainable building design. LEUKOS, 3(1), 7-31.

Rosenzweig, C., Solecki, W., Parshall, L., \& Gaffin, S. (2006). Mitigating New York City's heat island with urban forestry, living roofs and light surfaces. New York: New York City Heat Island Initiative.

Roulet, C.-A. (2001). Solar energy and global heat balance of a city. Solar Energy, 70(3), 255261.

Sailor, D. J. (1994). Simulated urban climate response to modifications in surface albedo and vegetative cover. Journal of Applied Meteorology, 34, 1694-1704.

Salamanca, F., Georgescu, M., Mahalov, A., \& Moustaoui, M. (2016). Citywide impacts of cool roof and rooftop solar photovoltaic deployment on near-surface air temperature and cooling energy demand. Boundary-Layer Meteorology, 161, 203-221.

Santamouris, M., \& Synnefa, A. (2016). Mitigating the Urban Heat With Cool Materials for the Buildings' Fabric. In M. Santamouris, \& D. Kolokotsa (Eds.), Urban Climate Mitigation Techniques (pp. 67-91). New York: Routledge. 
Santamouris, M., Haddad, S., Saliari, M., Vasilakopoulou, K., \& Synnefa, A. (2018). On the energy impact of urban heat island in Sydney: Climate and energy potential of mitigation technologies. Energy and Buildings, 166, 154-164.

Scherba, A., Sailor, D. J., Rosenstiel, T. N., \& Wamser, C. C. (2011). Modeling the impacts of roof reflectivity, integrated photovoltaic panels and green roof systems on sensible heat flux into the urban environment. Building and Environment, 46, 2542-2551.

Simon, H., Kropp, T., Sohni, F., \& Bruse, M. (2018). Downscaling climate models: running nested simulations in the microclimate model ENVI-met. Passive and Low Energy Architecture. Hong Kong.

Skoplaki, E., \& Palyvos, J. (2009). On the temperature dependence of photovoltaic module electrical performance: A review of efficiency/power correlations. Solar Energy, 83, 614624.

Skoplaki, E., A.G., B., \& Palyvos, J. (2008). A simple correlation for the operating temperature of photovoltaic modules of arbitrary mounting. Solar Energy Materials \& Solar Cells, 92, 1393 - 1402.

Stadt, K. J., \& Lieffers, V. (2000). MIXLIGHT: a flexible light transmission model for mixedspecies forest stands. Agricultural and Forest Meteorology, 102(4), 235-252.

Steadman, R. G. (1984). A Universal Scale of Apparent Temperature. Journal of Climate and Applied Meteorology, 23, 1674-1687.

Straube, J. F., \& Burnett, E. F. (2005). Building Science for Building Enclosures. Westford: Building Science Press.

Stultz, J. (1977). Thermal and Other Tests of Photovoltaic Modules Performed in Natural Sunlight. Pasadena, CA: NASA Jet Propulsion Laboratory.

Sun, T., Grimmond, C. S., \& Ni, G.-H. (2016). How do green roofs mitigate urban thermal stress under heat waves? Journal of Geophysical Research: Atmospheres, 121, 5320-5335.

Taha, H. (2013). The potential for air-temperature impact from large-scale deployment of solar photovoltaic arrays in urban areas. Solar Energy, 91, 358-367.

Taleghani, M., \& Berardi, U. (2018). The effect of pavement characteristics on pedestrians' thermal comfort in Toronto. Urban Climate, 24, 449-459. 
Taleghani, M., Sailor, D. J., Tenpierik, M., \& Dobbelsteen, A. v. (2014). Thermal assessment of heat mitigation strategies: The case of Portland State University, Oregon, USA. Building and Environment, 73, 138-150.

Taleghani, M., Sailor, D., \& Ban-Weiss, G. A. (2016). Micrometeorological simulations to predict the impacts of heat mitigation strategies on pedestrian thermal comfort in a Los Angeles neighborhood. Environmental Research Letters, 11.

Thorsson, S., Rocklöv, J., Konarska, J., Lindberg, F., Holmer, B., Dousset, B., \& Rayner, D. (2014). Mean radiant temperature - A predictor of heat related mortality. Urban Climate, 10(2), 332-345.

Tian, W., Wang, Y., Xie, Y., Wu, D., \& Ren, J. (2007). Effect of building integrated photovoltaics on microclimate of urban canopy layers. Building and Environment, 42, 1891-1901.

Toparlar, Y., Blocken, B., Maiheu, B., \& van Heijst, G. J. (2017). A review on the CFD analysis of urban microclimate. Renewable and Sustainable Energy Reviews, 80, 1613-1640.

Tsoka, S., Tsikaloudaki, A., \& Theodosiou, T. (2018). Analyzing the ENVI-met microclimate model's performance and assessing cool materials and urban vegetation applications-A review. Sustainable Cities and Society, 43, 55-76.

Unidata. (2019). NetCDF version 4.7.1. Boulder, CO: UCAR/Unidata. doi:https://doi.org/10.5065/D6H70CW6

Unidata. (2019, September 19). netcdf4-python version 1.5.2. Boulder: UCAR/Unidata.

VDI. (1996). Richtlinie VDI 3787: Methoden zur human-biometeorologischen Bewertung von Klima und Lufthygiene f ur die Stadt- und Regionalpla- nung Teil 1: Klima. Verein deutscher Ingenieure.

Wang, Y., Berardi, U., \& Akbari, H. (2016). Comparing the effects of urban heat island mitigation strategies for Toronto, Canada. Energy and Buildings, 114, 2-19.

Zachariou, A., \& Protogeropoulos, C. (2010). Photovoltaic module laboratory reflectivity measurements and comparison analysis with other reflecting surfaces. Valencia: 25th European Photovoltaic Solar Energy Conference. 